\title{
SPATIAL AND TEMPORAL MODELLING OF BIOPHYSICAL VARIABLES WITHIN A HIGH ARCTIC WETLAND
}

by

\author{
Gillian Ramsay \\ BSc, St Andrews University, St Andrews, Scotland, 2008 \\ MSc, Edinburgh Napier University, Edinburgh, Scotland, 2011
}

A thesis presented to Ryerson University

In partial fulfillment of the requirements for the degree of Master of Applied Science in the program of Environmental Applied Science and Management

Toronto, Ontario, Canada, 2015

CGillian Ramsay 2015 


\section{Author's Declaration}

\section{AUTHOR'S DECLARATION FOR ELECTRONIC SUBMISSION OF A THESIS}

I hereby declare that I am the sole author of this thesis. This is a true copy of the thesis, including any required final revisions, as accepted by my examiners.

I authorize Ryerson University to lend this thesis to other institutions or individuals for the purpose of scholarly research.

I further authorize Ryerson University to reproduce this thesis by photocopying or by other means, in total or in part, at the request of other institutions or individuals for the purpose of scholarly research.

I understand that my thesis may be made electronically available to the public. 


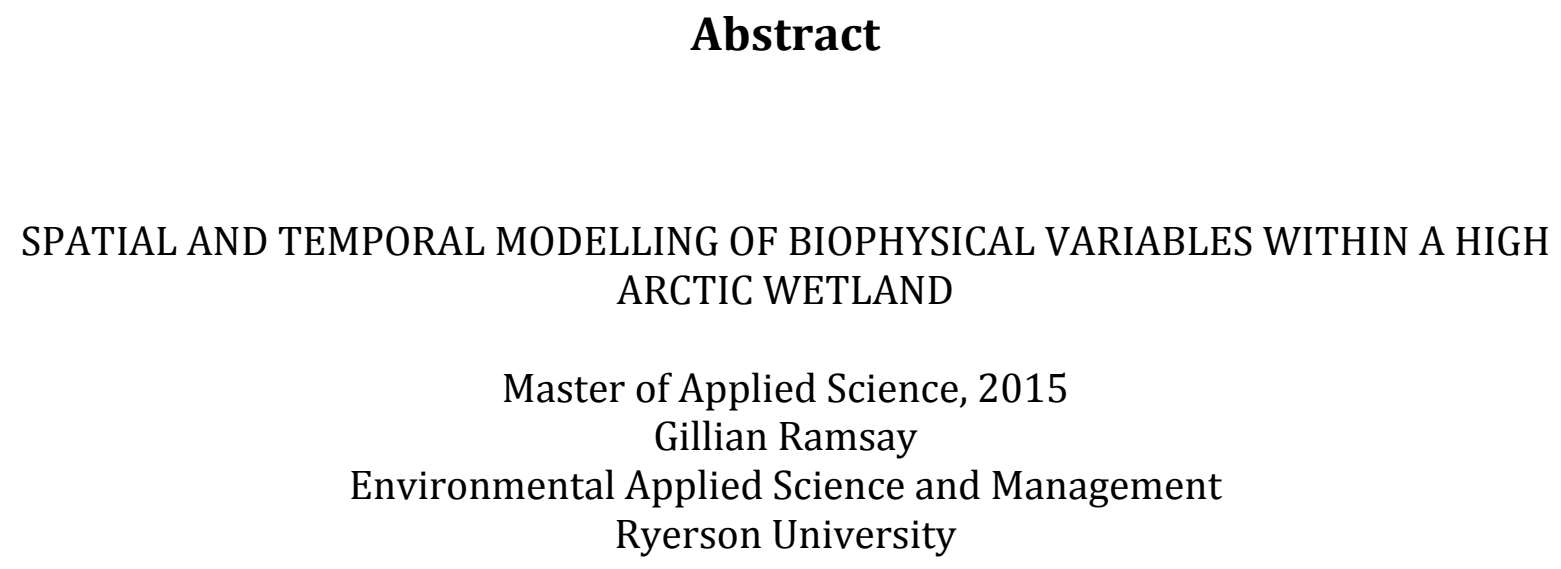

The Arctic has experienced greater climate warming in the last decade than anywhere else, potentially shifting its carbon status from a sink to a source. Increasing temperatures impact nival wetlands that rely on a strong hydrological input from melting perennial snowpacks. Soil moisture, soil temperature and active layer depth are key biophysical variables in predicting carbon flux trajectories in this environment. How these variables interact is crucial in delineating links between snowmelt and seasonal changes in wetland productivity. To date, there have been numerous studies that have examined these variables, but few have investigated the relationships between these biophysical variables and wetland thaw patterns at a high spatial and temporal scale. This study found a decrease in temporal variability and reduced interactions between variables as the wetland thawed as well as localized hot spots of increased values and an overall east to west trend across the site. This implies that Arctic wetland ecosystems are dynamic systems that reach a level of stability during peak growth. They also exhibit changeable spatial patterns that cannot be generalized. 


\section{Co-Authorship}

This thesis is based on the manuscript that follows:

Chapter 3: Ramsay, G., Atkinson, D, M. \& Collingwood, A., 2015. High spatial and temporal modeling of biophysical variables within a High Arctic wetland.

I wrote the manuscript and was responsible for experiement design, collection of

field data and analysis. My supervisor, Dr. D. M. Atkinson, provided guidance on the sampling design and study area, as well as editing of the manuscript. D. M. Collingwood provided the DEM of Cape Bounty used in this study. 


\section{Acknowledgements}

I would like to thank my supervisor, Dr. David Atkinson for his guidance in completing this thesis and research. His abundant knowledge within Arctic research was not only crucial in completing this study, but also in surviving a 61-day field season in the Canadian High Arctic. His advice, encouragement and support made this project and my field season possible.

I would also like to thank the Geography department at Ryerson University for their generous funding that allowed me to go north and study Arctic science. Thank-you also to the Polar Continental Shelf Program (PCSP) for providing logistical support and field supplies at Melville Island. Finally, thanks go to Dr. Scott Lamoureux, Director of the Cape Bounty Arctic Watershed Observatory, for allowing me the opportunity to conduct field research on Melville Island. 


\section{Table of Contents}

AUTHOR'S DECLARATION

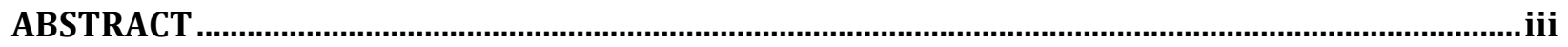

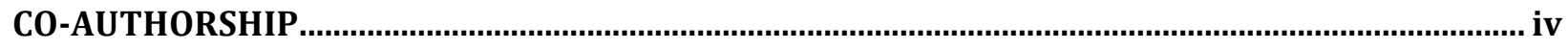

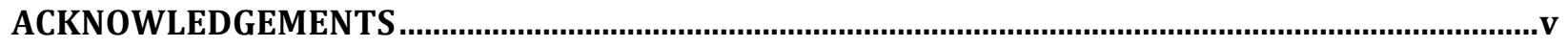

TABLE OF CONTENTS

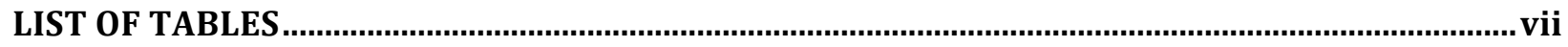

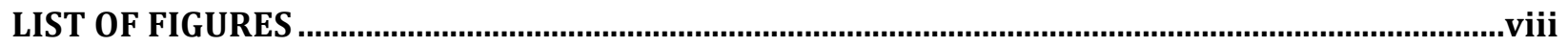

LIST OF APPENDICES

LIST OF ACRONYMS

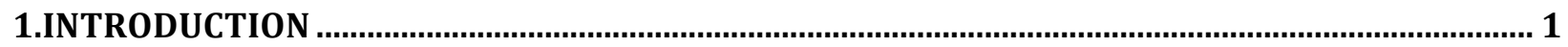

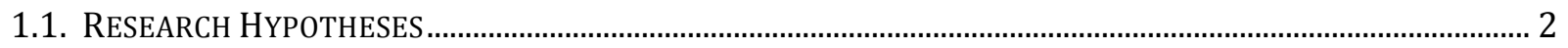

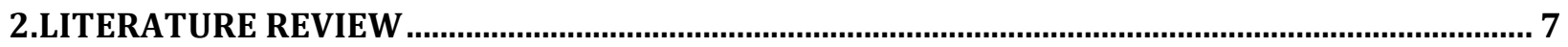

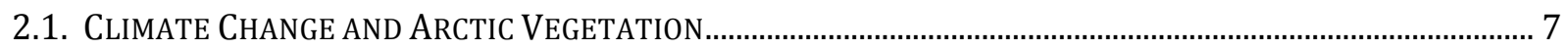

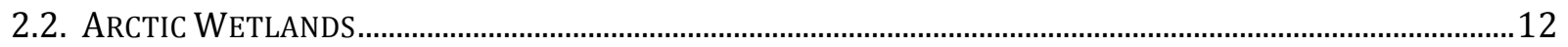

3.HIGH SPATIAL AND TEMPORAL MODELLING OF BIOPHYSICAL VARIABLES WITHIN A HIGH

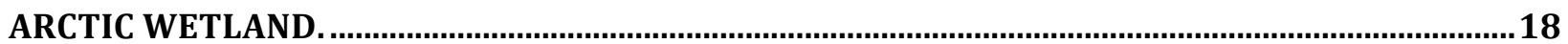

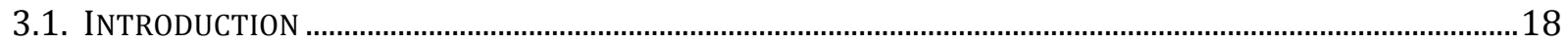

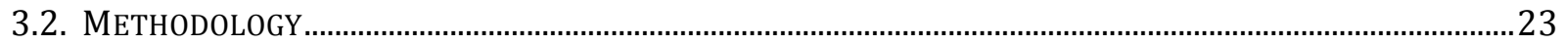

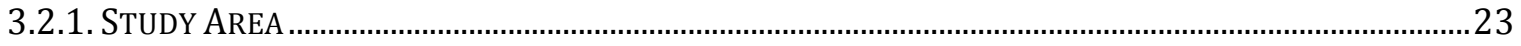

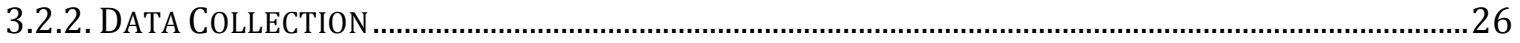

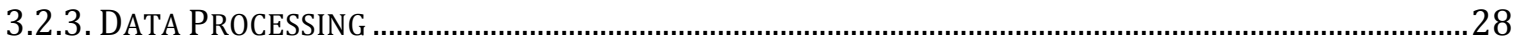

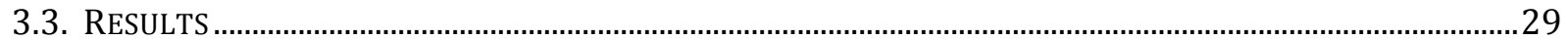

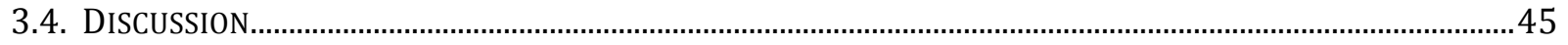

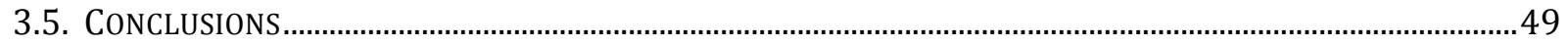

4.DISCUSSION

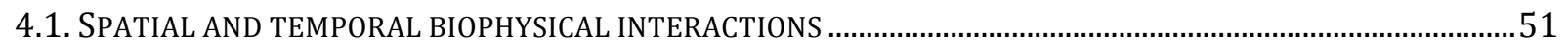

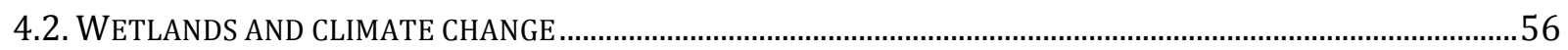

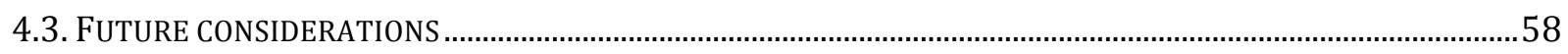

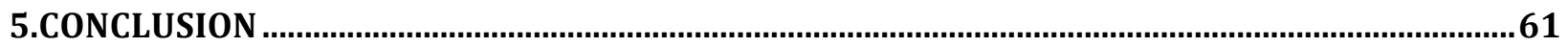

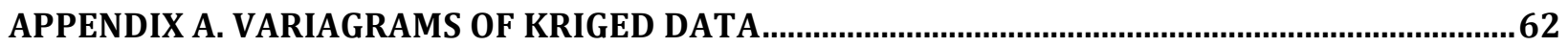

A.1. AL VARIAGRAMS.

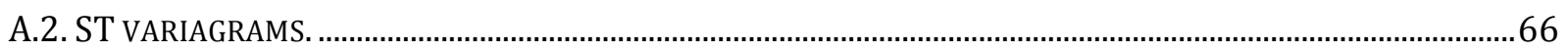

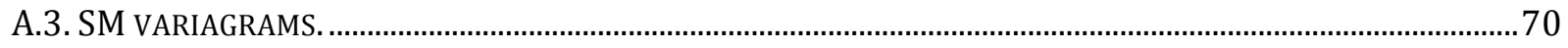

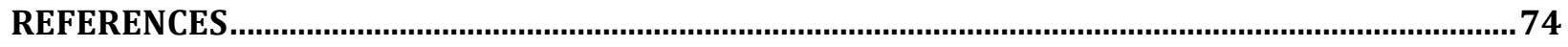




\section{List of Tables}

TABLE 3.1: TABLE SHOWING LINEAR REGRESSION VALUES FOR EACH BIOPHYSICAL INTERACTION WITHIN EACH SEASON.

TABLE 3.2: TABLES SHOWING SPATIAL INTERPOLATION ERROR STATISTICS WITHIN COMPLETED KRIGING

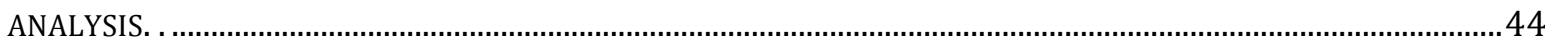




\section{List of Figures}

FIGURE 3.1: (A) LOCATION MAP OF THE WETLAND FIELD SITE WITHIN THE CAPE BOUNTY ARCTIC WATERSHED OBSERVATORY, MELVILLE ISLAND, NUNAVUT. (B) SCHEMATIC TRANSECT OF THE PERENNIAL SNOWPACK

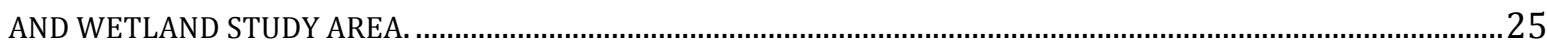

FIGURE 3.2: FIELD EQUIPMENT USED FOR DATA COLLECTION...........................................................................2

FIGURE 3.3: GRAPHS SHOWING AVERAGED BIOPHYSICAL VARIABLE VALUES FOR THE ENTIRE WETLAND FOR THE COMPLETE SAMPLING SEASON.

FIGURE 3.4: GRAPHS SHOWING TOTAL RAIN (A) AND INCOMING SOLAR RADIATION (B) FOR THE WETLAND FIELD SITE FOR THE ENTIRE SAMPLE SEASON.

FIGURE 3.5: STATISTICAL GRAPHS OF EACH BIOPHYSICAL VARIABLE SHOWING MEAN, MEDIAN AND COEFFICIENT OF VARIANCE.

FIGURE 3.6: KRIGED ST RESULTS SHOWING SPATIAL CHANGES IN THAW DEPTH ACROSS THE ENTIRE WETLAND FIELD SITE DURING THE THREE IDENTIFIED SEASONS OF "SPRING", "EARLY SUMMER", AND "PEAK GROWTH".

FIGURE 3.7: KRIGED AL RESULTS SHOWING SPATIAL CHANGES IN THAW DEPTH ACROSS THE ENTIRE WETLAND FIELD SITE DURING THE THREE IDENTIFIED SEASONS OF "SPRING", "EARLY SUMMER", AND "PEAK GROWTH".

FIGURE 3.8: KRIGED SM RESULTS SHOWING SPATIAL CHANGES IN THAW DEPTH ACROSS THE ENTIRE WETLAND FIELD SitE DURING THE THREE IDENTIFIED SEASONS OF "SPRING", "EARLY SUMMER", AND "PEAK GROWTH".

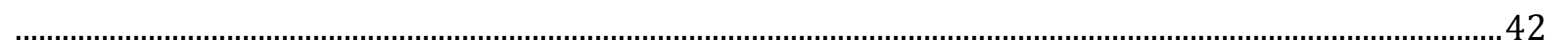

FIGURE 3.9: DEM ANALYSIS OF THE ELEVATION WITHIN THE WETLAND FIELD SITE AT CAPE BOUNTY. .44 


\section{List of Appendices}

APPENDIX A. VARIAGRAMS OF KRIGED DATA

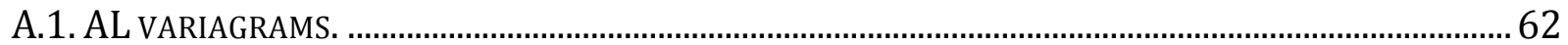

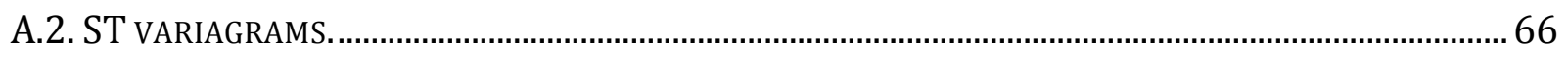

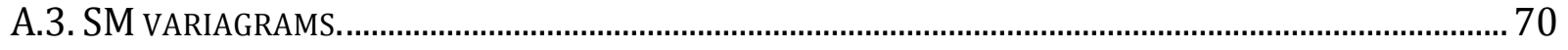




\section{List of Acronyms}

AL: Active layer. This is the area of ground above the permafrost layer that thaws during spring and summer, thus becoming biologically active.

APE: Average prediction error. A measurement used in cross-variance analysis of different kriged layers.

CV: Co-efficient of variance. This represents the variations within the sample data of the standard deviations around the mean values.

DEM: Digital elevation model.

GIS: Geographical information system. Analysis and manipulation of geographical data.

GPS: Global positioning system.

IKONOS: Observation satellite used to take images for remote sensing analysis.

MET: Meteorological data including net solar radiation, precipitation and air temperature.

MPE: Mean prediction error. This is a measure of bias during cross-validation of kriged layers. 
RMSSPE: Root mean square standardized prediction error. A measurement used in crossvariance analysis of different kriged layers.

RMSPE: Root mean square prediction error. Measures accuracy of interpolated values within spatial analysis.

SM: Soil moisture. The moisture content in \% volume within the organic soil layer situated $6 \mathrm{~cm}$ from the ground surface.

ST: Soil temperature. The temperature in ${ }^{\circ} \mathrm{C}$ of wetland soil at a depth of $5 \mathrm{~cm}$. 


\section{Introduction}

The Arctic has seen greater climate warming in the last decade than anywhere else on earth (Walker, 2000; Stieglitz et al., 2000; Stow et al., 2004; Walker et al., 2005; Nobrega \& Grogan, 2008; Elmendorf at al., 2012; Screen \& Simmonds, 2012). Considering the fragile ecosystems that exist in the Arctic and the large ground carbon stores that could be released, climate impacts in this region need to be understood (Walker, 2000; Walker et al., 2005; Wang et al., 2006; Nobrega \& Grogan, 2008; Screen \& Simmonds, 2012). Twice the volume of carbon currently in our atmosphere is estimated to be sequestered beneath Arctic wetlands, which are sustained by a strong hydrological input (Anisimov, 2007; Nobrega \& Grogan, 2008). Many wetlands form under perennial snowbanks (nival) or in topographic depressions that promote ponding and inhibit drainage, whilst others form adjacent to rivers and lakes where lateral ground water seepage occurs (Roulet \& Woo, 1986; Woo \& Young, 2006; Woo, Young \& Brown, 2006). Previous research within wetland ecosystems has focused on the vegetative community dynamics (Atkinson \& Treitz, 2012, 2013), hydrochemistry (Buttle \& Fraser, 1992; Thompson \& Woo, 2009) and the hydrological regimes (Roulet \& Woo, 1986a, 1986b; Woo \& Young, 1998, 2003, 2006; Woo, Young \& Brown, 2006; Abnizova \& Young, 2009) necessary to support these ecosystems. These studies have all considered soil moisture (SM), soil temperature (ST) and active layer depth (AL) in analyzing the biotic nature of these wetlands, but there is a lack of research into the spatial and temporal patterns of these biophysical variables, and their interactions. The active layer is commonly defined as the area of ground above the permafrost upper limit that thaws in summer, thus allowing it to become biologically "active". The growing 
season is short, consisting only of June and July (Stieglitz et al., 2000; Stow et al., 2004; Walker, 2005; Nobrega \& Grogan, 2008). How these three biophysical variables interact within a wetland during that time can help delineate the link between hydrological input, in this case from a perennial snowbank, and the driving forces behind wetland community existence.

Nobrega and Grogan (2008) conducted a study within a High Arctic wetland for a summer thaw season in Northern Canada measuring SM, ST and AL weekly at a single site in order to help explain $\mathrm{CO}_{2}$ flux. Similar field methodologies have been used in this study with the added dimension of sampling spatially not just temporally. As will be clarified further within the subsequent hypotheses section (1.1), there is conflicting evidence for the changes in SM values during June and July. For example, Woo and Young (2006) have evidence supporting the claim that SM values remain similar all season, whilst Roulet and Woo (1986a, 1986b) show declining values as AL increases. It can therefore be seen that a spatial component is needed to help investigate these biophysical variables. The assumptions made from point data at a single sample site may not be representative for an entire wetland. This study aims to build on the temporal aspect already utilized by previous studies by sampling every two days whilst also sampling spatially over an entire wetland in order to further enhance our understanding of this fragile ecosystem.

\subsection{Research Hypotheses}

\section{Research Question:}


What are the spatial and temporal patterns and relationships among the biophysical variables of SM, ST, and AL within a nival driven High Arctic wetland ecosystem?

The following four hypotheses aim to help answer this research question and are all addressed within the manuscript presented in Chapter 3. Chapters 4 and 5 will link the results presented in Chapter 3 back into this larger research question with limitations, problems and future implications of this study all being discussed at this time.

\section{Hypotheses:}

Research by Roulet and Woo (1986a, 1986b), Glen and Woo (1997), Woo and Young (2003, 2006), Nobrega and Grogan (2008), and Abnizova and Young (2010) all showed a deepening $\mathrm{AL}$ as the thaw season progressed through June and into July but it remained less than $1 \mathrm{~m}$ in depth. In addition, Woo and Young $(2003,2006)$ showed that the AL only thawed as snow cover decreased, implying shallower AL depths in proximity to an overlying perennial snowbank. Thus hypothesis one (HP1) can be made:

HP1- As the thaw season progresses, AL will increase in depth and sites farther from the snowbank will thaw sooner than sites closest, lending to a pattern of decreasing AL depths towards the snowbank.

Roulet and Woo (1986) and Nobrega and Grogan (2008) suggest a surge in ST values through spring (June) during peak solar radiation and then stable temperatures around $5^{\circ} \mathrm{C}$ until fall (August) when they decrease back to freezing. In fact, Nobrega and 
Grogan (2008) proposed a two-day time lag between incoming solar radiation values and subsequent increases or decreases in ST within Arctic wetlands. Rouse (2000) explained that wetlands exhibit a strong change in ST vertically due to saturated soil requiring more energy to heat than dry soil. This allows hypotheses two and three (HP2, HP3) to be made:

HP2- A link between ST and SM will be apparent with drier soils exhibiting higher average ST values than saturated sites.

HP3- ST will be seen to vary directly according to incoming solar radiation values.

Roulet and Woo (1986a, 1986b), Woo and Young (2003, 2006), Woo, Young and Brown (2006), Nobrega and Grogan (2008), and Atkinson and Treitz (2013) all conducted limited SM and water table sampling with the former calculated in the lab upon return from the Arctic and the latter in situ through the use of permanent wells. Water table in this respect can be considered the upper limit at which soils are completely saturated whilst SM is anything less than saturation. In these studies, data was collected with limited spatial coverage, with most having only one sample point and weekly measurements. Their data showed that saturation values were prevalent throughout the wetland but were sampled with limited spatial data and they generalized their results. The main conclusion drawn from these studies was that increases in SM lead to increases in above ground biomass. Woo and Young (2006), and Nobrega and Grogan (2008) found results that relate more specifically to this study. They generalized in saying that SM values remained similar throughout June and July for their entire wetland as the data they collected remained at a 
consistent value all season. Roulet and Woo (1986a, 1986b) showed a decrease in water table content by $20 \%$ at their study site. Woo, Young and Brown (2006), and Glen and Woo (1997) also indicated a drop in water table depth during the latter thaw season (July) due to increased thaw depth and an increase in evaporation after the initial snow melt period in June. These studies also showed that as AL increases with summer thaw, the storage capacity of the wetland also increases but is limited by the absorption properties of peat, implying that any losses to SM can be attributed mainly to evaporation. However, considering the limited spatial sampling of these previous studies, it could be possible that a generalized relationship between SM and AL cannot be applied to the entire wetland. Perhaps Woo and Young (2006) and Nobrega and Grogan (2008) sampled a site where inflow of melt remained all summer and allowed for a high water table to persist whilst the others saw an increasing AL depth with less inflow after peak melt creating a lowering water table and therefore soil moisture values. The presence of a late lying perennial snowbank within this study implies that there will be a continuous supply of meltwater throughout June and July and with limited data on drainage at this field site, it is expected that there will be wide spread saturated conditions. This allows hypothesis four (HP4) to be established:

HP4-SM will not vary with time across the study site and most sites will show complete saturation due to limited drainage and the presence of small AL depths due to the continuous hydrological input from the perennial snowbank at this location. 
As mentioned, the spatial and temporal aspect of this study will be one of the key defining features in this research. A concentrated sampling effort over an entire Arctic thaw season has never been undertaken at this intense level. Yang et al. (2011) is an example of an intense spatial sampling study of SM in an Arctic wetland in Tibet. Yang et al. (2011) used a geostatistical method of data analysis called kriging (full explanation within chapter two) and this analysis method was used within this study but with an added temporal dimension. Yang et al. (2011) showed that the measured SM values were moderately varied and showed a normal distribution of data. The wetland they studied had wide spread saturated conditions resulting in a low variance of results. As a similar Arctic wetland ecosystem is being investigated in this study, comparable results are expected. 


\section{Literature Review}

\subsection{Climate Change and Arctic Vegetation}

It is recognized widely that our global climate is changing (IPCC, 2014). With the publication of the latest IPCC report on climate change, not only is it clear that our oceans are warming, sea levels are rising and snow is diminishing, but also that anthropogenic sources of carbon are a major contributor to this changing climate (IPCC, 2014). The impacts are being seen globally and affecting almost every facet of life from loss of biodiversity of animal species as well as changes to migratory patterns (Chen et al., 2011; Martin \& Maron, 2012) to changes in crop yields leading to food security issues (Lobell, Schlenker \& Costa-Roberts, 2011). Water security is a growing concern with many mid latitudinal regions experiencing droughts, whilst higher latitudes are facing increased flooding (Hyndman, 2014). In the Arctic, glaciers, snow packs, sea ice, and ice sheets, are shrinking and causing an overall reduction in albedo (Vincent et al., 2011; Screen \& Simmonds, 2012; Liu et al., 2013; Vaughn et al., 2013). Increases in shortwave radiation absorption lead to enhanced thawing of permafrost and potentially releasing increased amounts of $\mathrm{CH}_{4}$ and $\mathrm{CO}_{2}$, which may enhance climate change (Wang et al., 2006; Anisimov, 2007; Nobrega \& Grogan, 2008; Shuur et al., 2009; Tarnocai et al., 2009; Dag \& Lafleur, 2011; Vincent et al., 2011). This is in addition to releasing large volumes of freshwater that could have huge detrimental effects to the global thermohaline circulation (Schellnhuber \& Cramer, 2006; Schlesinger et al., 2006; Levermann et al., 2012).

The geographic focus of this study is on Arctic regions, specifically the Canadian High Arctic, as these areas play a vital role in our global climate system. Any climate change effects in this region are felt particularly strongly and will in turn have global consequences 
(Walker, 2000; Walker et al., 2005; Wang et al., 2006; Nobrega \& Grogan, 2008; Screen \& Simmonds, 2012). There is strong evidence showing that the ambient air temperature within polar latitudes has been warming at a rate twice that of the rest of the world (Walker, 2000; Stieglitz et al,. 2000; Stow et al., 2004; Walker et al., 2005; Nobrega \& Grogan, 2008; Elmendorf et al., 2012; Screen \& Simmonds, 2012). This is cause for concern. Sea ice, glaciers and snow pack all contribute to the albedo effect that allows the earth to reflect much of the incoming shortwave solar radiation and helps decrease global temperatures. Arctic warming is causing these frozen surfaces to melt rapidly during summer months, increasing shortwave radiation absorption, altering evapotranspiration, and precipitation patterns resulting in a positive feedback loop with decreases in snow and ice accumulation each winter (Nobrega \& Grogan, 2008; Vincent et al., 2011; Screen \& Simmonds, 2012; Atkinson \& Treitz, 2013). Stieglitz et al. (2000) estimated that by the year 2060, snow will fall later and melt earlier, there will be an overall decrease of $43 \%$ in Arctic snowpacks, a $1.25^{\circ} \mathrm{C}$ increase in soil temperatures and an increase in ground thaw depth (active layer) of $35 \mathrm{~cm}$. However, the effects of Arctic warming are not limited to biophysical impacts. There is growing concern over food and water security for Inuit communities as a result of a loss of freshwater storage and reliable food provisions (White et al., 2007; Sharma, Couturier \& Côté, 2009; Ford \& Beaumier, 2011). There have been modifications to hunting and food supplies as caribou and muskox migration patterns change due to alterations in habitat (Ford \& Pearce, 2012; Ford et al., 2012). Permafrost degradation leads to surface water losses (White et al., 2007) and less sea ice is leading to issues with seal hunting and therefore a reduction in the significance of traditional knowledge from elders (Ford et al., 2012; Macdonald et al., 2012). 
One of the largest concerns after decreased albedo is the effect of permafrost thaw. Permafrost can be defined as any ground that remains below $0^{\circ} \mathrm{C}$ for more than two consecutive years. In the Arctic, $54 \%$ of the soil area is permafrost that contains almost twice the volume of carbon currently in our atmosphere. This is due to reduced plant respiration, shorter growing seasons and thinner active layers (Shuur et al., 2009; Tarnocai et al., 2009). Any warming effects could cause $\mathrm{CO}_{2}$ and $\mathrm{CH}_{4}$ to be released and produced at a greater rate. In fact, potential changes to permafrost carbon stores are one of the least understood and yet most significant potential impacts of Arctic warming (Tarnocai et al., 2009). Stored greenhouse gases could be released if more areas of permafrost were to thaw through increased warming (Vincent et al., 2011). This would only feed into the already damaged climate system and exacerbate the problem, creating a positive feedback loop of increased warming and increased thaw (Lova \& Grogan, 2004; Tarnocai et al., 2009; Nobrega \& Grogan, 2008; Shuur et al., 2009; Dag \& Lafleur, 2011).

Despite this potential terrestrial carbon catastrophe, the Arctic accounts for $7 \%$ of the world's land surface at six million $\mathrm{km}^{2}$ (Nobrega \& Grogan, 2008; Atkinson \& Treitz, 2012), yet contains up to $50 \%$ of our global soil organic carbon stores (Stieglitz et al., 2000; Tarnocai et al., 2009; Dag \& Lafleur, 2011). The vegetation that exists within this environment is key in helping delineate some concerns in permafrost thaw as it can be seen to be both an integrator and indicator of climate change (Atkinson \& Treitz, 2013). The importance of vegetation and varying tundra types in this northern region cannot be underestimated. The fragile Arctic ecosystems of plant communities are highly sensitive to disturbances in climate (Stow et al., 2004; Walker et al., 2005). Currently the entire vegetation ecosystem is helping mitigate climate change, but if the extent of vegetative 
species were to change due to climate warming or cooling, then the Arctic could become an integrator in climate change (Stieglitz et al., 2000; Tarnocai et al., 2009; Nobrega \& Grogan, 2008; Atkinson \& Treitz, 2012; Atkinson \& Treitz, 2013).

At present, the Arctic vegetative ecosystem is a carbon sink as photosynthesis allows for the uptake of $\mathrm{CO}_{2}$ in a greater capacity than is released though plant and microbial respiration (Stieglitz et al., 2000; Anisimov, 2007; Nobrega \& Grogan, 2008; Dag \& Lafleur, 2011; Williams et al., 2001; Atkinson \& Treitz, 2012; Atkinson \& Treitz, 2013). This balance is key. However, changes to soil moisture, air temperature, precipitation, hydrological regime, soil organic matter, active layer depth and nutrient availability (Walker et al., 2005; Elmendorf et al., 2012; Atkinson \& Treitz, 2013) could allow for this scale to tip and the Arctic would become a source instead of a sink (Lova \& Grogan, 2004; Atkinson \& Treitz, 2012). The effect of climate warming would be two fold. It would promote plant growth and therefore more carbon sequestration, but it would also allow for more microbial respiration and permafrost thaw thereby releasing more carbon (Tarnocai et al., 2009; Elmendorf et al., 2012; Atkinson \& Treitz, 2013). If the second factor out weighs the first, a positive feedback system is established thereby increasing the problem (Atkinson \& Treitz, 2013). The main drivers in determining vegetation distribution, and therefore "sink" status, are soil moisture and topography, which create variations in hydrological regimes (Walker, 2000; Nobrega \& Grogan, 2008; Atkinson \& Treitz, 2013) whilst the limiters to growth, or promoters of "source" status are climate and nutrient availability with both saturated soils and dry soils being nitrogen poor (Atkinson \& Treitz, 2012).

Almost 34\% of vegetation within the Arctic is in the high Arctic where, aside from approximately two months of the year, temperatures are consistently below freezing and 
the ground remains snow covered (Elmendorf et al., 2012). This means that the harsh climate environments lend to a short, slow growing season and the existence of a fragile ecosystem where even small changes can have a huge impact on species diversification and productivity (Stow et al., 2004). Many studies have been completed examining the variations in vegetation within the Arctic. It can be concluded that temperature varies with latitude, which in turn drives changes in the moisture gradient of the soils. In this study area, the High Arctic, the low temperatures and limited moisture availability creates three main tundra types that exist to form a patchy landscape: dry, mesic and wet (Walker, 2000; Nobrega \& Grogan, 2008; Dag \& Lafleur, 2011; Atkinson \& Treitz, 2012; Atkinson \& Treitz, 2013). As described by Atkinson \& Treitz (2013), these three classes can be identified through differences in soil moisture content and vegetation extent at a given bioclimatic zone. The first class is the dry, polar desert tundra environment that is moisture and nutrient poor and therefore deprived of flora. There is low species diversity and it can be described as barren (Walker, 2000). The mesic tundra environments have a moderate level of soil moisture and nutrients lending to a comparatively greater intensity of vegetation. The final tundra class type is wet sedge tundra, which can be considered a wetland due to high soil moisture saturation and the presence of expansive vegetation and greater species diversity. For the purpose of this study, the terms wet sedge tundra and wetland shall be used interchangeably. The polar desert tundra is the most spatially extensive of the three environments in this area of the High Arctic (Atkinson \& Treitz, 2013) with wet sedge communities covering only 7\% of the Canadian Arctic (Walker, 2000; Walker et al., 2005). This implies that these small, localized areas of wetland communities that provide the greatest concentrations of vegetation but within far smaller areas are of great importance. 
In fact, there is four times the volume of carbon stored in wet sedge environments than both the mesic and polar desert tundras, with estimates at $50 \mathrm{Gt}$ in Arctic wetland soils alone (Anisimov, 2007; Nobrega \& Grogan, 2008).

\subsection{Arctic Wetlands}

It has been mentioned that polar desert environments are common in the High Arctic and that isolated patchy wetlands exist sporadically within the tundra ecosystem. Despite their decreased numbers, these wetlands contribute more to our global climate carbon system, through photosynthesis and low respiration rates from soil moisture saturation, than the common polar desert tundra. In addition, these wetlands contain more carbon stores (Walker, 2000; Ellis \& Rochefort, 2006; Anisimov, 2007; Nobrega \& Grogan, 2008; Dag \& Lafleur, 2011). They are also an important ecological habitat for insects, birds, muskox and caribou (Glen \& Woo, 1997; Woo \& Young, 2003, 2006; Woo, Young \& Brown, 2006). In spite of their obvious importance to the Arctic ecosystem, there is a lack of research and publication within this area (Roulet \& Woo, 1986; Woo \& Young, 2003, 2006). Previous studies have focused mostly on the biotic nature and hydrological regime of these wetlands with limited data on the biophysical interactions within them.

Atkinson and Treitz (2012; 2013) focused on biophysical variables (above ground biomass, percent vegetation cover, soil moisture and carbon flux) within tundra communities and their relation to spectral indices; this research was the first of its kind in the Canadian High Arctic. Buttle and Fraser (1992), and Thompson and Woo (2009) focused on defining the hydrochemistry of these wetland communities whilst Roulet and Woo (1986a, 1986b), Woo and Young (1998; 2003; 2006), Woo, Young and Brown (2006), and Abnizova and Young (2009) determined the hydrological regimes under which these 
environments form. The conclusions drawn from these studies help outline how the ecological processes and functions of these wetlands form within the Arctic environment. It can be seen that wet sedge tundra is characterized by prevalent saturation of the AL for most of the summer thaw season where the water supply into the wetland surpasses losses to evaporation and outflow (Roulet \& Woo, 1986; Woo \& Young, 1998, 2003, 2006; Woo, Young \& Brown, 2006). The initial melt of snow covering the wetlands happens in spring (early June) and causes a wash of nutrients to be deposited on top of the frozen wetland (Thompson \& Woo, 2009). At this point, the frozen wetland inhibits the percolation of this melt water down into the soil and therefore promotes lateral flow over the wetland (Roulet \& Woo, 1986; Woo \& Young, 2003). As the AL thaws, the consistent inflow of meltwater from overlying perennial snowbanks allows the water table to increase and remain near the soil surface for the remainder of the summer (July), whilst the impermeable permafrost below inhibits percolation of this meltwater (Roulet \& Woo, 1986; Woo \& Young, 1998; 2006). These saturated ground conditions create anoxic environments within the shallow organic soil layer, which slows decomposition and promotes peat formation (Rouse, 2000; Woo \& Young, 2003). Arctic wetlands are rich in peat, which has a high porosity and a high potential for water retention, both of which enhance saturation of these wetlands (Roulet \& Woo, 1986; Woo \& Young, 1998, 2003; Rouse, 2000; Stieglitz, 2000; Ellis \& Rochefort, 2006). Additionally, peat is a good insulator, which helps aggrade the underlying permafrost, but ground ice requires much latent heat to thaw and with the high water content of the overlying soil and short summer season, a shallow AL depth is created (Rouse, 2000; Woo \& Young, 1998, 2003, 2006). Wetland communities have a comparably smaller AL depth at less than 1m (Roulet \& Woo, 1986; Woo, Young \& Brown, 2006) 
compared to polar desert or mesic environments that can have AL depths of over $1 \mathrm{~m}$ (Nobrega \& Grogan, 2008; Wang et al., 2011). Walker (2000), Walker et al. (2005), and Atkinson and Treitz $(2012 ; 2013)$ all indicate that the wet sedge tundra is comprised of abundant sedge species and underlain predominantly (>90\%) by Bryophytes. These species thrive in saturated environments with shallow root zones in limited organic soil horizons that quickly become inactive if experiencing a lack of SM (Rouse, 2000; Woo \& Young, 2003). The lack of SM and ground water flow into the polar desert environments makes their capacity for AL thaw greater, so they exhibit larger AL depths and higher soil temperatures (ST) and lower SM values than wetland tundra systems (Woo \& Young, 1998).

With hydrological regime and a high water table being such key drivers for this ecosystem, there is limited research on SM and its interaction with other biophysical variables like AL and ST. Nobrega and Grogan (2008) looked at all three biophysical variables but with limited spatial and temporal range, having only six sample sites. Woo and Young $(2003 ; 2006)$ took SM measurements within an Arctic wetland and proved that the use of point data was poor in determining the spatial component of SM and concluded by identifying the need for further research into the biophysical interactions within these wetlands. Within many of these studies, SM was measured only at peak growing season with limited spatial coverage and not in situ, drawing conclusions from this can be considered unreliable due to the high spatial variability of SM (Yang et al., 2011). Studies by Lin et al., 2006, and Yang et al., 2011, both applied simple kriging to interpolate SM values with great success. The former study included a temporal aspect similar to this study but within a different ecological setting. Both found the kriging method of statistical 
interpolation of missing values to be accurate with viable results for comparison with other data.

In this study, kriging analysis was performed on each variable to create interpolated data for missing points and therefore a completed surface of values for the entire wetland. By looking at the distribution of data, heterogeneity of values and spatial autocorrelation of data points, interpolated values for missing areas were created (Siska \& Hung, 2001; Johnston et al., 2001; Petrone et al., 2004). Spatial autocorrelation allows patterns in heterogeneity to be investigated. Variagram analysis was used to look at spatial autocorrelation between sample sites whereby the assumption is made that objects farther apart from one another show a greater difference in value than objects closer together (Nyberg, 1996; Schneider et al., 2008; Yang et al., 2011). In this way, variagram analysis creates a graph plotting distance between two points against the squared difference in value between those two points. From this, a variogram model can be applied to the averaged values in order to create a regression line that best represents the distribution of data. This can then be used to interpolate the missing values in order to create one complete surface map of $\mathrm{AL}, \mathrm{ST}$ and SM values at that moment in time. Cross-validation analysis between measured and interpolated values is used to check kriging accuracy (Nyberg, 1996; Petrone et al., 2004; Schneider et al., 2008; Yang et al., 2011).

Lin et al., 2006, and Yang et al., 2011, both illustrate the high variability in SM within small areas and it has been clearly stated how important SM is to the creation of wetland ecosystems. More so, it has been illustrated that inter-seasonal soil moisture changes may be a determining factor in the formation of the various high Arctic tundra vegetation communities through the production of Nostoc, a nitrogen-fixing cyanobacterium that is 
much needed in a nutrient poor soil environment (Lennihan, Chapin, \& Dickson, 1994; Woo \& Young, 2003, 2006; Atkinson \& Treitz, 2012). This suggests that further work is needed both spatially and temporally with regard to soil moisture interactions within these arctic wetlands. To address this the four hypotheses laid out previously were established to guide the investigation of each variable within this environment and their interactions over time.

HP1- As the thaw season progresses, AL will increase in depth and sites farther from the snowbank will thaw sooner than sites closest lending to a pattern of decreasing AL depths towards the snowbank.

HP2- A link between ST and SM will be apparent with drier soils exhibiting higher average ST values than saturated sites.

HP3-ST will be seen to vary directly according to incoming solar radiation values.

HP4-SM will not vary with time across the study site and most sites will show complete saturation due to limited drainage and the presence of small AL depths due to the continuous hydrological input from the perennial snowbank at this location.

Currently, there is very little research into the potential impacts that a changing climate may have to these wetlands. Increased temperatures are causing late lying snowbanks to melt faster and at a greater volume which will lead to a net decrease in size over time if the predictions of a warming Arctic are true (Woo \& Young, 2006; Woo, Young 
\& Brown, 2006). Considering that a strong, reliable hydrological input is key in maintaining these wetlands, any changes or decreases to this source will cause these ecosystems to be unable to persist (Woo, Young \& Brown, 2006). The research presented here can contribute to this field of study through development of methodologies, and the application of spatial modeling of the point data collected. This research will help connect late season and perennial snowmelt with the adjacent wetlands. Not only does this study build on previous research by Atkinson and Treitz $(2012 ; 2013)$ within this specific field, but it also forms a high spatial and temporal resolution dataset for future biophysical and biogeochemical studies. 


\section{High spatial and temporal modelling of biophysical variables within a High Arctic wetland.}

\subsection{Introduction}

The Arctic has seen greater climate warming in the last decade than anywhere else on earth (Walker, 2000; Stieglitz et al., 2000; Stow et al., 2004; Walker et al., 2005; Nobrega \& Grogan, 2008; Elmendorf et al., 2012; Screen \& Simmonds, 2012; IPCC, 2014). Considering the fragile ecosystems that exist in the Arctic and the large ground carbon stores that could be released from permafrost thaw, climate impacts in this region need to be addressed (Walker, 2000; Walker et al., 2005; Wang et al., 2006; Nobrega \& Grogan, 2008; Screen \& Simmonds, 2012). Twice the volume of carbon currently in our atmosphere is sequestered beneath Arctic wetlands (Anisimov, 2007; Nobrega \& Grogan, 2008). Previous studies within wetland ecosystems have focused on the vegetative communities (Atkinson \& Treitz, 2012, 2013), hydrochemistry (Buttle \& Fraser, 1992; Thompson \& Woo, 2009), inter-seasonal $\mathrm{CO}_{2}$ flux (Nobrega \& Grogan, 2008; Tarnocai et al., 2009; Dag \& Lafleur, 2011; Elmendorf et al., 2012), and the hydrological regimes necessary to support this ecosystem (Roulet \& Woo, 1986a, 1986b; Woo \& Young, 1998, 2003, 2006; Woo, Young \& Brown, 2006; Abnizova \& Young, 2009). These studies have all considered soil moisture (SM), soil temperature (ST) and active layer depth (AL) in analyzing the biotic nature of these wetlands and their resultant $\mathrm{CO}_{2}$ fluxes, but there is a lack of research into these biophysical interactions alone at a high spatial and temporal scale. This study aims to investigate the high spatial and temporal resolution patterns and relationships between 
the biophysical variables of SM, ST, and AL within a nival driven High Arctic wetland ecosystem. How these three biophysical variables interact within a wetland during the summer thaw season can help delineate the links between snowmelt and the driving forces behind wetland community existence. The spatial aspect of this study will aid in investigating a new aspect of biophysical variability that has limited previous study.

Wetland tundra is characterized by prevalent saturation of the AL for most of the summer thaw season where the water supply into the wetland surpasses losses to evaporation and outflow (Roulet \& Woo, 1986; Woo \& Young, 1998, 2003, 2006; Woo, Young \& Brown, 2006). Many wetlands form under perennial snowbanks (nival) or in topographic depressions that promote ponding and inhibit runoff, whilst others form adjacent to rivers and lakes where lateral ground water seepage occurs (Roulet \& Woo, 1986; Woo \& Young, 2006; Woo, Young \& Brown, 2006). The initial melt of snow covering the wetlands happens in spring (June) and causes a wash of nutrients to be deposited on top of the frozen wetland with limited percolation due to the frozen AL (Thompson \& Woo, 2009). As the AL thaws, it is limited by the large volume of latent heat required to thaw frozen soil under saturated conditions lending to a shallow AL depth that in turn limits the percolation of this meltwater down into the soil. The consistent inflow of meltwater from overlying perennial snowbanks allows the water table to increase and remain near the soil surface for the remainder of the summer (July), whilst the impermeable permafrost below inhibits percolation of this meltwater (Roulet \& Woo, 1986; Woo \& Young, 1998, 2003, 2006). These isolated patches of wet ground lead to the growth of lush vegetation and are vital to the Arctic environment providing many ecological benefits including wildlife habitats for insects, birds, muskox and caribou (Glen \& Woo, 1997; Woo \& Young, 2003, 
2006; Woo, Young \& Brown, 2006). However the dry, nutrient deprived, vegetation poor polar desert tundra is the most spatially extensive within the Arctic (Woo \& Young, 1998, 2003, 2006; Atkinson \& Treitz, 2013) with wetland communities covering only $7 \%$ of the Canadian Arctic (Walker, 2000; Walker et al., 2005).

The effect of climate warming on these ecosystems would be two fold. It would promote plant growth and therefore more carbon sequestration, but it would also allow for more microbial respiration and permafrost thaw thereby releasing more carbon (Tarnocai et al., 2009; Elmendorf et al., 2012; Atkinson \& Treitz, 2013). If the second factor out weighs the first, a positive feedback system is established thereby increasing the problem (Atkinson \& Treitz, 2013). The main drivers in determining vegetation distribution, and therefore "sink" status, are soil moisture and topography, which create variations in hydrological regimes (Walker, 2000; Nobrega \& Grogan, 2008; Atkinson \& Treitz, 2013) whilst the limiters to growth, or promoters of "source" status are climate and nutrient availability with both saturated soils and dry soils being relatively nitrogen poor (Atkinson \& Treitz, 2012). Despite their decreased numbers, these wetlands contribute more to our global climate carbon system, through photosynthesis and low respiration rates (caused by soil moisture saturation) than the common polar desert tundra as well as containing more stored carbon (Walker, 2000; Ellis \& Rochefort, 2006; Anisimov, 2007; Nobrega \& Grogan, 2008; Dag \& Lafleur, 2011).

Previous studies focused on vegetation variables (above ground biomass, percent vegetation cover, and carbon flux) within wetland communities, with Atkinson and Treitz $(2012,2013)$ being the first of their kind at this field site. However, SM was measured only at peak growing season and with limited spatial coverage. Nobrega and Grogan (2008) 
conducted a study within a High Arctic wetland for a summer thaw season in Northern Canada measuring SM, ST and AL weekly at a single site in order to help explain $\mathrm{CO}_{2}$ flux. Similar field methodologies have been used in this study with the added dimension of sampling spatially not just temporally. As SM was measured with limited spatial coverage and not in situ, drawing conclusions from these previous studies can be considered unreliable due to the high variability of SM (Yang et al., 2011). Studies by Lin et al., 2006, and Yang et al., 2011, both applied simple kriging to interpolate SM values with great success. The former study included a temporal aspect similar to this study but within a different ecological setting. Both found the kriging method of statistical interpolation of missing values to be accurate with viable results for comparison with other data.

In this study, kriging analysis was performed on each variable to create interpolated data for missing points and therefore a completed surface of values for the entire wetland. By looking at the distribution of data, heterogeneity of values and spatial autocorrelation of data points, interpolated values for missing areas were created (Siska \& Hung, 2001; Johnston et al., 2001; Petrone et al., 2004). Spatial autocorrelation allows patterns in heterogeneity to be investigated. Variagram analysis was used to look at spatial autocorrelation between samples sites whereby the assumption is made that objects farther apart from one another show a greater difference in value than objects closer together (Nyberg, 1996; Schneider et al., 2008; Yang et al., 2011). In this way, variagram analysis creates a graph plotting distance between two points against the squared difference in value between those two points. From this, a variogram model can be applied to the averaged values in order to create a regression line that best represents the distribution of data. This can then be used to interpolate the missing values in order to 
create one complete surface map of AL, ST and SM values at that moment in time. Crossvalidation analysis between measured and interpolated values is used to check kriging accuracy (Nyberg, 1996; Petrone et al., 2004; Schneider et al., 2008; Yang et al., 2011).

Lin et al., 2006, and Yang et al., 2011, both illustrate the high variability in SM within small areas and it has been clearly stated how important SM is to the creation of wetland ecosystems. More so, it has been stated that inter-seasonal soil moisture changes may be a determining factor in the formation of the various high Arctic tundra vegetation communities through the production of Nostoc, a nitrogen fixing bacteria that is readily needed in a nutrient poor soil environment. This suggests that further work is needed both spatially and temporally in regards to biophysical interactions within these arctic wetlands.

Currently, there is very little research into the potential impacts that a changing climate may have to these wetlands. The research presented here can contribute to this field through development of methodologies, and the application of spatial modelling of the point data collected. This research will help connect late season and perennial snowmelt with the adjacent wetland. Through an increase in the spatial and temporal sampling of SM, ST and AL readings, it is hoped that a deeper understanding of the driving biophysical variables for this vegetation community can be achieved. Not only does this data build on to the previous studies, (Atkinson and Treitz, 2012; 2013), but it also forms a high spatial and temporal resolution dataset for future and expanding studies into other biophysical and biogeochemical studies. 


\subsection{Methodology}

\subsubsection{Study Area}

The data collected for this report came from the Cape Bounty Arctic Watershed Observatory located on Melville Island, Nunavut $\left(74^{\circ} 55^{\prime} \mathrm{N}, 109^{\circ} 35 \mathrm{~W}\right.$ ) (Figure 3.1.A). Melville Island is located west of Ellesmere Island within the Canadian High Arctic. Cape Bounty is situated on the south of Melville close to the Nunavut and North West Territories border. The area has an average daily temperature during summer of $3.7^{\circ} \mathrm{C}$, and the weather generally includes minimal precipitation, intermittent fog and frequent high winds. Two large lakes fed by two separate rivers and watersheds characterize the area that is underlain by Devonian sedimentary rocks covered in Holocene marine sediments and glacial till (Hodgson, Vincent \& Fyles, 1984).

The 4.0 ha field site chosen for this study was located directly beneath a large perennial snowbank that provided the hydrological input for this area (Figure 3.1.B). The sample site selected is located within a previous study area used by Atkinson and Treitz $(2012,2013)$ and can be classified as wet-sedge with a high soil moisture content leading to localized saturation with an abundance of sedge grasses and mosses (Walker et al., 2005; Nobrega \& Grogan, 2008). The summer melting period generally starts at the beginning of June with temperatures steadily rising throughout the following two months before falling to below freezing in mid-August and remaining there until June the following year (Steiglitz, 2000; Nobrega \& Grogan, 2008). This allows for a short period (two months approximately) when temperatures are consistently above freezing and so it presents a unique opportunity to study an entire Arctic thaw event. Peak vegetation growth can be

commonly seen mid to late July (Atkinson \& Treitz, 2013) whilst peak SM values can be 
seen in late June (Nobrega \& Grogan, 2008). In 2014 it was a comparatively colder season to previous years, with warmer temperatures not occurring until late June and therefore peak melt being seen in early July. Temperatures then decreased back down to freezing with snowfall beginning once again in early August. 

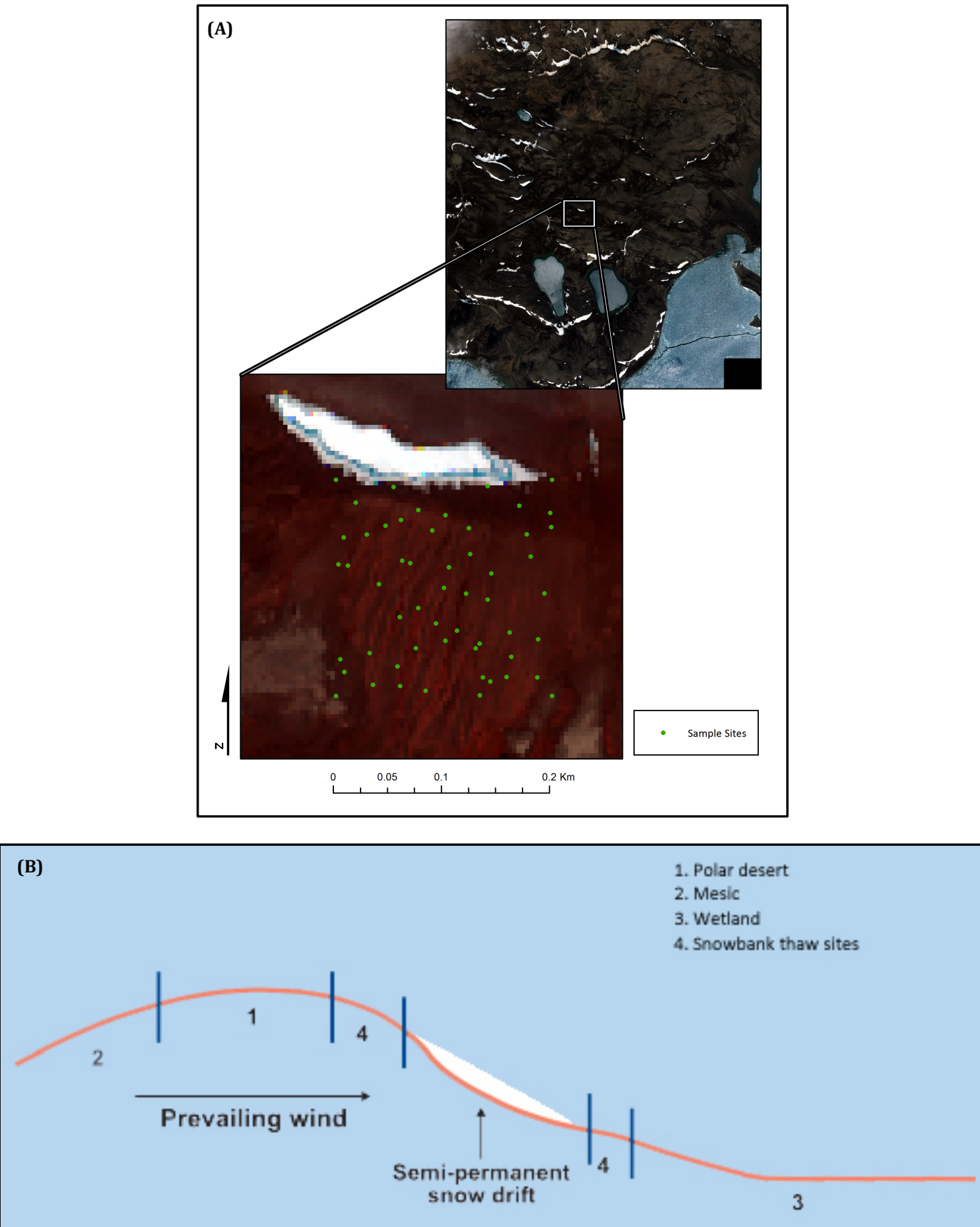

Figure 3.1: (A) Location map of the wetland field site within the Cape Bounty Arctic Watershed Observatory, Melville Island, Nunavut. Second IKONOS image displayed as a colored infrared composite image showing the locations of all sample collection sites. (B) Schematic transect of the perennial snowpack and wetland study area showing the location of the three tundra types present. Image has been adapted from Walker, 2000. 


\subsubsection{Data Collection}

Data collection for this study was completed from June 19 to July 30, 2014. A stratified random sampling technique was used in the 4 ha site (200 $\mathrm{m} \times 200 \mathrm{~m})$, it was subdivided divided into four cardinal quadrants $(100 \mathrm{~m} \times 100 \mathrm{~m})$. Within each quadrant, sample sites were randomly generated and their GPS co-ordinates uploaded to a GarminGPS map 76. In total, 55 of the intended 65 sample sites were used for analysis with ten removed for being too close to another site or in an area that could not be analyzed, on a rock for example. The wetland sample site finished with two quadrants containing 12 sites (SW and NE), one with 16 sites (SE) and finally one with 14 (NW). Only the specified 55 sites were selected for sampling and their locations allowed for adequate coverage over the field area for spatial interpolation (Figure 3.1.A) (Petrone et al., 2004; Pan et al., 2008; Yang et al., 2011). As of June $19,75 \%$ of the data sites were clear of snow and therefore determined suitable for sampling.

Biophysical variable data collection was performed individually for ST, AL and SM at each site. AL $(\mathrm{cm})$ was measured using an active layer probe inserted vertically down into the ground with force until resistance was met (Figure 3.2.A)(Woo \& Young, 1998; Nobrega \& Grogan, 2008). The probe was calibrated daily in the field to within $1 \mathrm{~cm}$. All ST $\left({ }^{\circ} \mathrm{C}\right)$ measurements were performed using a Taylor Precision Products Inc. digital thermometer model $9878 \mathrm{E}$ at a depth of $5 \mathrm{~cm}$ (Figure 3.2.B)(Nobrega \& Grogan, 2008). Finally, SM (\%Vol) was measured using a theta probe with attached HH2 moisture logger (Delta $\mathrm{T}$ Devices Ltd) at a depth of $5 \mathrm{~cm}$ (Figure 3.2.C). 

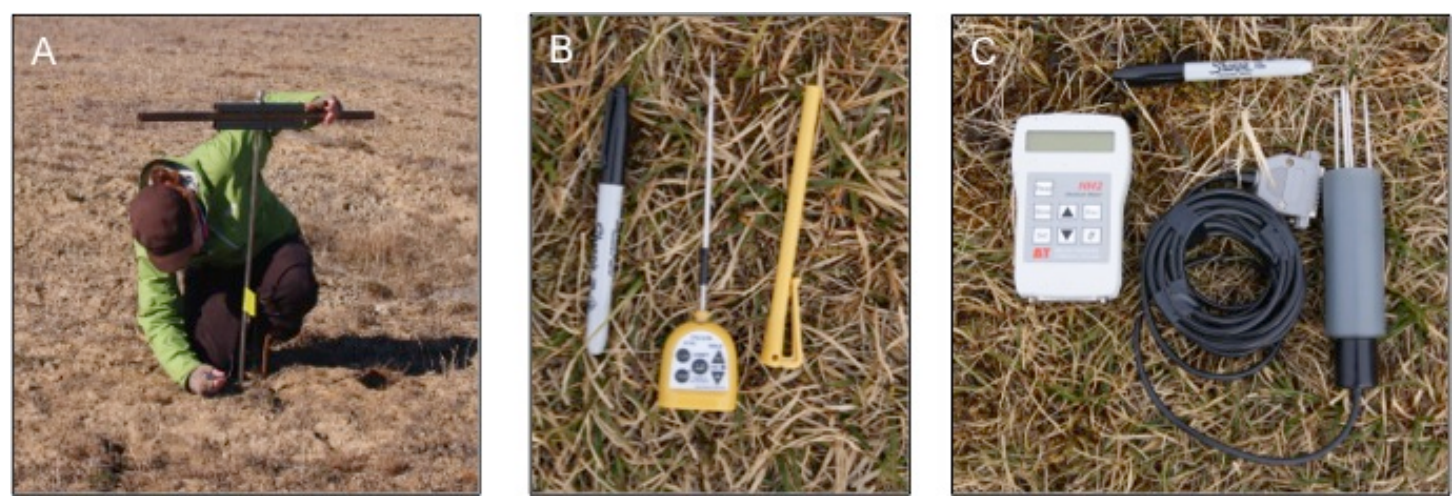

Figure 3.2: Field equipment used for data collection. (A)- AL probe. (B)- ST thermometer. (C)- SM Theta probe and data logger.

If AL was less than $5 \mathrm{~cm}$, ST and SM were not recorded. Not all sites thawed at the same rate and so it was decided that sampling be done daily but rotationally around the variables being measured. In this way, a series of 20 data sets were collected throughout the season, within which, all three biophysical variables were sampled and each set covered a 48-hour period. On the first day of each set, AL was measured at all 55 sample sites, which allowed variations in thaw depth to be studied. On the second day of sampling, only sites that showed an AL depth greater than $5 \mathrm{~cm}$ the previous day were sampled for ST and SM, thus completing the data set. This intensive daily sampling allowed for the temporal changes in this wetland to be investigated thoroughly with each sample point being measured for AL, SM and ST every 48 hours. This was deemed appropriate considering the fast changes in temperature and snowmelt seen in this environment. Sampling began June $19^{\text {th }}$ and within five days the snow covered sample sites reduced from $25 \%$ to $5 \%$, and within 10 days the sites available for SM sampling increased from $40 \%$ to $82 \%$ of the field area. The areas closest to the snowpack remained frozen longest and data collection at all 55 sample sites was not possible until July $20^{\text {th }}$. Due to this, sample size for SM and ST varies throughout 
the season. Additionally, there are 10 days of lost data during mid July due to issues with wildlife invading the field area, bad weather and broken equipment.

Two additional sources of field data were acquired through other sources. A digital elevation model (DEM) was acquired from Collingwood (2014) at a high spatial resolution of $1 \mathrm{~m}$. The DEM was acquired during the 2012 summer field season at Cape Bounty and was analyzed to study slope and aspect in order to investigate drainage patterns alongside the SM data. In addition, Queen's University (Kingston, ON) provided hourly meteorological (MET) data for the Cape Bounty sample site for the period of June 1 to July 31 which allowed incoming solar radiation analyses to be completed in order to investigate changes in ST and therefore potentially AL.

\subsubsection{Data Processing}

\section{KRIGING}

In total, eight data sets were chosen for kriging analyses that fairly represent the spring, early summer and late summer periods already identified. Two sets from June were chosen to represent early and late spring, a third set a week later representing early summer and finally, five sets from the last two weeks of July will show spatial changes during peak vegetation growth. These sets were also chosen as all three biophysical variables could be sampled at these times allowing for no missing data.

Spatial interpolation was applied to the values of the samples to examine spatial patterns within the data. General information on data outliers, distribution of data, and data variability within each data set were calculated before variagram analysis allowed a model of best fit to be added to the data values. Finally, cross-validation allowed for 
accuracy between models to be examined so that the most statistically accurate model was used for the final kriged layer (Pan et al., 2008; Yang et al., 2011). In order to have reliable data for each sample site for each set, assumptions had to be made in regards to frozen sample sites. As the AL of all sites differed there were examples of frozen ground where no SM reading could be taken. It was decided that the missing values would be set to the first unfrozen reading that could be taken as Stieglitz et al. (2011) showed that limited percolation of surface water occurs between fall freezing and spring thaw. In this respect, it was presumed that due to the intensity of sampling every 48 hours, it would be reasonable to presume that the moisture content of the soil would not have changed significantly in the time between the active layer thawing to below $5 \mathrm{~cm}$ (the threshold for theta probe analysis) and sampling.

\subsection{Results}

\section{TEMPORAL CHANGES}

Data were collected from June 19 to July 30, representing an entire thaw season. Temporally, the data sets cover both spring and summer and so these changes in season have been identified on all temporal graphs. As mentioned, a single set of data was collected every 48 hours with ST, SM, and AL all measured in this time. In total, 20 sets were collected covering 40 days from June 19 to July 29. In order to divide these sets up into comparable seasons, the following was decided. Sets 1 to 6 (June 19 to 30) represent initial spring thaw and snow melt. The remaining sets have been split into early summer from July 1 to 15 (sets 7 to 13) and peak growth or late summer from July 16 to 29 (sets 14 to 20$)$. 
Within Figure 3.3 the temporal changes to the three biophysical variables of SM, AL and ST are shown for the entire sampling season. First, the SM values remain fairly consistent throughout the wetland and only slightly increase in \% vol between peak growth and spring. The logarithmic trend line fit to the entire wetland SM data shows an $\mathrm{R}^{2}$ value of 0.65 , showing that there is a weaker relationship with this variable over time. This is to be expected if the averaged values show little change between seasons. However, it would be expected that after initial snowmelt the values would increase during early summer but despite lack of data, this does not seem the case. There is however, a strong difference in values between quadrants with SE and NE areas showing a higher average saturation level than the NW and SW quadrants by almost $20 \%$ vol creating an east to west (E/W) trend. The other hydrological input of rain can be seen to have minimally affected the wetland and SM values, Figure 3.4.A. There was no precipitation for spring and most of early summer. Peak growth saw the greatest input of rain, but with limited changes in SM values.

Second, it can be seen that AL increases in depth throughout spring and summer. The second order polynomial trend line fits the average data well to give an $\mathrm{R}^{2}$ value of 0.99 . The rate of change decreases as the season progresses with the period of peak growth showing a slower rate of thaw than in spring and early summer. At the quadrant level, the SE has a shallower overall thaw depth with the NW having a much deeper AL depth throughout the season. Both the NE and SW quadrants have similar thaw depths and so the average for the entire wetland is situated here.

Finally, ST values show a steady increase during spring thaw and early summer, but then erratic fluctuations during peak growth. The second-order polynomial trend line shows an $\mathrm{R}^{2}$ squared value of 0.73 for changes in ST with time. This is higher than SM but 
lower than AL. It can be seen that the fastest changes in ST were seen during spring, before the rate of change slowed during early summer and eventually plateaued through peak growth, similar to the changes seen in AL. At the quadrant level, throughout both spring and summer, the SE and NE quadrants have lower average ST values similar to the SM and AL, which further implies a potential E/W spatial trend. Despite the plateau of changing ST values during peak growth, highly variable short-term fluctuations in ST values are clearly seen. These erratic variations in temperature can be explained partially by investigating incoming solar radiation levels (Figure 3.4.B). It can be clearly seen that ST values steadily increase during spring and early summer despite fluctuating solar radiation and air temperatures. As the season reaches peak growth, the ST values begin to fluctuate as previously explained, but the solar radiation and air temperature values change on the same temporal scale. The ST values within the wetland clearly match up with the air temperature and solar radiation fluxes during late July. 

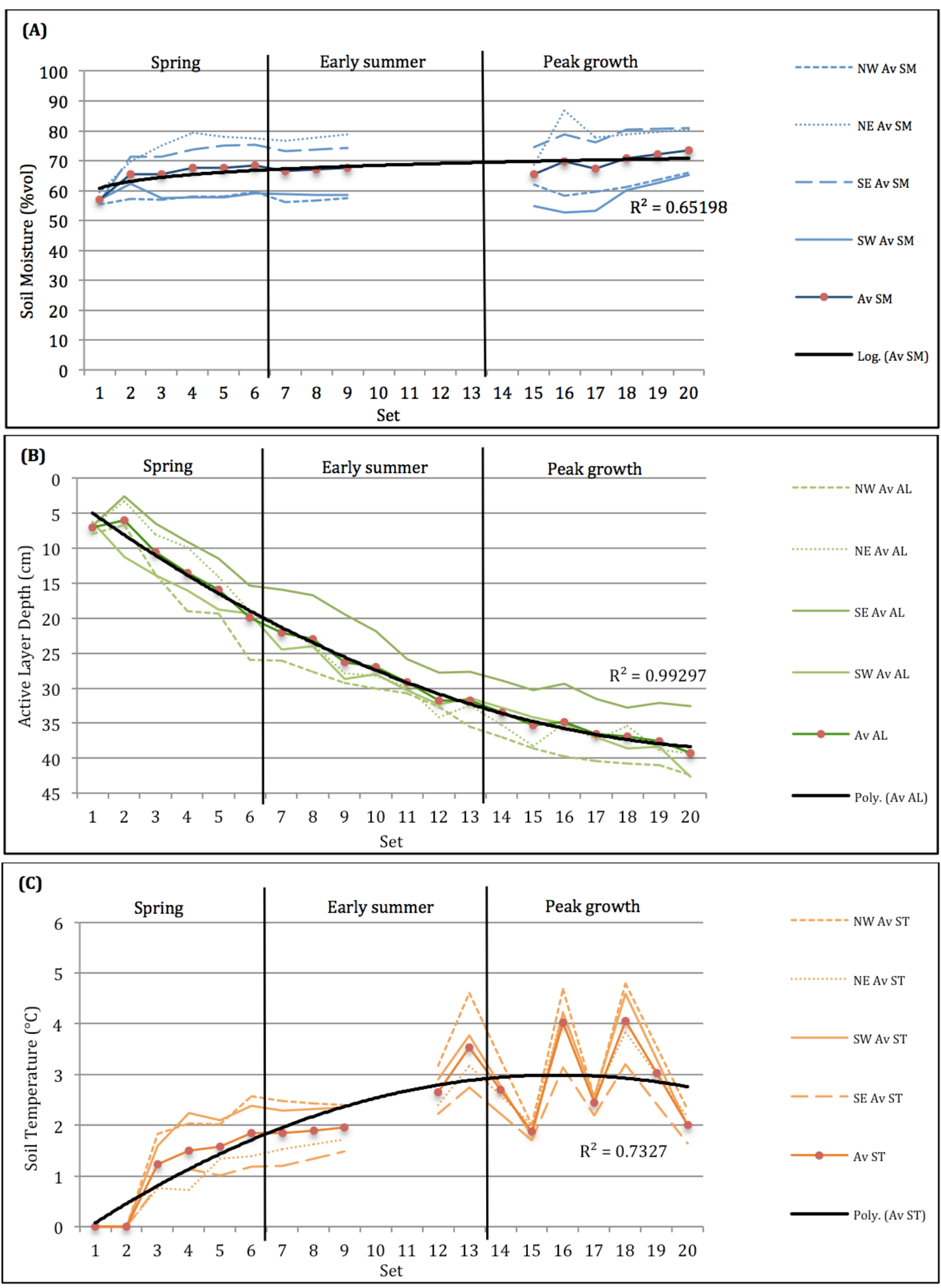

Figure 3.3: Graphs showing averaged biophysical variable values for the entire wetland for the complete sampling season. (A) SM. (B) AL. (C) ST. 

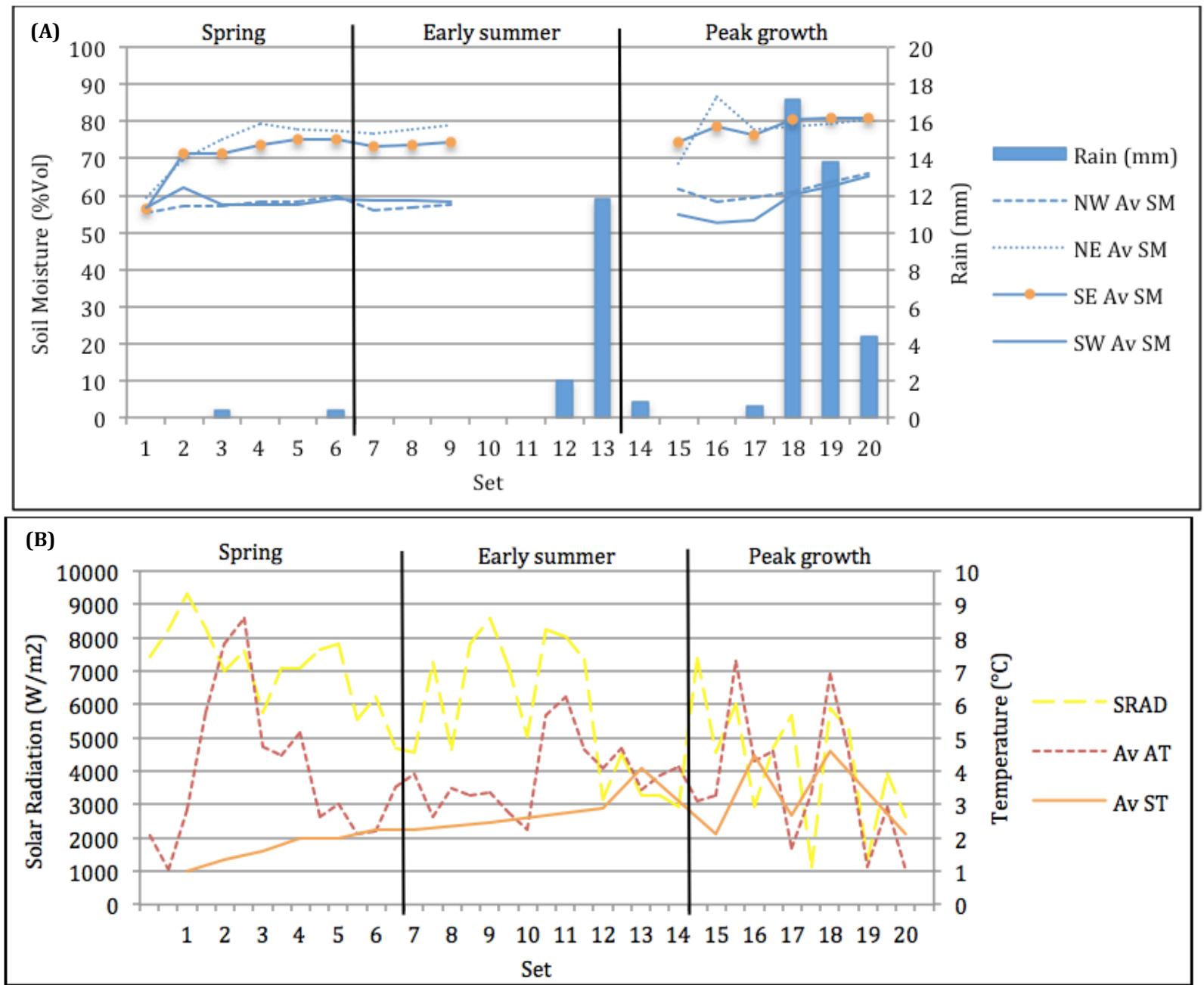

Figure 3.4: Graphs showing total rain (A) and incoming solar radiation (B) for the wetland field site for the entire sample season.

The general descriptive statistics in Figure 3.5 allow for variations between sample sets to be looked at further. As expected, the temporal changes in mean and median values are identical to the relationships just described. However, what is key to note is that the median values remain similar to their corresponding means implying that outliers do not dominate any of the data sets. In addition, the coefficient of variance has all results being greater than $30 \%$, the threshold for data showing "strong variation" between values (Yang 
et al., 2011). This means that as well as showing variations between sets, there are strong variations in values within individual sets. The lowest values were seen within the SM data sets with variance remaining consistently around $30-35 \%$ all season. This is still considered statistically as "strong variation" but comparatively lower to both ST and AL data sets, which both have variance values above $70 \%$ and do not lower to a comparative level (30-40\%) until peak growth in late summer. The SM values within the wetland as a whole must therefore be more similar around the average than ST and AL at the beginning of the season. In Figure 3.5.A, an additional calculation of total number of saturated $(>95 \%$ vol) samples was calculated that ranged from $18 \%$ at the beginning of sampling to $38 \%$ by the end. This increase in total saturation can be seen in the mean value increasing from $66.35 \%$ vol to $73.58 \%$ vol for the sample site overall implying an increase in overall wetness for the wetland as the season progresses. Figure 3.5.B shows that as AL increased in depth across the entire field site, the variance between samples decreased from $72 \%$ to $33 \%$. As the season progressed, not all sites thawed at the same rate but once warmer temperatures allowed more sites to thaw further into the season, the variation between sample sites decreased. Air temperatures increase moving into summer from spring (Figure 3.5.C), allowing for higher ST values to occur and therefore lowering the variability between sample sites. During peak growth at the end of July, ST fluctuates as explained previously. Despite this, the coefficient of variance stabilizes and remains at its lowest value of $38 \%$. This implies that despite a large variation in temperature between sampling sets, there are consistently lower and higher values within each set and the wetland itself.

These temporal relationships are based on averages for all sample sites throughout the wetland and per quadrant, however there are relationship changes temporally on a 
localized level too. To investigate the relationships between all three variables laid out in Figure 3.3, $\mathrm{R}^{2}$ values for each variable interaction for each season were calculated (Table 3.1). There is little to no relationship between AL depth and SM, which is backed up by looking at the regression values within Table 3.1 that show an $\mathrm{R}^{2}$ value of 0.33 in Spring that subsequently drops to 0.03 by peak growth. There is a fairly loose relationship between increasing ST values and marginally increasing SM readings during spring thaw that then disappears during early summer and peak growth. Within Table 3.1, the regression values of SM vs. ST show an average $R^{2}$ value in spring of 0.41 that drops to 0.03 by peak growth. Finally, Al depth increases with ST values. This is further emphasized within Table 3.1 with strong $\mathrm{R}^{2}$ values ranging from 0.68 to 0.76 throughout June and July. By looking at all of the regression changes from different seasons of data it can be seen that relationships at the beginning of the spring season are not reflected as strongly during late summer with the exception of AL vs. ST. 

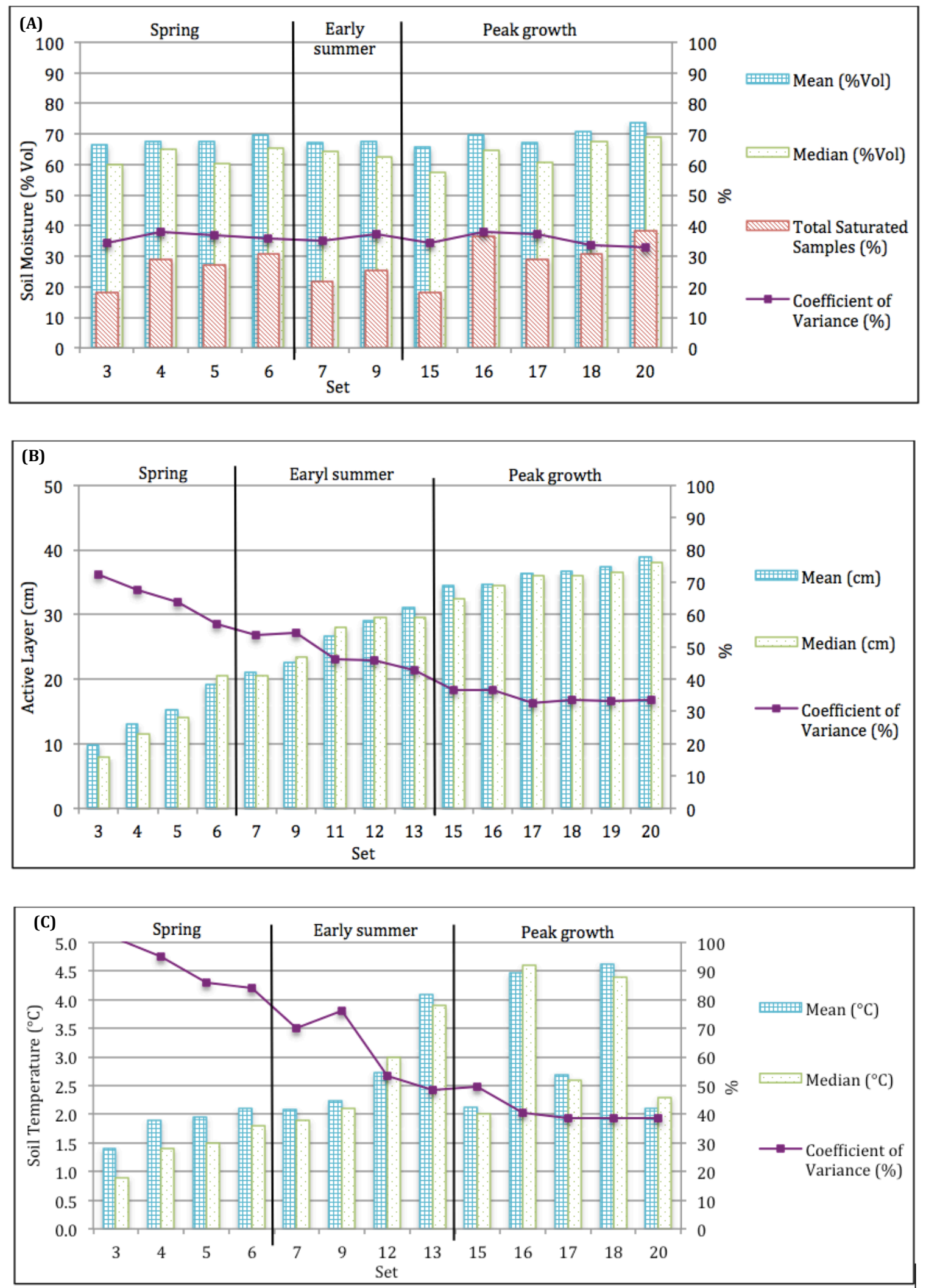

Figure 3.5: Statistical graphs of each biophysical variable showing mean, median and coefficient of variance. (A) SM. (B) AL. (C) ST. 
Table 3.1: Table showing linear regression values for each biophysical interaction within each season.

\begin{tabular}{|l|l|l|l|}
\hline & Spring & Early summer & Peak growth \\
\hline SM vs. ST (R²) & 0.41 & 0.29 & 0.06 \\
\hline SM vs. AL (R²) & 0.33 & 0.14 & 0.03 \\
\hline AL vs. ST (R²) & 0.68 & 0.75 & 0.76 \\
\hline
\end{tabular}

\section{SPATIAL CHANGES}

To begin, each set of data was investigated for normality and the histograms produced showed that almost all the data sets had non-normally distributed data. Within SM data sets, due to the high frequency of saturated samples, all sets showed bimodal distributions with two peaks in data values whilst many ST and AL sets had either positively or negatively skewed data. In order for kriging to be most effective, data must be transformed to as close to normally distributed as possible. Therefore, all data sets underwent a "Normal Score" transformation within the geostatistical wizard in ArcMap in order to achieve the most statistically accurate interpolations. Subsequently, variagram analyses of average binned values allowed for various models to be applied to the data values (Appendix A) that then predicted the unknown values.

ST and AL data sets were all fitted with either rotational quadratic or exponential models. SM data sets were all fitted with either Gaussian or circular models. This difference in modelling is likely due to the different variability patterns SM values show compared to AL and ST within the wetland. This would imply that ST and AL spatial changes are more closely linked than SM. If they both show the same distributary patterns of variability it would imply that their interactions are more closely related. This seems plausible considering that as ST increases, AL will also increase due to the increased thaw. It also 
perhaps disproves the theory of increased AL causing decreased SM values as their spatial relationships are different.

The kriged results for the three biophysical variables, Figures 3.6 to 3.8, all show the temporal relationships previously discussed. However, the added spatial dimension allows us to see that not all sites show the same relationships throughout the season as expected by the regression analyses. By first looking at the ST analyses, Figure 3.6, it can be seen that temperatures increase steadily in spring and early summer within the wetland as a whole with a couple of hot spots in the NW and SW corners. As the season moved into peak growth in late July, the small temporal temperature fluctuations discussed previously can be seen clearly. The maximum temperatures seen on July 21 and 25 , peak at $9.3^{\circ} \mathrm{C}$ whilst 48 hours either side, the temperatures peak at $4.7^{\circ} \mathrm{C}$. However, there are still small, localized cold spots within the center of the field site and to the south. This suggests that the generalization that could be made from the temporal data does not hold true for the entire field site. Had a single sample site within the center of the plot been used for measuring ST, the previous variations may not have been as strong.

Considering the similar variagrams exhibitied by ST and AL, the kriged results should also show similar spatial variability patterns. Within Figure 3.7 it can be seen that AL depths gradually increase through spring and into early summer. The appearance of localized hot spots of increased depths once again occurs in the NW and SW corners of the field area. This seems plausible considering the relationship of increased ST with more thaw and therefore increased AL depths. Moving into late summer and peak growth season, the AL depth continues to increase as expected, but the appearance of isolated shallower and deeper regions becomes apparent. The center points create an area of shallower 
depths $(<30 \mathrm{~cm})$ whilst the NW, SW and NE corners are hot spots for much deeper AL depths $(>50 \mathrm{~cm})$. This shows that even though the wetland is thawing as a whole and AL depths are deepening throughout, it is not uniform within the entire field area.

Finally, Figure 3.8 shows the variations in SM throughout the wetland. Due to the differences in variagram analyses, it is expected that the patterns of variability within the field site will differ from that seen previously within ST and AL. Looking at the kriging results for spring and early summer, a general increase in SM is seen within the site as a whole as thaw and snow melt increase hydrological input into the wetland. The NW and SW hot spots previously seen within ST and AL are more generalized to create a strong E/W trend across the entire wetland with the eastern side containing more saturated conditions than in the west. As the season progresses into peak growth, this E/W trend continues. The increase in total saturation sites verified in Figure 3.5 are clearly seen moving into late summer. The initial spring melt of the snowpack and overflow of melt water in June is seen as isolated patches of intense SM that spread to form larger areas by late July. The western side of the field plot is drier and is also the area associated with higher ST values and deeper AL thaw. It would seem plausible that perhaps this change in AL depth causes the ground to be drier by increasing the soil's storage capacity. 


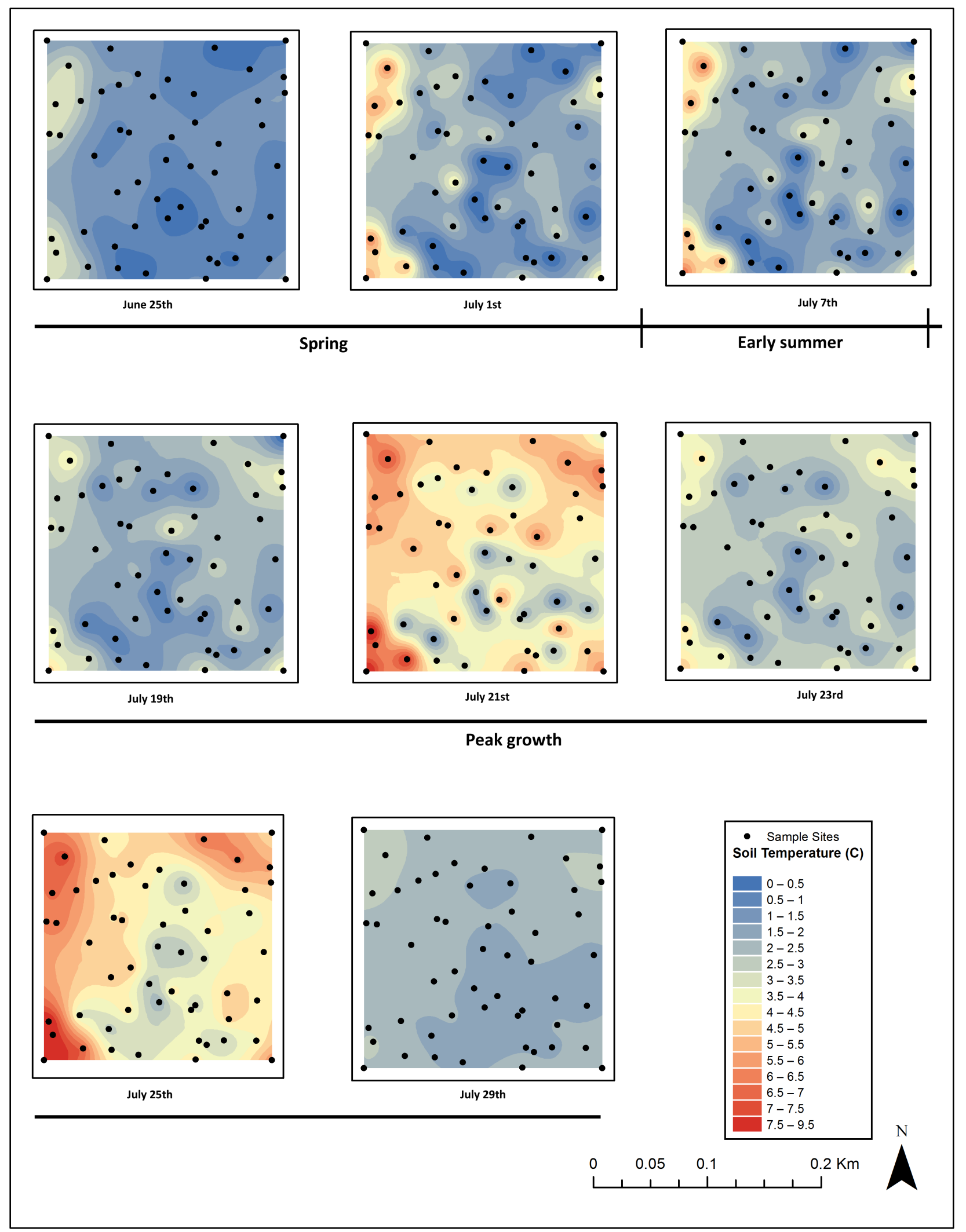

Figure 3.6: Kriged ST results showing spatial changes in thaw depth across the entire wetland field site during the three identified seasons of "Spring", "Early summer", and "Peak growth". 


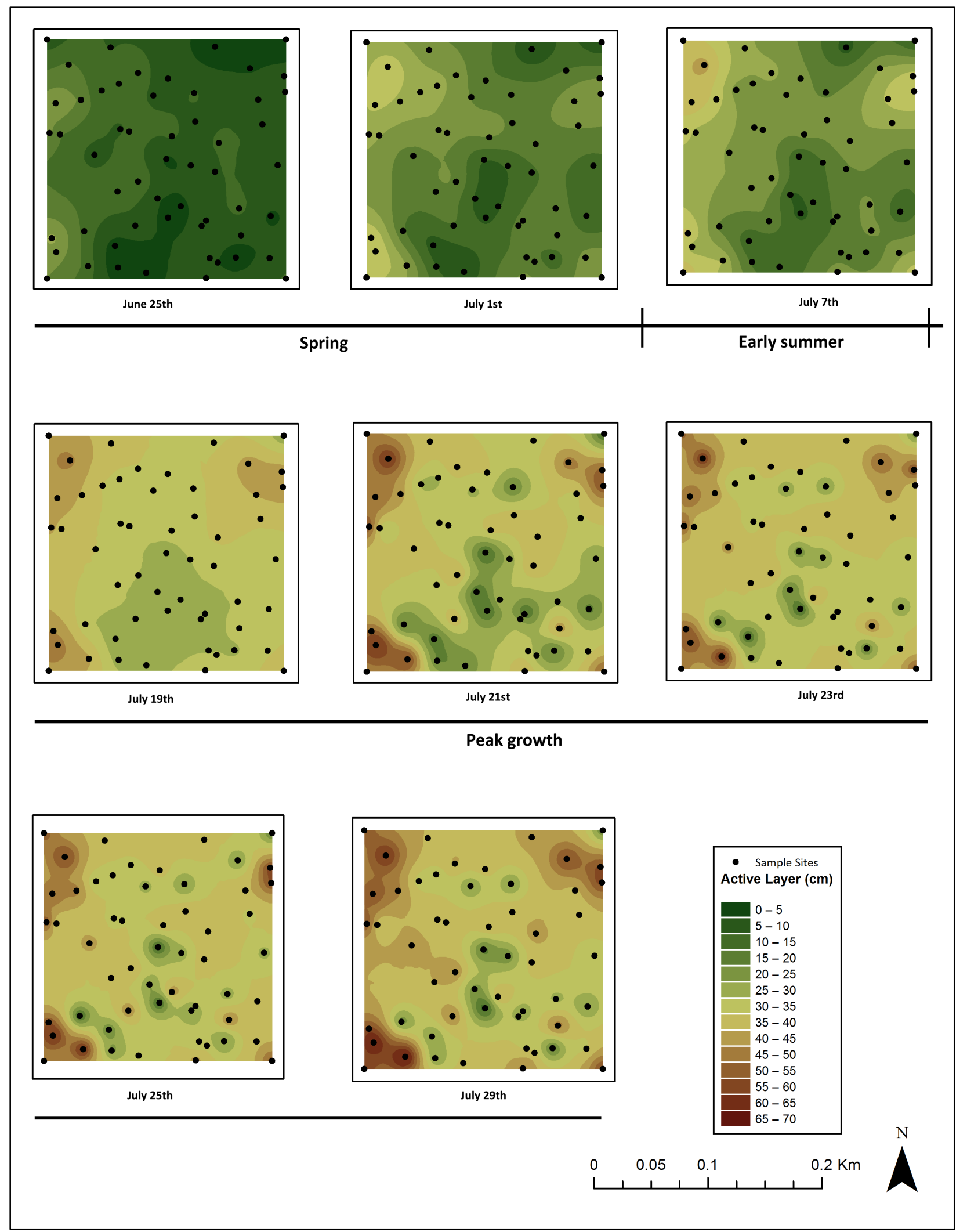

Figure 3.7: Kriged AL results showing spatial changes in thaw depth across the entire wetland field site during the three identified seasons of "Spring", "Early summer", and "Peak growth". 


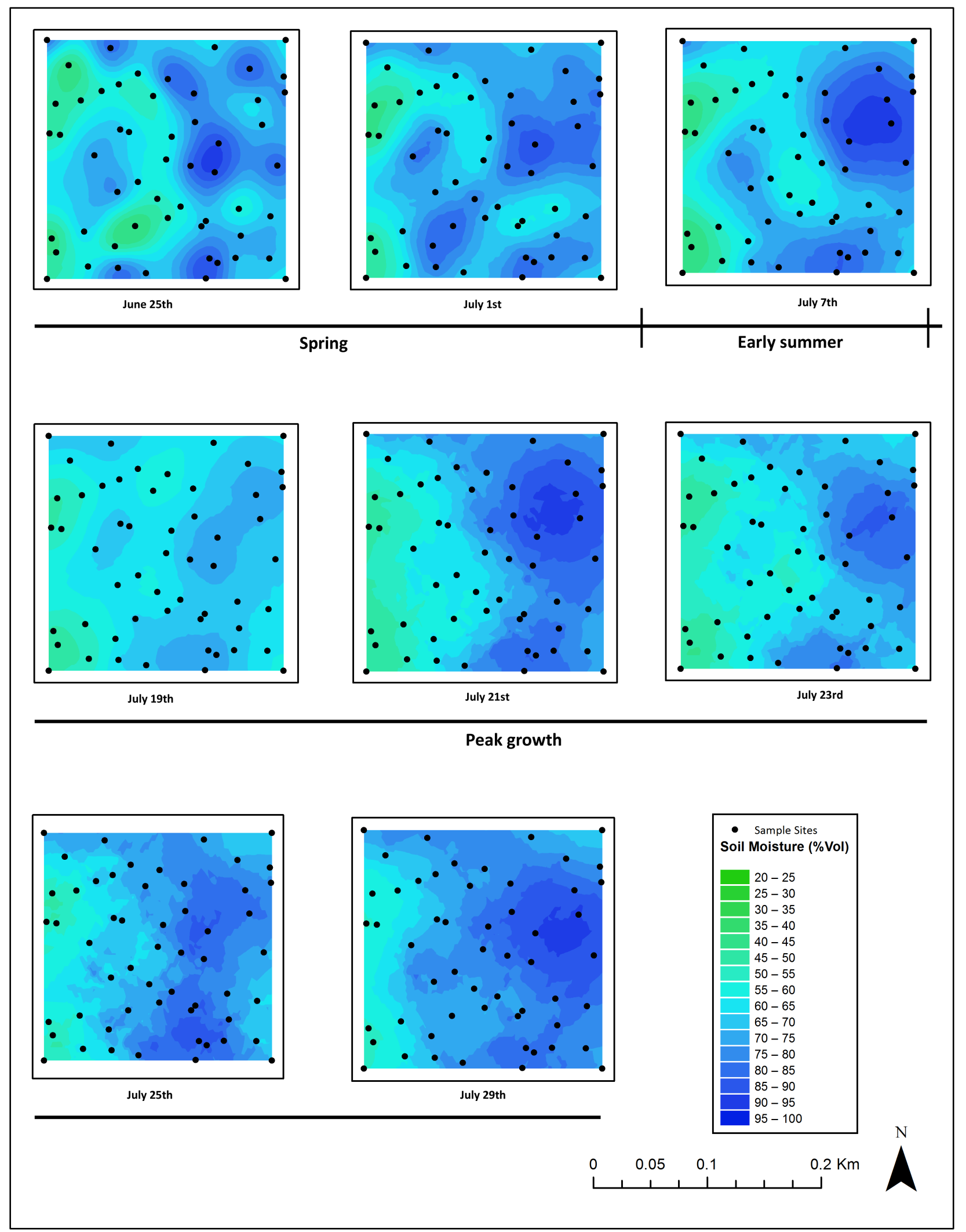

Figure 3.8: Kriged SM results showing spatial changes in thaw depth across the entire wetland field site during the three identified seasons of "Spring", "Early summer", and "Peak growth". 
The DEM for this area allows for differences in slope, elevation and aspect to be investigated. Figure 3.9 is an elevation map and shows that the wetland is fairly flat in topography with a maximum elevation difference of only $9 \mathrm{~m}$ (Figure 3.9). The aspect analysis produced a mean of 191 degrees meaning that most of the wetland is facing south to south west. Analysis of slope showed a mean of 4 degrees with a maximum value of 16 degrees implying that most of the wetland is low lying. This would suggest that, overall, the wetland slopes predominantly south but with minimal slope and a total rise of only $9 \mathrm{~m}$ between the SW and NE corners. It would seem obvious to assume that the wetland should then drain to the S but this is not represented within the SM results that show an E/W trend.

In order to check the strength of the models that were fit to the various variagrams and therefore the validity of the kriged surface layers in their value predictions, key regression statistics were calculated that show how valid the interpolated values are. Validity statistics were investigated for all three variables and presented in Table 3.2. The mean prediction error (MPE) is a measure of bias and needs to be as close to zero as possible. The root mean square standardized prediction error (RMSSPE) is a measure of validity and should be as close to one as possible if the predicted errors are valid. The root mean square prediction error (RMSPE) and average prediction error (APE) represent the level of error in the predicted results and therefore interpolated surface. They should both be as small as possible and as similar to each other as possible. From Table 3.2 it can be seen that for all surfaces and for all three variables, the largest MPE was 0.06, and the biggest RMSSPE was 1.13. The surfaces created for ST have the smallest RMSPE and APE with SM having the highest. This large variation in values and non-spatial heterogeneity of 
the data creates these larger numbers, as this data does not show strong spatial autocorrelation. This would imply that SM variability has a greater irregular spatial pattern than ST or AL. Despite the larger errors associated with the kriged SM surfaces, the ecological variability is accurate. The patterns shown in Figure 3.8 were witnessed during sampling where a strong E/W trend was clearly apparent during the spring and summer 2014 field season.
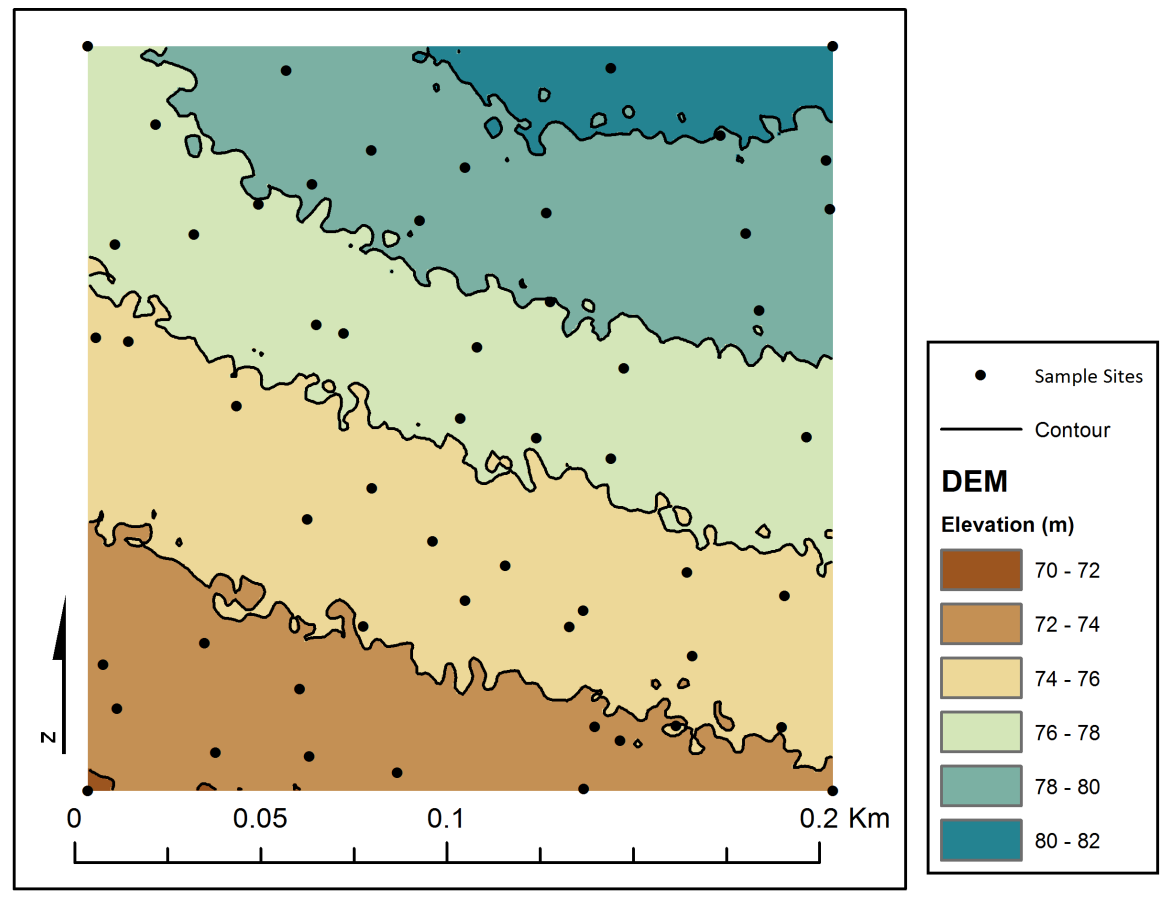

Figure 3.9: DEM analysis of the elevation within the wetland field site at Cape Bounty.

Table 3.2: Tables showing spatial interpolation error statistics within completed kriging analysis. (A) AL. (B) ST. (C) SM.

\begin{tabular}{|c|c|c|c|c|c|c|c|c|c|c|}
\hline (A) Set & MStPE & RMSqStPE & RMSqPE & AStPE & (B) & Set & MStPE & RMSqStPE & RMSqPE & AStPE \\
\hline (11) 3 & 0.00 & 1.00 & 5.42 & 5.29 & & 3 & 0.05 & 1.05 & 1.24 & 1.16 \\
\hline 6 & 0.00 & 1.06 & 9.60 & 9.05 & & 6 & 0.05 & 1.06 & 1.51 & 1.40 \\
\hline 9 & 0.03 & 1.13 & 11.20 & 9.69 & & 9 & 0.05 & 1.09 & 1.56 & 1.39 \\
\hline 15 & 0.04 & 1.09 & 11.87 & 10.78 & & 15 & 0.05 & 1.09 & 0.98 & 0.86 \\
\hline 16 & 0.04 & 1.04 & 10.96 & 10.45 & & 16 & 0.04 & 1.02 & 1.66 & 1.58 \\
\hline 17 & 0.04 & 1.04 & 11.14 & 10.57 & & 17 & 0.06 & 1.03 & 0.98 & 0.92 \\
\hline 18 & 0.04 & 1.04 & 11.41 & 10.81 & & 18 & 0.05 & 1.09 & 1.45 & 1.33 \\
\hline 20 & 0.05 & 1.03 & 11.66 & 11.07 & & 20 & 0.06 & 1.01 & 0.79 & 0.78 \\
\hline
\end{tabular}




\begin{tabular}{|ccccc|}
\hline (C) $\begin{array}{c}\text { Set } \\
3\end{array}$ & MStPE & RMSqStPE & RMSqPE & AStPE \\
6 & 0.05 & 1.05 & 21.87 & 20.68 \\
9 & 0.04 & 1.06 & 23.86 & 22.40 \\
15 & 0.01 & 1.02 & 22.41 & 21.77 \\
16 & 0.01 & 1.03 & 21.69 & 21.07 \\
17 & 0.00 & 1.02 & 23.89 & 23.53 \\
18 & 0.00 & 1.01 & 22.68 & 22.63 \\
20 & 0.03 & 1.05 & 22.56 & 21.51 \\
& 0.01 & 1.06 & 22.72 & 21.51 \\
\hline
\end{tabular}

\subsection{Discussion}

This study aimed to look at the high spatial and temporal resolution patterns and relationships between the biophysical variables of SM, ST, and AL within a nival driven High Arctic wetland ecosystem. It was found that when looking at the wetland ecosystem as a whole, the temporal and spatial patterns of increasing AL depth, increasing and erratic ST values and consistent SM levels are dominant and easy to identify. However, upon closer inspection, it is clear that these relationships do not occur throughout the entire wetland but rather spatial variability allows for inconsistencies to these patterns. The spatial pattern analysis shows clearly they cannot be generalized to the entire wetland. AL and ST are more closely inter-related with each other than with SM. Similar ST and AL spatial variability patterns are seen across the wetland that are not witnessed as clearly within the SM kriged results.

The changes in SM regime can be linked to the presence and location of the late lying snowbank directly north of the wetland. The initial spring thaw would have caused a massive influx of meltwater from the snowpack that must have washed over the entire wetland similar to that proposed by Thompson and Woo (2009). The relatively short time span since the sample sites became snow free would have allowed for very little thaw to take place, thus inhibiting percolation of this meltwater as predicted by Roulet and Woo, 
1986 and Woo and Young (2003). SM values show less localization to individual sites and more so to general areas. It is likely that as the ground is thawing, the saturated areas are able to spread out within the wetland. In addition, it must not be forgotten, that during the summer season the overlying perennial snow pack is continuously melting. This is providing a steady hydrological input that is not limited to spring only, unlike many wetlands that form within topographic depressions or beside lakes and rivers (Woo \& Young, 2006). With this steady, reliable influx of water all season long, the general saturation of the wetland exhibited during peak growth in late summer is easily accounted for. Increasing AL depths and a steady influx of melt water allows the SM values within this wetland to remain near saturation and spread westwards as the summer progresses. It should also be noted that considering the importance of this snowpack resource and in turn the wetland itself to our carbon cycle, any changes to hydrological input will directly affect the SM regime of the wetland ecosystem (Nobrega \& Grogan, 2008).

However, the deep AL hot spots within the NW, NE and SW corners of the wetland are the driest in regards to SM. Perhaps the AL depths are of a sufficient level that saturation is not possible regardless of hydrological input strength. Previous studies by Woo and Young $(2003,2006)$ showed AL depths of less than $1 \mathrm{~m}$ in High Arctic wetlands that are continually saturated. The sample sites located within the center of the wetland have comparably shallower AL depths up to half of the maximum recorded depth within the entire field site. This would imply that perhaps shallower $(\sim 30 \mathrm{~cm})$ AL depths are the thresholds for saturated conditions. This can be an important consideration for future studies. How AL depth varies across a wetland where vegetation type is the same, incoming solar radiation is similar and a reliable hydrological input is present should be investigated 
further. Perhaps soil type and organic layer depth is key in determining where saturation is likely and how it will spread within these wetland ecosystems.

It was noted in the field that snow cover was uniform across the wetland field site but it did not melt at a uniform rate. In fact, the NE corner was the slowest to melt with snow cover remaining into late summer. Once the overlying snow was thawed, this site thawed quicker with deeper AL depths and higher ST values than sites in the center of the field site that had been snow free since spring. Perhaps this late lying snow cover had insulated the ground to a sufficient level so that less energy was needed once snow free for this area of wetland to reach its maximum state of thaw. However, this does not explain how the sample sites that were snow free from spring did not achieve deeper AL depths or higher ST values compared to sites that were snow covered for a longer length of time. Rouse (2000) wrote that saturated soils required more energy to heat and thaw than drier. In this case the more centrally located saturated sites that were snow free for longer would require more energy to thaw whilst the NE corner sites that have lower SM values needed less time despite being snow covered for longer.

From a temporal perspective, the descriptive statistics within each data set imply that the wetland reaches a level of stability in late July during peak growth. Despite SM remaining similar all season, AL depth increases yet thaw rate slows whilst ST values also increase and subsequently fluctuate. This is similar to the results witnessed by Roulet and Woo (1986) and Nobrega and Grogan (2008). Therefore despite a set of results showing "strong variance" between measured values, the variance percentage decreased, then remained at a consistent level marginally above $30 \%$ for all three variables during late summer. This means that the difference in all three biophysical variable values within the 
wetland during late summer has less diversity than during spring and early summer. Spatially, however, the range of values does not decrease across the wetland but more sample points must fall around the average for each set in order for the variance to lower to a comparatively stable level. Thus suggesting that the wetland is more stable at this point than during spring and early summer where the variance was over $70 \%$ for both $\mathrm{AL}$ and ST. From these results, it can be considered that if any point sampling were to be done in future studies on SM, ST and AL, late summer would show the most consistent results for the entire wetland.

The stronger relationships seen between SM, ST and AL mostly disappear by peak growth and late summer except for ST and AL depth which remain consistently strong throughout both spring and summer. This decrease in relationship as the season progresses is clearly seen in the reduced regression values for ST vs. SM and SM vs. AL. This would then suggest that the wetland becomes less stable and more erratic, or perhaps more simply, the variables cease to interact once the season progresses into late summer. It can be hypothesized that perhaps the wetland biophysical values remain at a consistent level of variability during peak growth, which in turn allows biomass production to be steady at this time and therefore ST, AL and SM to behave on a more independent level and not be driven by each other to the extent previously thought.

During the spring and early thaw, variability within the wetland is high as different areas emerge and thaw at different rates, but by late summer the wetland has established itself and so variability between values lowers. If the interactions show such strong relationships during spring and these fade into summer and peak growth, perhaps they are only closely related during this time. When the wetland is established and biomass 
production is at its peak during the end of July, perhaps ST, AL, and SM operate separately and have reached their optimum values. It should also be considered that any changes to any variable during the beginning of the season would affect the others at a greater level than later on. Future studies may perhaps explore how these variables and relationships change as the season finishes with sampling continuing into August. It would be expected that as air temperatures cool along with reduced solar radiation levels, the wetland would start to re-freeze and the broken thaw pattern witnessed during spring would once again be apparent during fall. Perhaps the relationships observed in spring and early summer will become apparent once more as the wetland de-stabilizes and re-freezes. The Arctic wetland study by Nobrega and Grogan (2008) continued though to August where the researchers mention the area undergoing "fall senescence" when the plants stop functioning biologically and begin to freeze for winter. It was shown that ST values decrease gradually as observed during spring and AL depth stops increasing. In fact, AL depths were not seen to increase until September within the study by Nobrega and Grogan (2008). However, as mentioned, this study did not take into consideration spatial variability therefore future studies into greater temporal and spatial analysis of how a High Arctic wetland re-freezes during autumn are required.

\subsection{Conclusions}

The results of this study show that the three biophysical variables of SM, ST and AL vary both spatially and temporally within an Arctic thaw season. The variation in values within the wetland decreases temporally from spring to late summer, thus implying a degree of stability during peak growth/late summer. The moderately average relationships between 
the biophysical variables reduces to non- existent as the season progresses, once again promoting the idea of a steady wetland ecosystem late in the summer season.

The changes spatially show that uniform variability is not present but rather localized to NE, NW and SW hot spots on the perimeter of the wetland along with a strong E/W SM trend. The moderately similar ST and AL spatial patterns coupled with their strong regression relationships throughout the season imply that this is the only variable association to remain throughout the spring and summer season within a wetland ecosystem. Further study is needed into how these interactions, variations and spatial patterns change during August and whether these relationships once again become more apparent as erratic re-freezing becomes evident. 


\section{Discussion}

\subsection{Spatial and temporal biophysical interactions}

The manuscript presented in the previous chapter helped answer the research question of this thesis by examining the spatial changes and temporal patterns of relationships between the biophysical variables of SM, ST, and AL within a nival-driven High Arctic wetland ecosystem. The main results and conclusions from the previous outlined study show that the wetland ecosystem is erratic and highly variable during spring thaw with rough, loosely linked relationships between all three biophysical variables. These loose relationships seen temporally during spring melt were increased soil temperatures with decreased soil moisture values and increased soil moisture saturation with decreased thaw depth. A strong trend of increased thaw depth with increasing soil temperature values was showcased throughout the entire sampling season. These relationships dissolve by peak growth in late summer as the wetland somewhat stabilizes and variance between values decreases. It is spatially evident that the wetland does not exhibit similar patterns of variance between variables with ST and AL showing clear localized hot spots for increased values within the NW, SE and NE corners whilst SM shows a general E/W trend across the entire wetland. These conclusions as well as the discussions and analyses previously addressed within chapter three, help answer the central research question and hypotheses of this thesis as set out in chapter one.

\section{RESEARCH HYPOTHESES}


HP1- As the thaw season progresses, AL will increase in depth and sites farther from the snowbank will thaw sooner than sites closest lending to a pattern of decreasing AL depths towards the snowbank.

AL depth did increase during the season as predicted and similar to research by Roulet and Woo (1986a, 1986b), Glen and Woo (1997), Woo and Young $(2003,2006)$, Nobrega and Grogan (2008), and Abnizova and Young (2010). However, it can be seen from the spatial analysis that AL depth clearly does increase as the season progresses but not in the pattern suggested by Woo and Young $(2003,2006)$. There is no N/S trend of AL depth exhibited within this field site but rather localized hot spots of deeper thaw depths within the NW, SW and NE corners. This pattern is not similar to the overlying snowpack as the NW quadrant was snow free in spring whilst sites in the NE corner remained under snow until peak growth and yet showed a comparable AL depth to other sites once thawing began. The corners with increased thaw are on the edges of the wetland with the center sites showing the shallowest AL values. These corner sites were also the driest of the field area lending to the idea that perhaps the middle section of the snow pack, which remained all summer, is thicker and thus contains more water for a stronger hydrological input. This would reinforce the research by Rouse (2000) that these more saturated areas require a greater latent heat to thaw to a greater depth than the drier corner areas where snow cover was less as the snowpack decreased above it. It would seem prudent to suggest that perhaps instead of an AL pattern linked to distance from the snowpack, there is instead a pattern of AL depth linked to proximity to greatest snowpack depth and melt and therefore increased SM saturation. 
HP2- A link between ST and SM will be apparent with drier soils exhibiting higher average ST values than saturated sites.

Overall, the temporal ST relationship was increasing values through spring and early summer before fluctuating every 48 hours in peak growth. This pattern is similar to that witnessed by Roulet and Woo (1986a, 1986b) and Nobrega and Grogan (2008) who suggested a surge in ST values in spring followed by a plateau during peak growth before returning to freezing. Interestingly, the relationship of high ST and decreased SM, as interpreted from Rouse (2000), differs depending on whether a spatial or a temporal analysis is studied within the wetland.

Temporally, this relationship was only apparent during spring melt and quickly deteriorated as the season progressed. Regression values for this variable association decreased from 0.41 to 0.06 . As the wetland thawed, the variance of points became more spread out and a greater range of temperatures was experienced. This caused the relationship to disappear. During peak growth, the temperature fluctuations meant a lower variance between points as more now fell around an average. As the temperature fluctuated, the wetland as a whole would increase and decrease in temperature. However, due to the widespread saturated SM values throughout the wetland that do not respond to differences in air temperature, the relationship of SM and ST would not hold. It was found that during late summer when ST fluctuated every two days, the warmer days showed a stronger relationship of ST to SM ( $\mathrm{R}^{2}$ of 0.24$)$ than colder days $\left(\mathrm{R}^{2}\right.$ of 0.01$)$. This would 
suggest that higher ST values have a stronger relationship with saturated SM readings, opposite to what was suggested in HP2.

However, spatially, it can be seen that the hot spots of increased ST values were seen in the NW and SW corners along with an E/W trend of decreasing SM saturation leading to the impression that increased temperatures do have lower SM values. If a closer examination is taken of individual sites in these locations, it can be seen that HP2 is correct and areas with low SM values have higher than average ST readings. This result emphasizes the importance of conducting both a spatial and temporal analysis, as had temporal data alone been used, generalizing the relationship would have resulted in a rejection of the hypothesis, but spatially and individually, many sites accept the hypothesis.

HP3- ST will be seen to vary directly according to incoming solar radiation values.

The two-day time lag proposed by Nobrega and Grogan (2008) between solar radiation and ST values was not seen in this field study as it can be clearly seen that ST, air temperature and solar radiation fluctuations match during peak growth. Temporally this hypothesis can only be accepted for a small portion of the season. During spring and early summer, incoming solar radiation values fluctuate yet ST steadily increases. This links into the theory identified by this study of the wetland establishing itself during the beginning of the season before stabilizing in late summer. During the last two weeks of summer, ST begins to fluctuate along with air temperature values and solar radiation measurements, thus agreeing with the hypothesis. 
HP4-SM will not vary with time across the study site and most sites will show complete saturation due to limited drainage and the presence of small AL depths due to the continuous hydrological input from the perennial snowbank at this location.

This hypothesis can be split into both a spatial and temporal assumption. The first, that SM did not change temporally for the entire wetland as witnessed by Woo and Young (2006), and Nobrega and Grogan (2008), and second, that spatially the wetland showed widespread saturated conditions due to continual hydrological input from the melting perennial snowpack.

Temporally, there were minimal changes in SM values during the season as also witnessed by Woo and Young (2006), and Nobrega and Grogan (2008). In this site, average SM values show a generally consistent temporal pattern throughout spring and summer because of the existence of the perennial snowbank feeding the wetland allowing for a steady hydrological input. However, at the individual level, spatial changes show that not each site remained at a consistent SM level throughout the sampling season. For the whole site, a general E/W trend remained throughout spring and summer, however the extent that this trend changed as the wetland thawed into late summer. This shows that some temporal differences exist with sample sites in the NE corner showing a decreased in saturated value during peak growth compared to spring whilst sites in the SE show an increase in SM saturation.

Spatially, the presence of an E/W trend was not anticipated by this study as limited research has been previously done on the differing tundra and AL depths within this 
particular wetland field site that likely caused this trend. The shallower AL depths within the center of the wetland lend themselves to increased saturation as suggested by Rouse (2000) and there are many areas of complete saturation that remained all season as expected. The kriged results show slight variations between sets, especially during peak growth. This could be attributed to the temperature fluctuations also seen at this time with peaks in solar radiation and air temperature causing increased snowmelt, but without studying changes in melt rates, this cannot be proven. All moisture sampling was taken at the same time every 48 hours, therefore changes in sampling time cannot account for this pattern either. It is also possible that these slight changes can be attributed to possible errors in interpolation due to the high variability in SM values and lack of spatial autocorrelation across the site. The statistical results for SM kriging show that whilst having a high standard deviation value for each set, the mean remained relatively high and similar all season, keeping the coefficient of variance at $\sim 30 \%$. However, the spatial statistical values emphasize how variable the data is spatially. Therefore, despite having a lower variance to $\mathrm{ST}$ and $\mathrm{AL}, \mathrm{SM}$ has a greater spatial variability and poorer spatial autocorrelation across the wetland. Overall, the SM remained similar all season with a strong E/W trend and widespread saturation of many sites.

\subsection{Wetlands and climate change}

The wetland within this study was fed by a strong hydrological input from an overlying perennial snowbank for the entire 2014 field season. Wetlands can form in topographic depressions, adjacent to lakes and rivers, within coastal environments, and be fed by a strong ground water supply as well as by snowpacks (Woo \& Young, 2003). The 
variety of hydrological settings under which environmental conditions are conducive to wetland formation make it likely that the biophysical traits within each type will differ in spatial and temporal pattern. In this study, the presence of a season long hydrological input is a key feature allowing for widespread saturated conditions even after peak melt in spring. The limited rain throughout June and July is seen to have little effect on the SM regime, further enhancing the knowledge that constant snowpack melt is required for the continuation of this type of wetland. The plant species native to these ecosystems are a combination of mosses and sedge grasses that thrive in saturated conditions (Walker, 2000; Walker et al., 2005; Atkinson \& Treitz, 2012, 2013). It can then be considered that any changes to the wetland's moisture regime will directly affect the vegetation. As this is ultimately the primary mechanism for carbon sequestration into the ground, the continual growth and development of this biome is extremely important (Dag \& Lafleur, 2011; Elmendorf et al., 2012; Atkinson \& Treitz, 2012, 2013). Continually increasing temperatures will cause a net decrease in snowpack volume over time (Screen \& Simmonds, 2012) as increased melt in summer combined with shorter winters and less snow will reduce the final volume of snowpack available for hydrological input every thaw season (Atkinson \& Treitz, 2013).

It can be seen how variable SM is from the results given in the previous chapter. In a predominantly nutrient poor environment, any sources of nitrogen (a limiting nutrient for plant growth) are key. Within this ecosystem the production of Nostoc (a nitrogen-fixing bacteria) helps drive the existence of these wetland plant communities (Woo \& Young, 2003, 2006; Atkinson \& Treitz, 2012). The differential pattern in variability of SM to ST and 
AL imply that simply monitoring one variable cannot accurately predict where SM will be prevalent.

Along with affecting SM regimes and therefore plant growth and photosynthesis production, changes in climate and increased warming will disturb the permafrost distribution (Shuur et al., 2009; Tarnocai et al., 2009). Within this study alone, a maximum difference in AL depth of approximately $60 \mathrm{~cm}$ is seen at this small-scale level. Polar desert environments typically have AL depths >1 m (Nobrega \& Grogan, 2008; Wang et al., 2011) and the NW, SW, and NE hotpots within this wetland had AL depths approaching $70 \mathrm{~cm}$. By peak growth and the end of the sampling season, many central sites had AL depths around $30 \mathrm{~cm}$ on average. Scientists predict that Arctic warming will continue to rise over the next decade (Schellnhuber \& Cramer, 2006). This would not only alter the volume and extent of the snowpacks previously mentioned, but would increase AL depths resulting in permafrost thaw. Thawing will release the stores of carbon sequestered beneath these wetlands and also allow for more microbial respiration and decay producing more $\mathrm{CO}_{2}$ and $\mathrm{CH}_{4}$. A changing climate will therefore affect these wetlands in many ways and likely affect their crucial sink status (Atkinson \& Treitz, 2012).

\subsection{Future considerations}

It has been mentioned how important it is to have consistent, saturated conditions for wetland production and existence. Changes in climate are no longer a question of if and when, but rather to what extent. This research investigates how a wetland ecosystem establishes itself every thaw season and how SM, ST and AL interact with each other during that time. What is not explicitly known is how this will be affected by climate. Future 
studies should consider investigating how a wetland endures and changes under different projected climate scenarios.

For one, investigating how increased AL depths may affect SM regimes within a wetland needs greater investigation. Studying the differing soil types and depth extent of mineral and organic soils could help explain patterns in SM. If organic layer depth is similar, perhaps there is an AL depth threshold after which SM saturation greatly reduces. In addition, it may be interesting to explore what happens to these three biophysical variables after peak growth. Looking at how the relationships and variance between values changes during re-freezing. Perhaps the same broken pattern of thaw will be exhibited during freezing. The stability that the wetland has during peak growth will likely dissolve and highly variable values will once again appear. The loose relationships between ST, SM and AL may once again appear. This would help characterize the wetland throughout an entire season from spring to autumn. If climate warming continues to affect lengths of Arctic seasons, knowing how these important ecosystems change and act during current spring, summer and autumn seasons will allow projections to be made if they were to change. It can also be considered that if the relationships between variables are stronger during spring, any effect to one may affect the others. Knowing how SM, ST and AL interact under a variety of conditions is key in investigating this further.

Finally, are the spatial and temporal results seen within this study similar across the wetland ecosystem regardless of hydrological regime? Arctic wetlands form under a variety of conditions (Woo \& Young, 2003) but all are closely linked to a strong hydrological resource that provides consistently saturated conditions. These sources are all similarly linked to climate like the perennial snowbank is within this study. How these 
driving biophysical variables operate within different wetland environments will help investigate how climate changes could affect all the different wetland ecosystems spatially and temporally. 


\section{Conclusion}

Temporal sampling was completed every two days at 55 single sample sites within a High Arctic wetland. The concluding temporal results showed a decrease in relationships between SM, ST and AL as the season progressed, as well as a decrease in variability of values across the wetland. Spatially, it was concluded that generalizing temporal relationships across the wetland could not be done as localized hot spots of increased AL and ST values appeared in the NW, SW and NE corners of the wetland as well as a clear E/W trend in SM across the entire site. It can be hypothesized that during spring melt, the wetland exhibits a patchy thaw pattern that continues until peak growth in late summer where it reaches a level of stability with less variance across the site and the biophysical variables working almost independently.

The loose relationships seen temporally during spring melt were increased soil temperatures with decreased soil moisture values and increased soil moisture saturation with decreased thaw depth. A strong trend of increased thaw depth with increasing soil temperature values was showcased throughout the entire sampling season. It was seen spatially that these relationships do not exist within the entire wetland and so conducting both a spatial and temporal study is necessary for future research in this area.

It is necessary to investigate these wetland ecosystems and how they change seasonally in order to make predictions as to how they may be affected under a changing climate. Considering their importance within our global carbon cycle and their key sink status in sequestering carbon through photosynthesis, this study aims to contribute to this field and help understand more about these fragile yet essential ecosystems. 


\section{Appendix A. Variagrams of Kriged data}

\section{A.1. AL variagrams.}

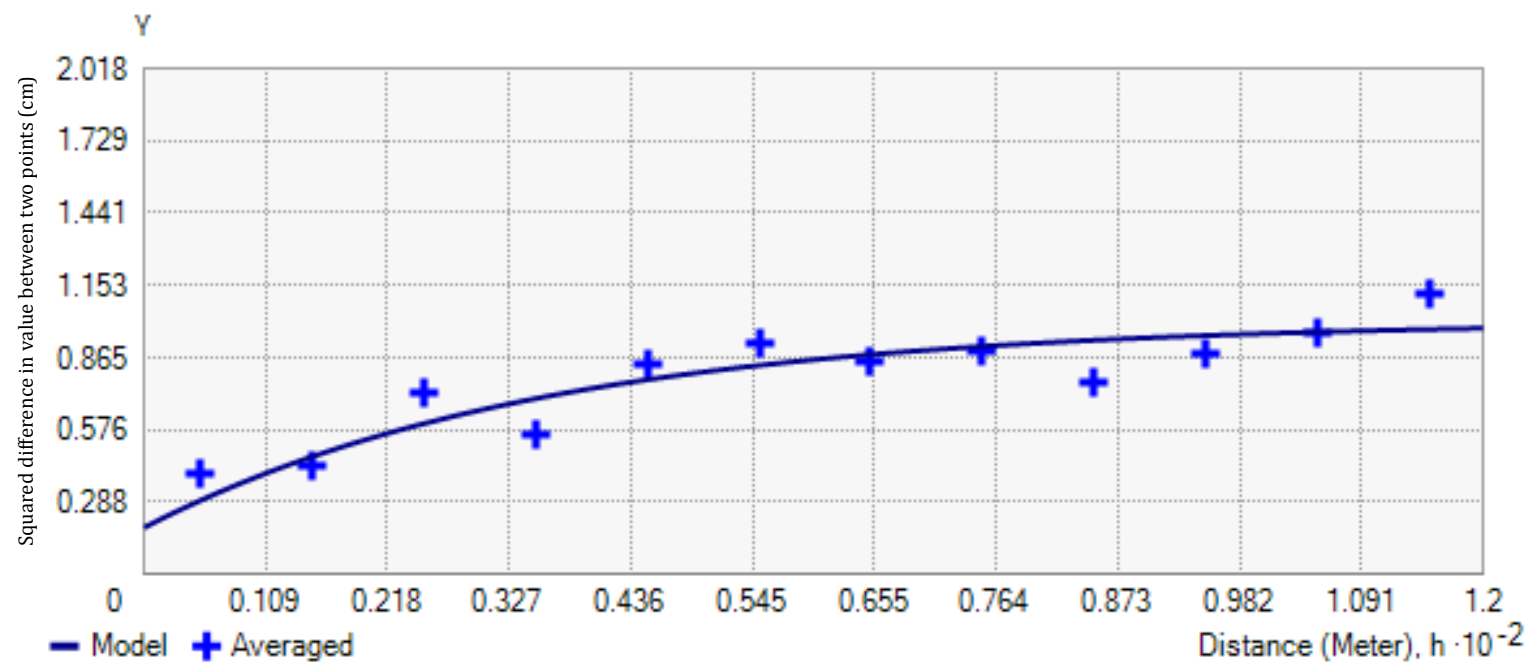

Set 3: Exponential

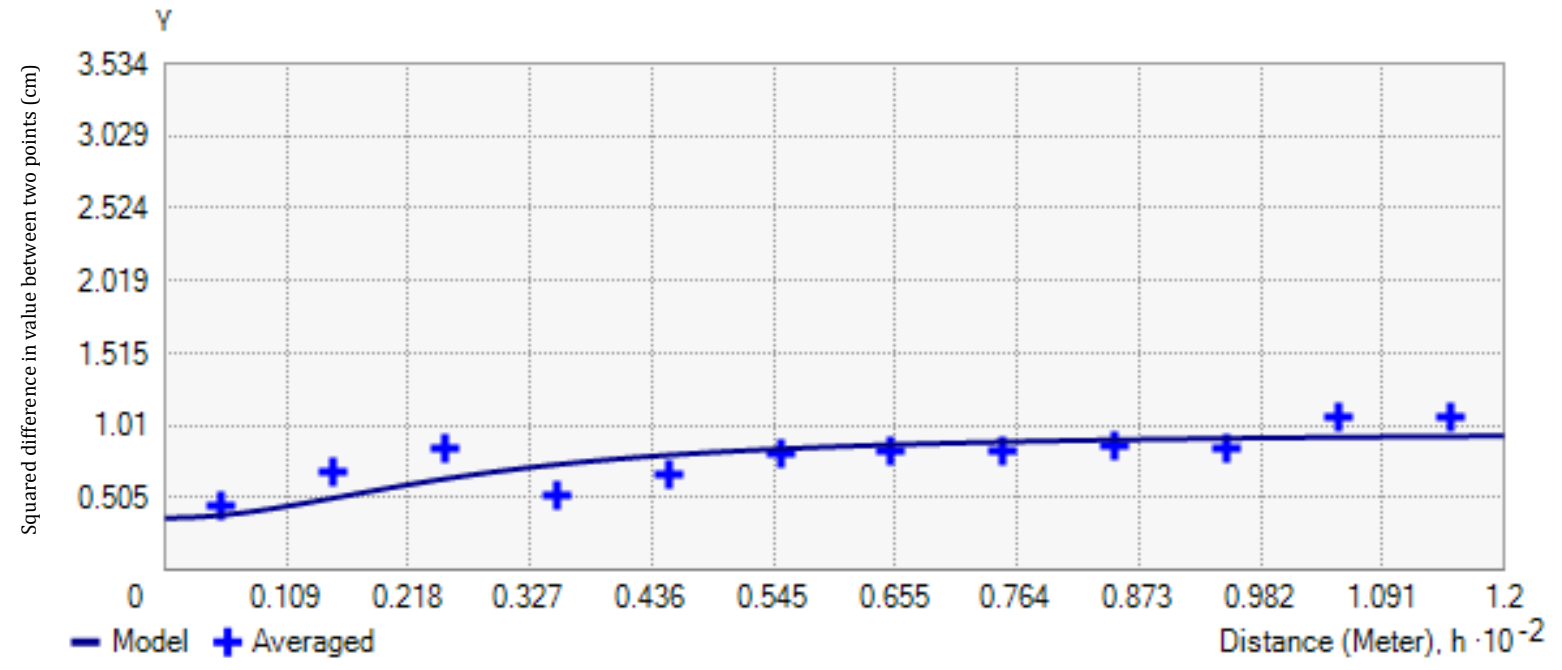

Set 6: Rotational quadratic 


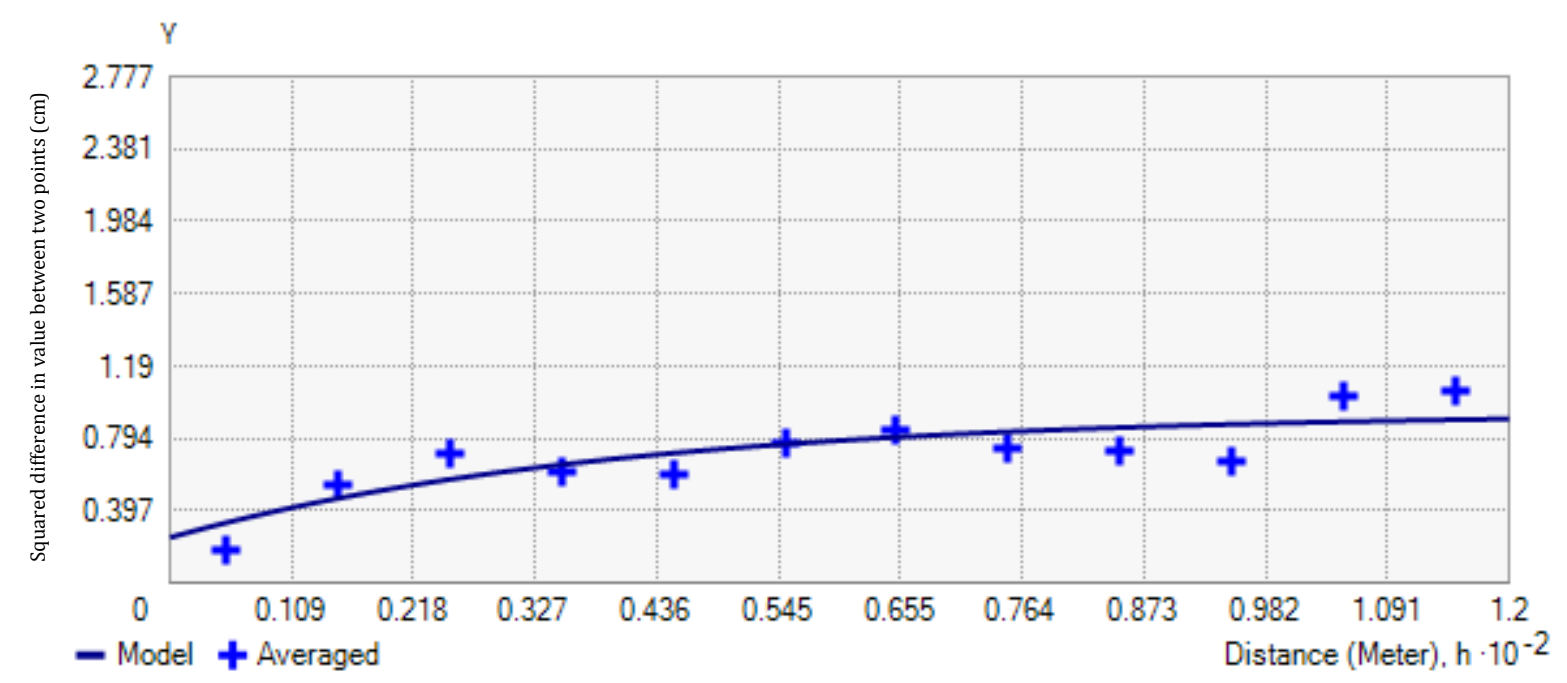

Set 9: Exponential

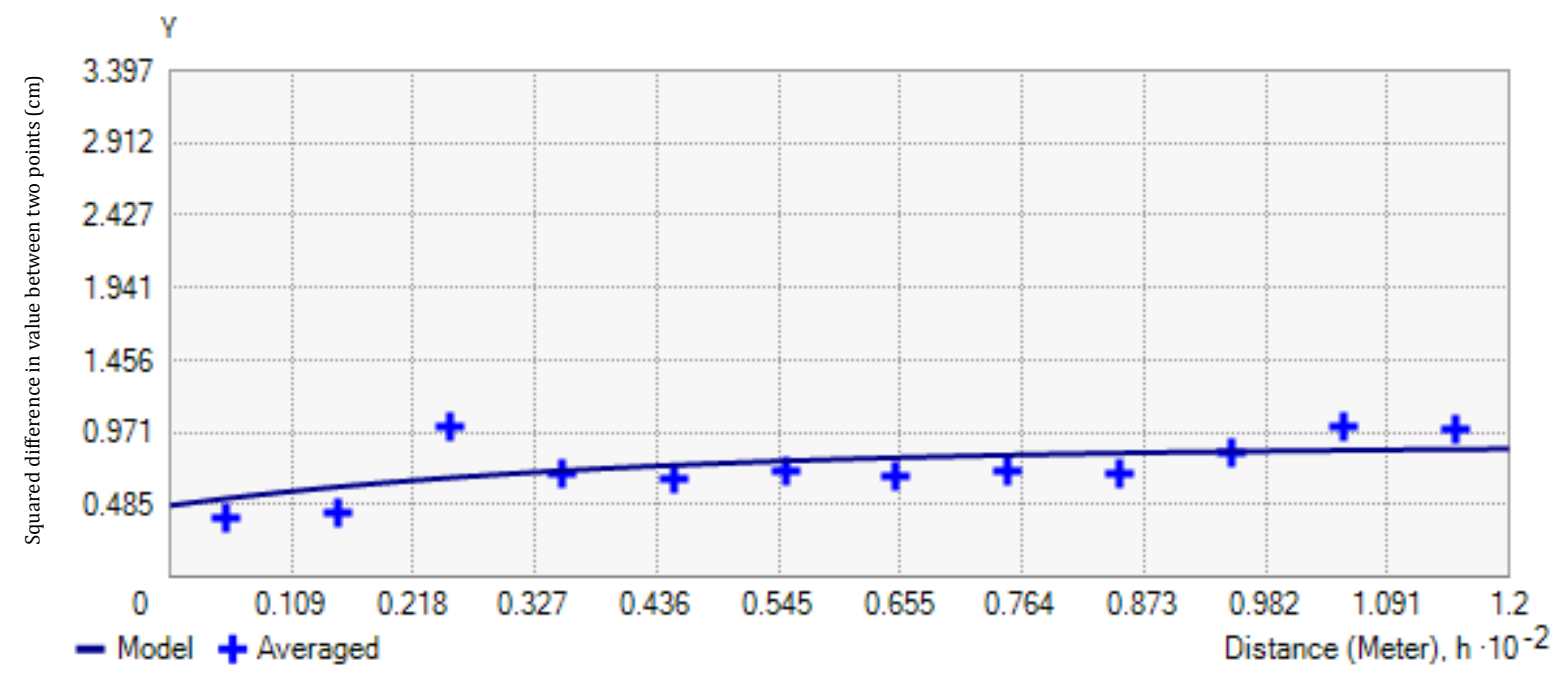

Set 15: Exponential 


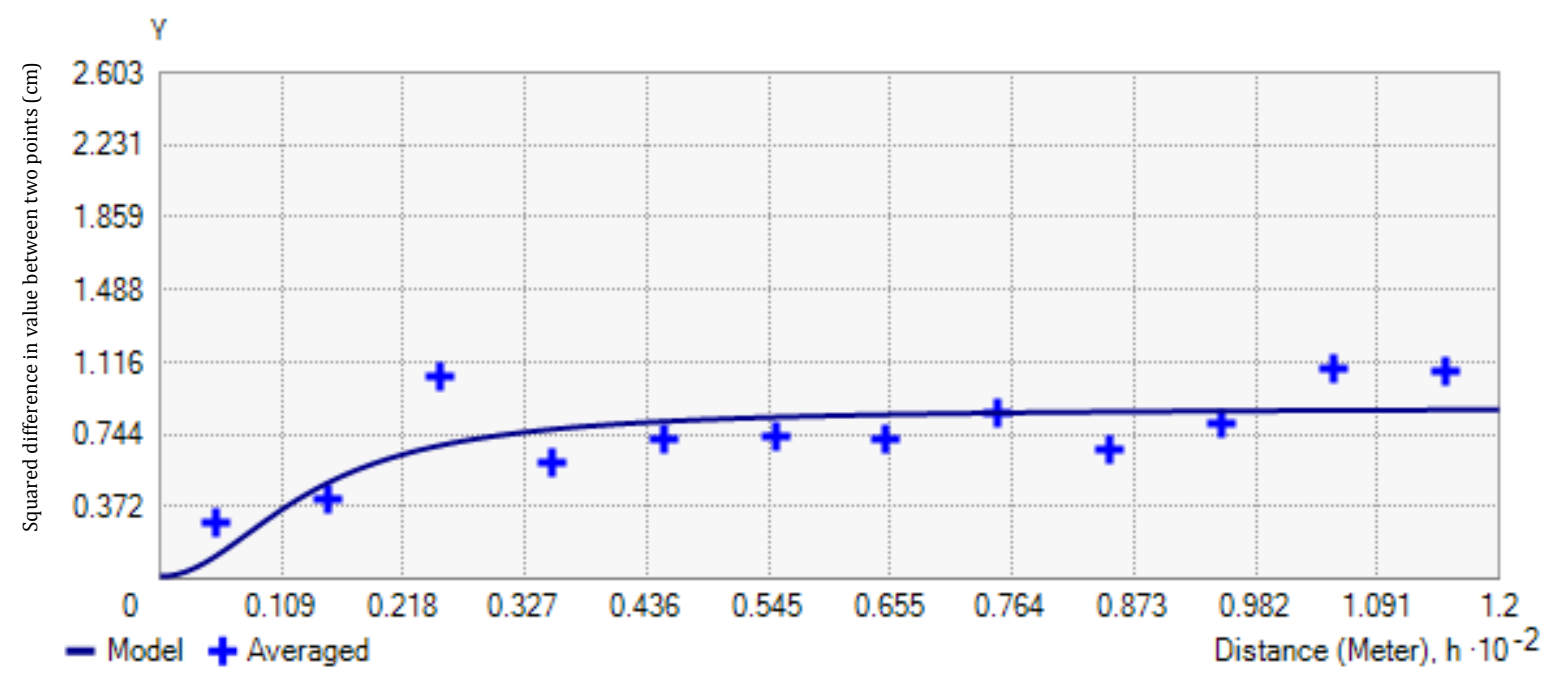

Set 16: Rotational quadratic

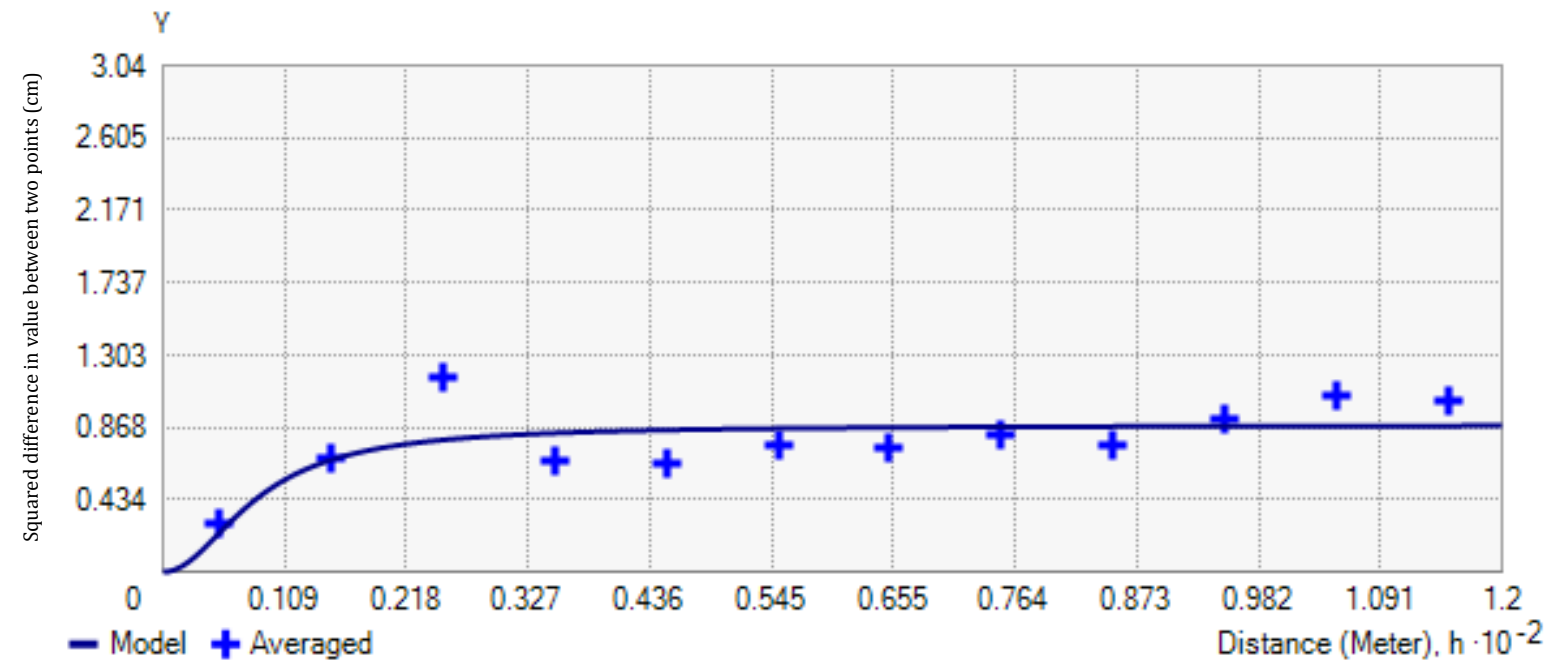

Set 17: Rotational quadratic 


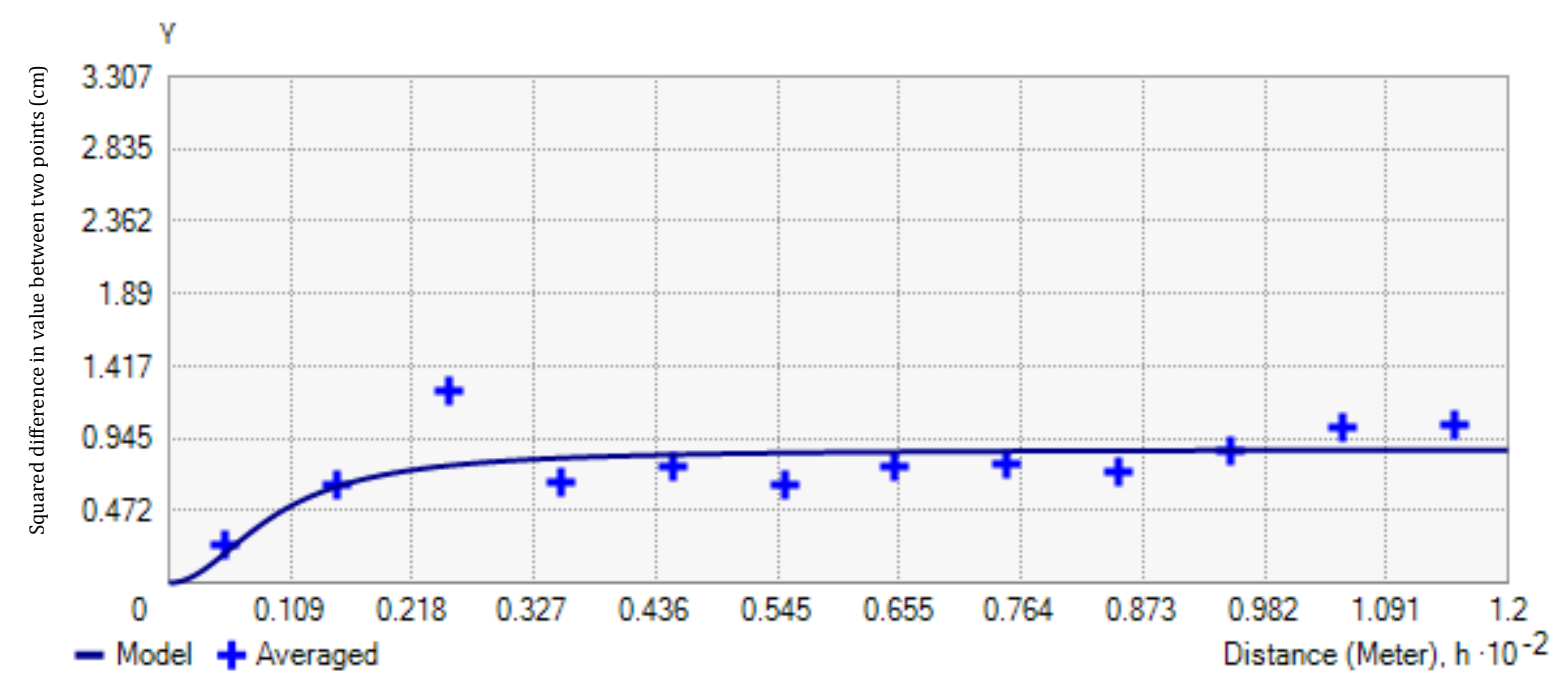

Set 18: Rotational quadratic

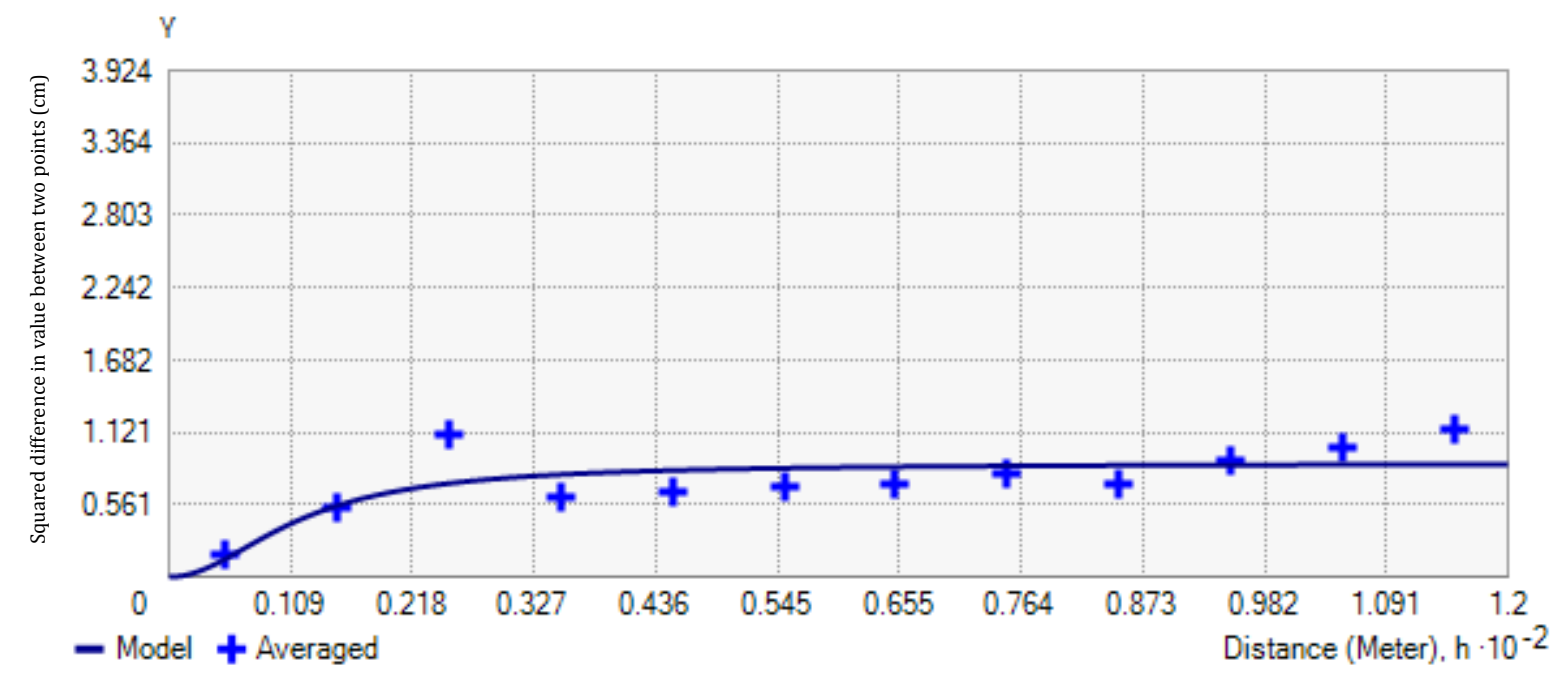

Set 20: Rotational quadratic 


\section{A.2. ST variagrams.}

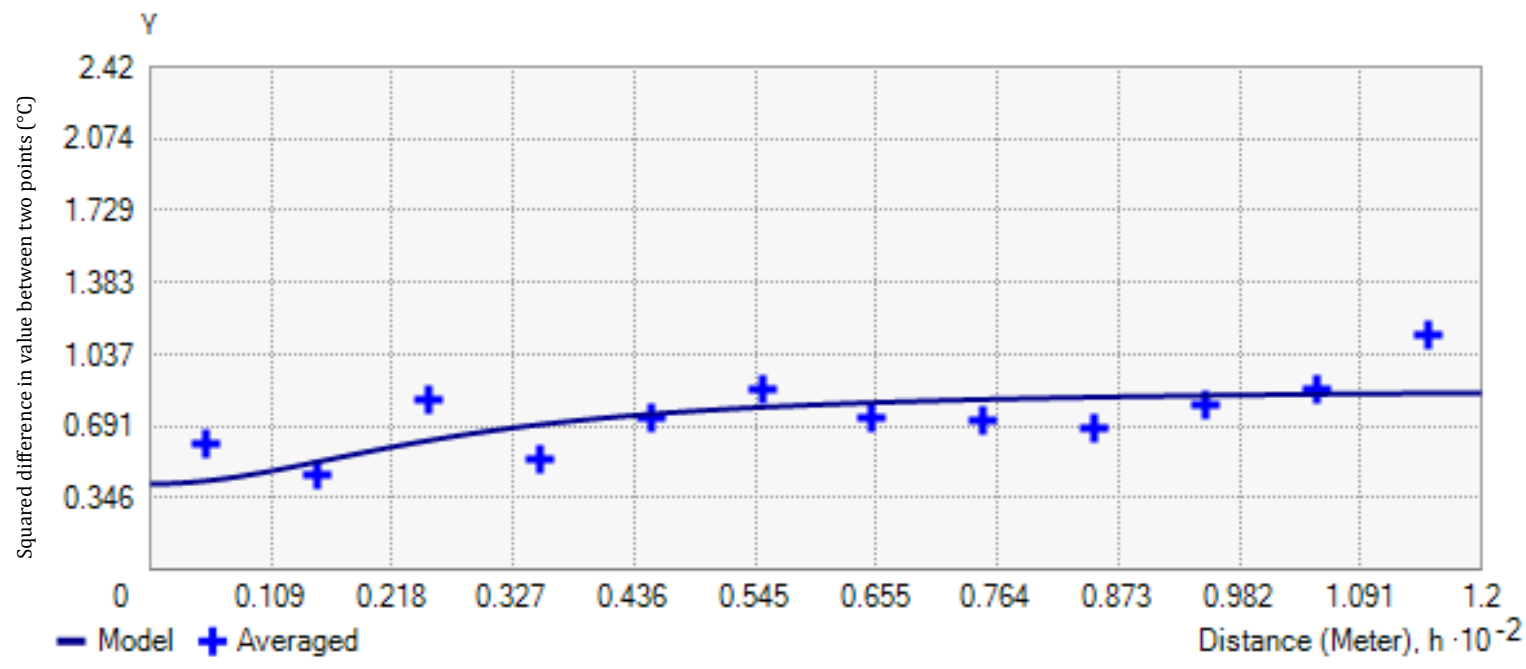

Set 3: Rotational quadratic

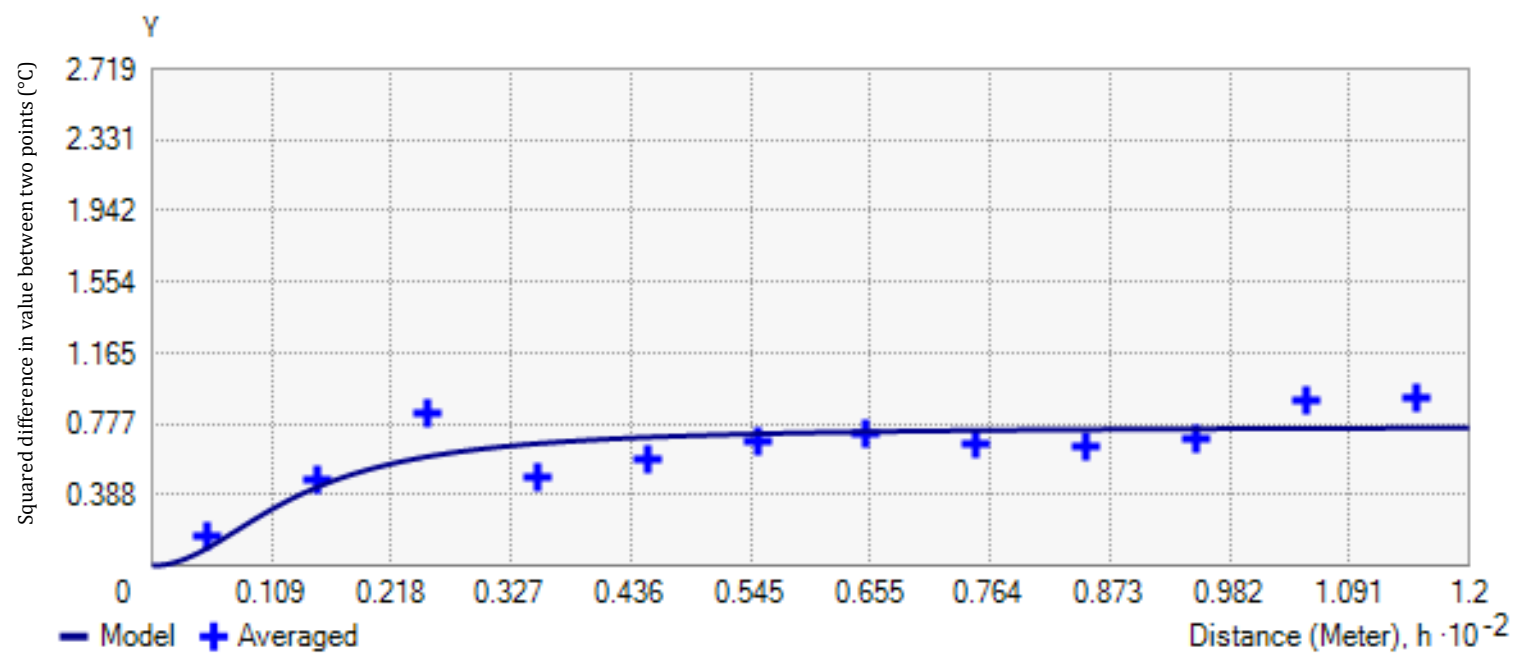

Set 6: Rotational quadratic 


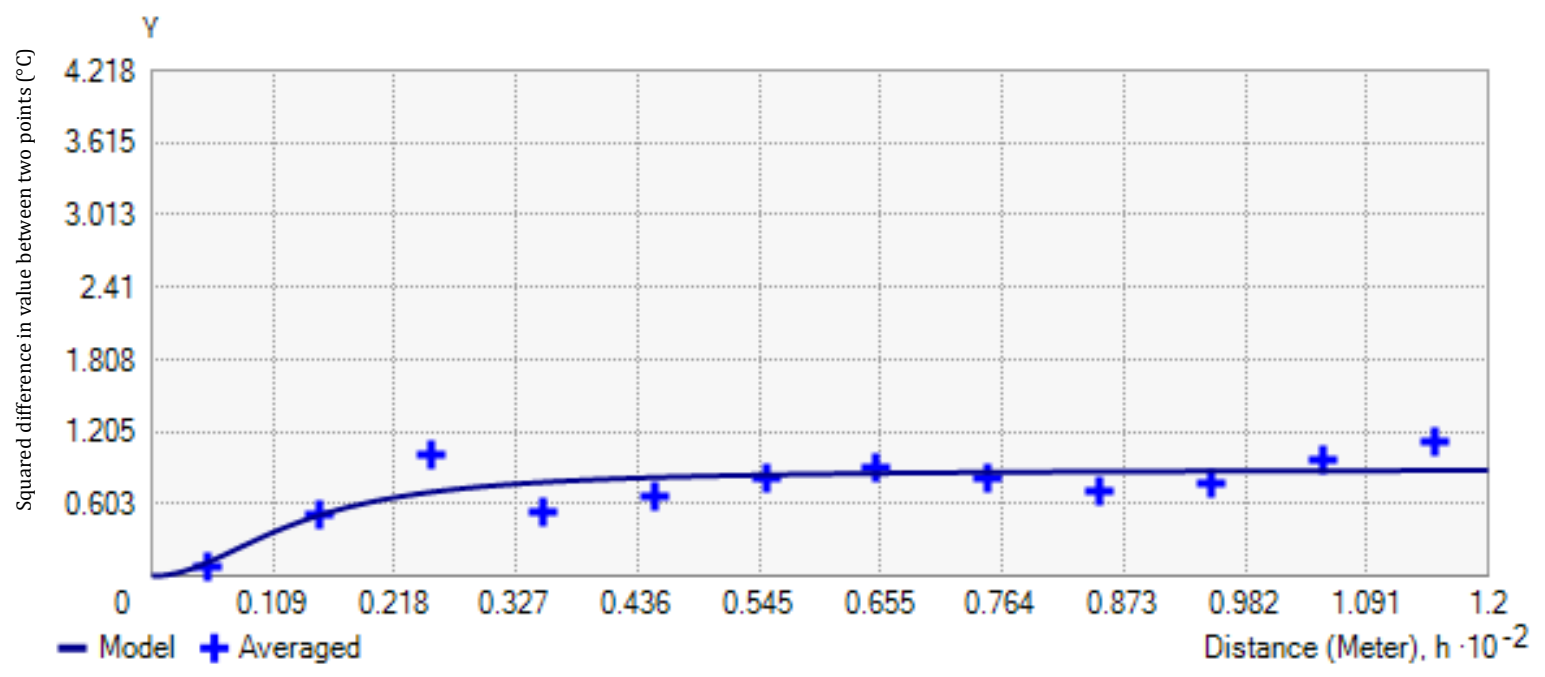

Set 9: Rotational quadratic

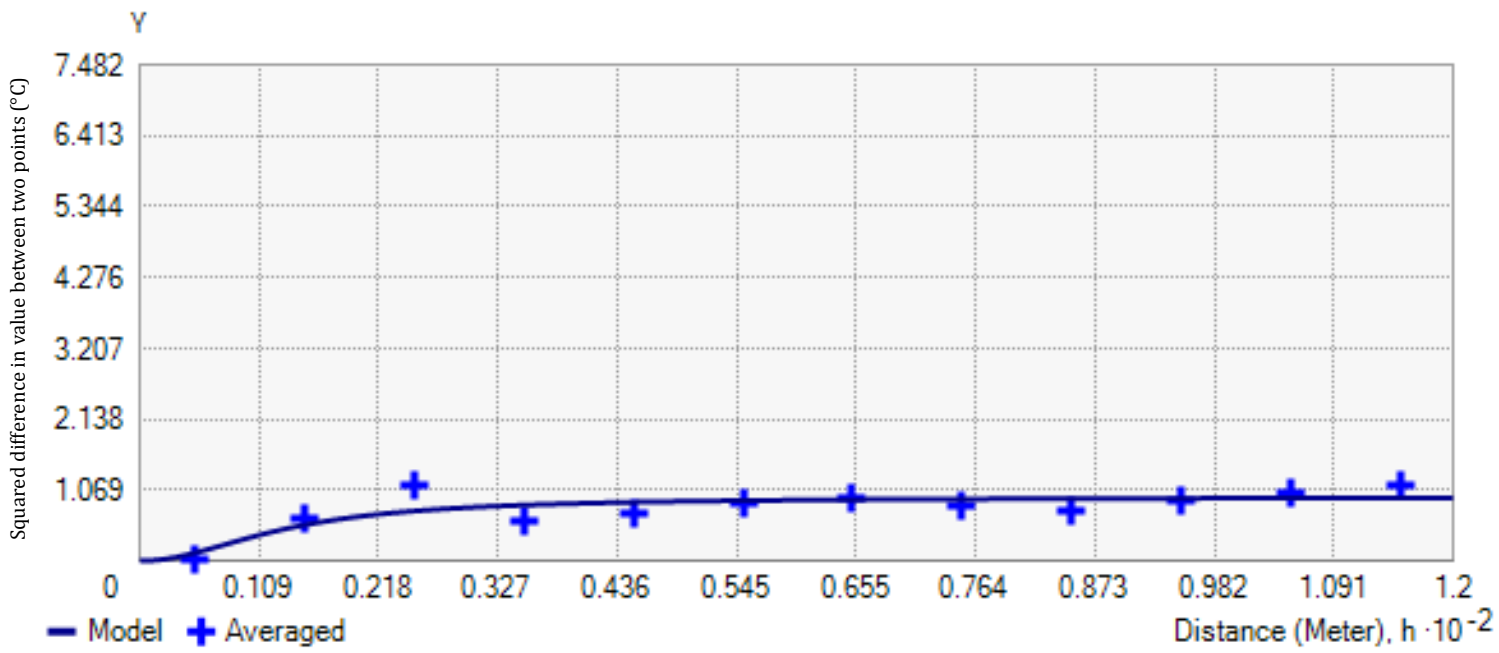

Set 15:Rotational quadratic 


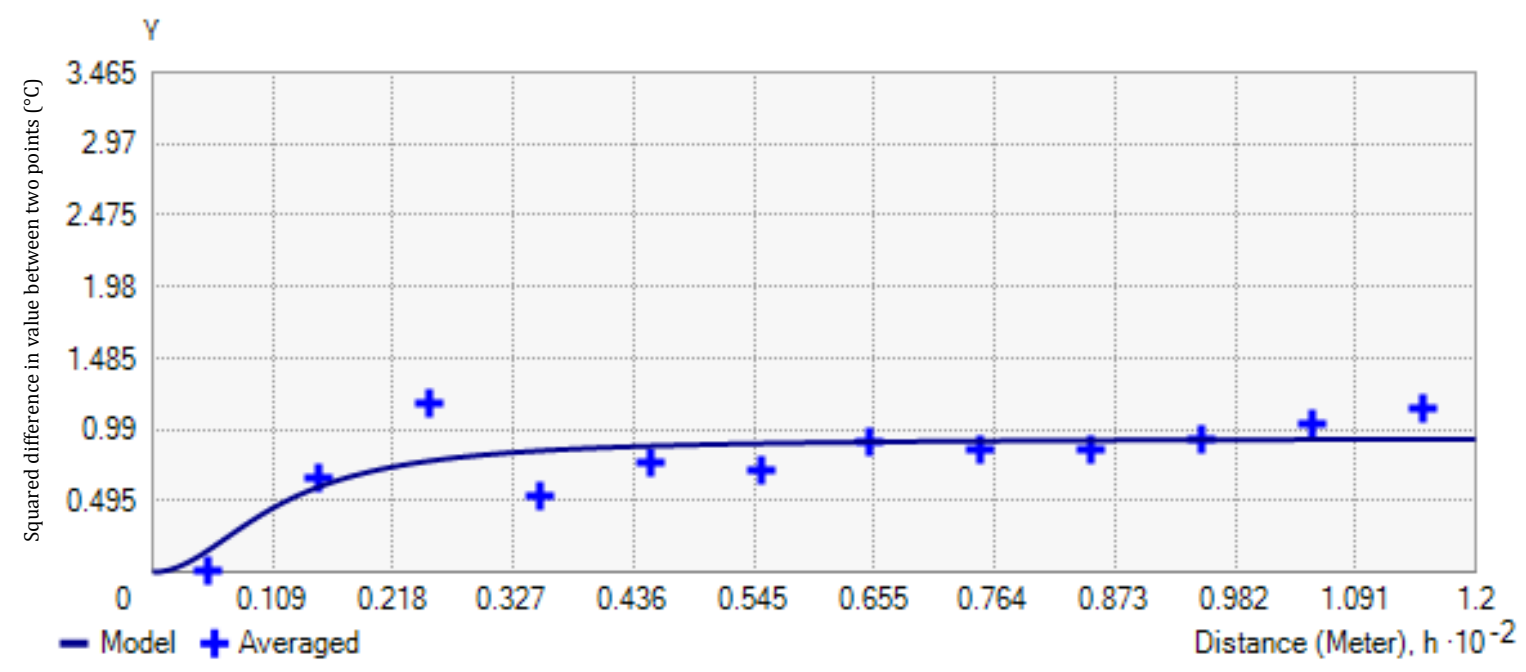

Set 16: Rotational quadratic

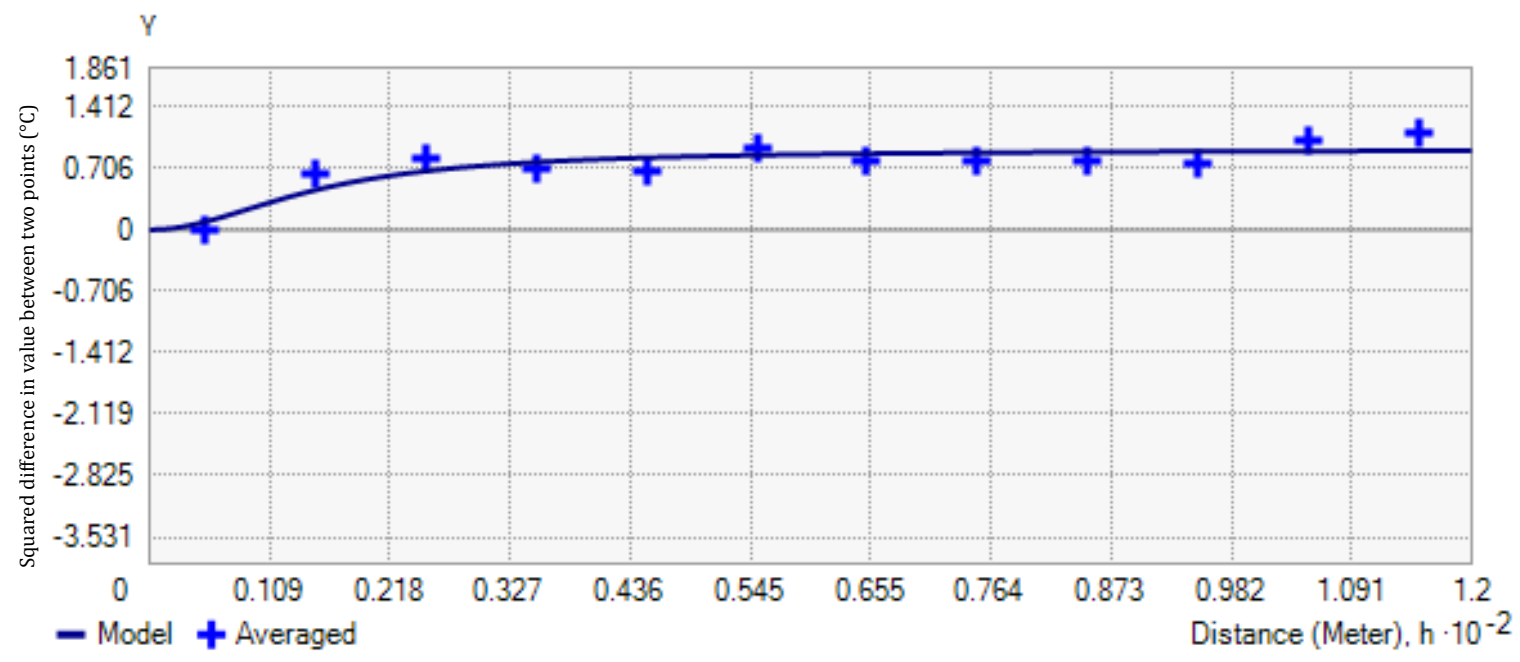

Set 17: Rotational quadratic 


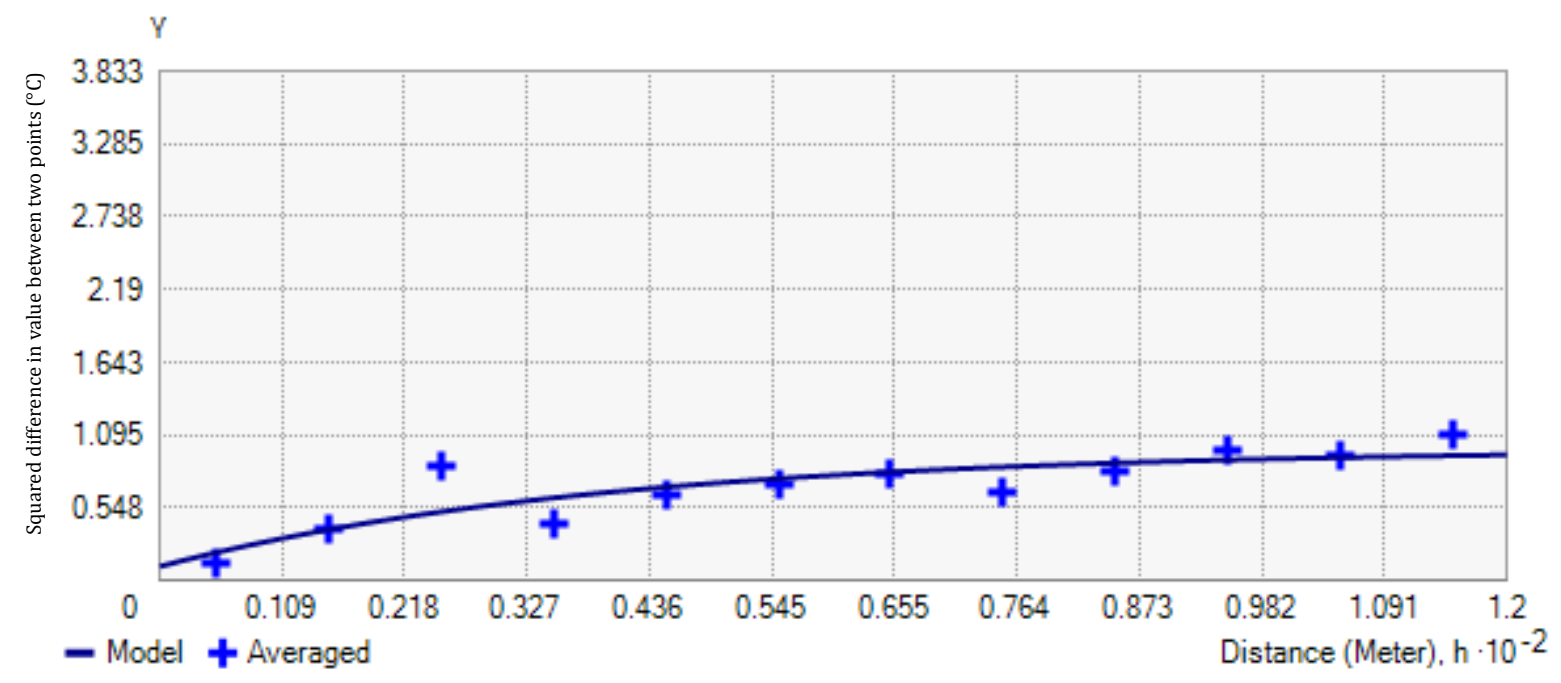

Set 18: Exponential

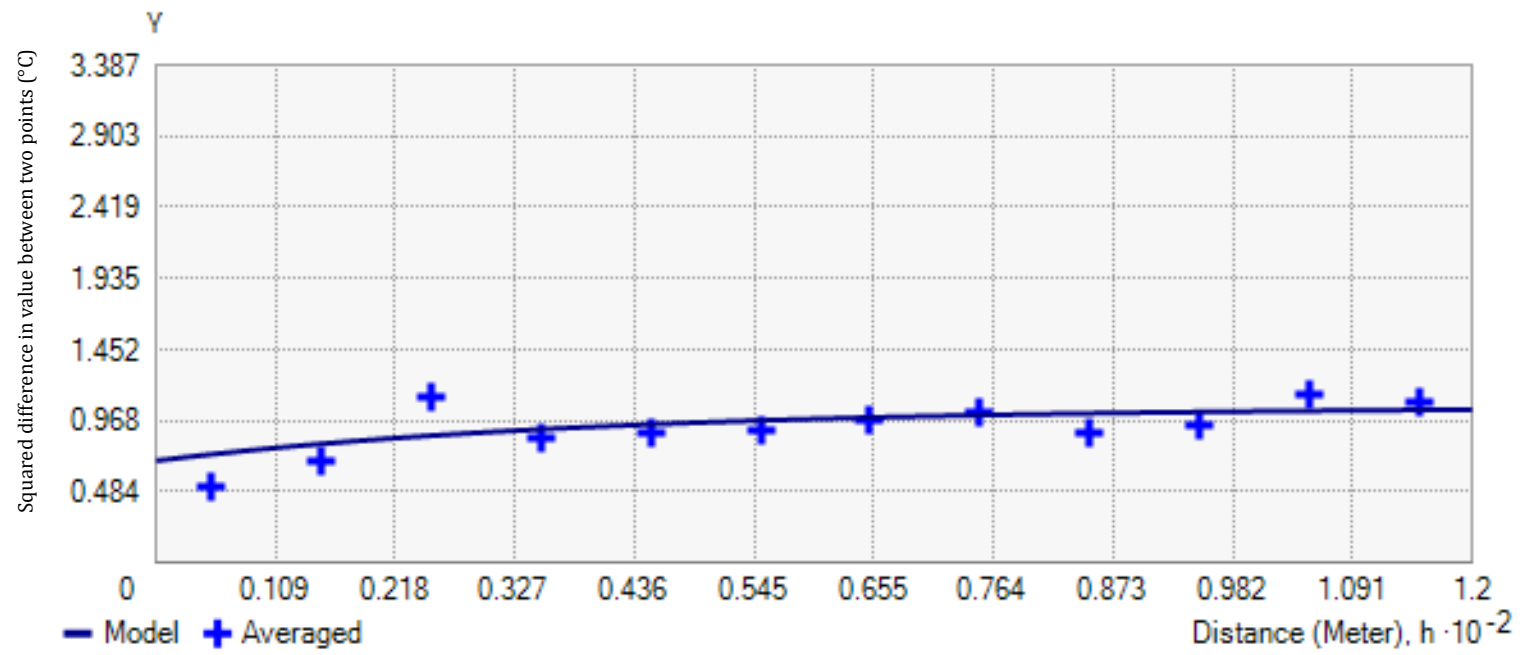

Set 20: Exponential 


\section{A.3. SM variagrams.}

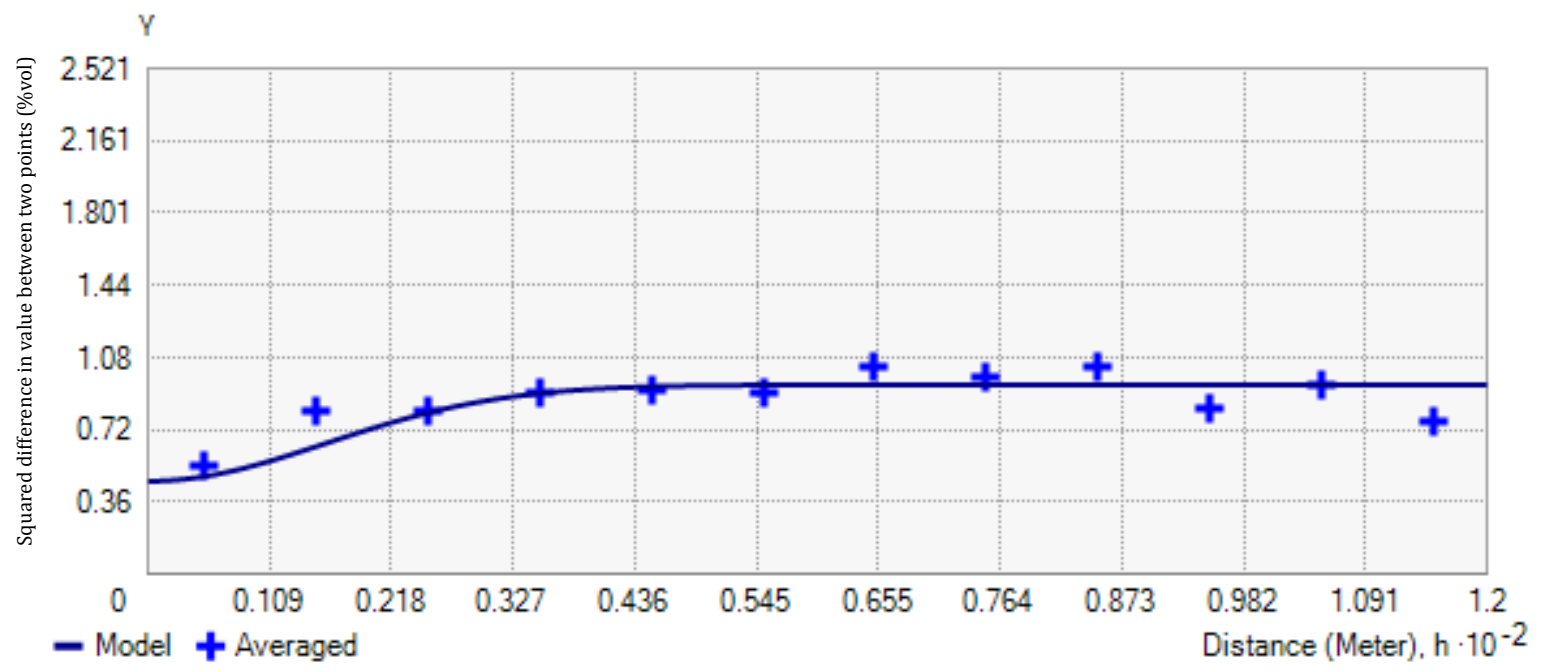

Set 3: Gaussian

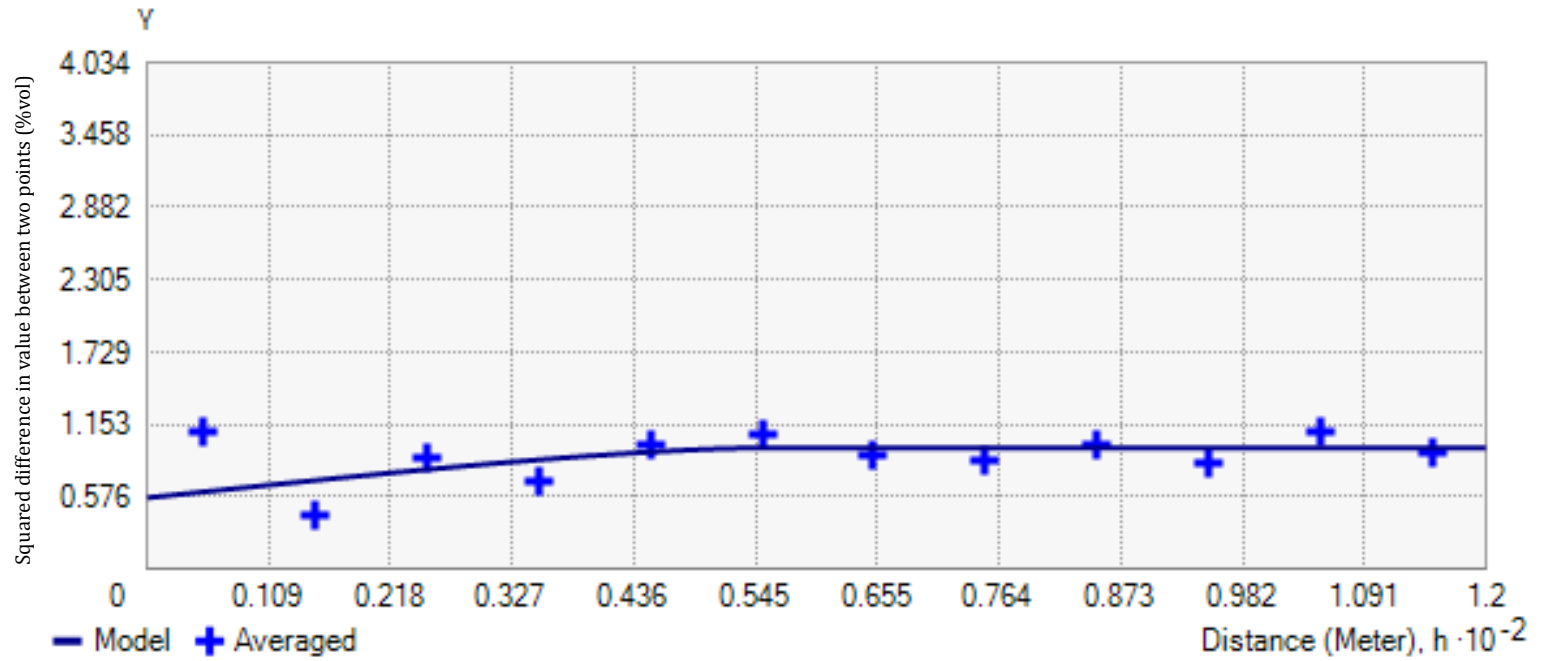

Set 6: Circular 


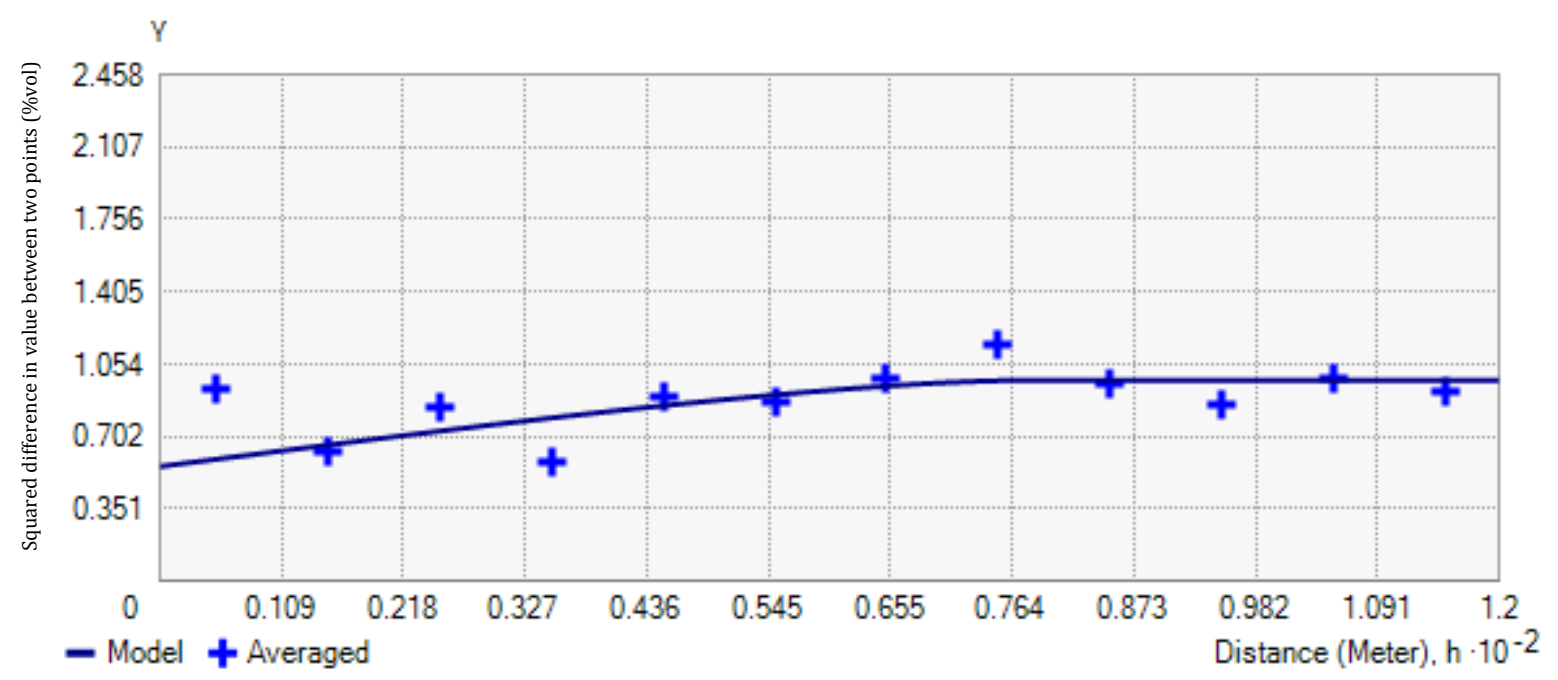

Set 9: Circular

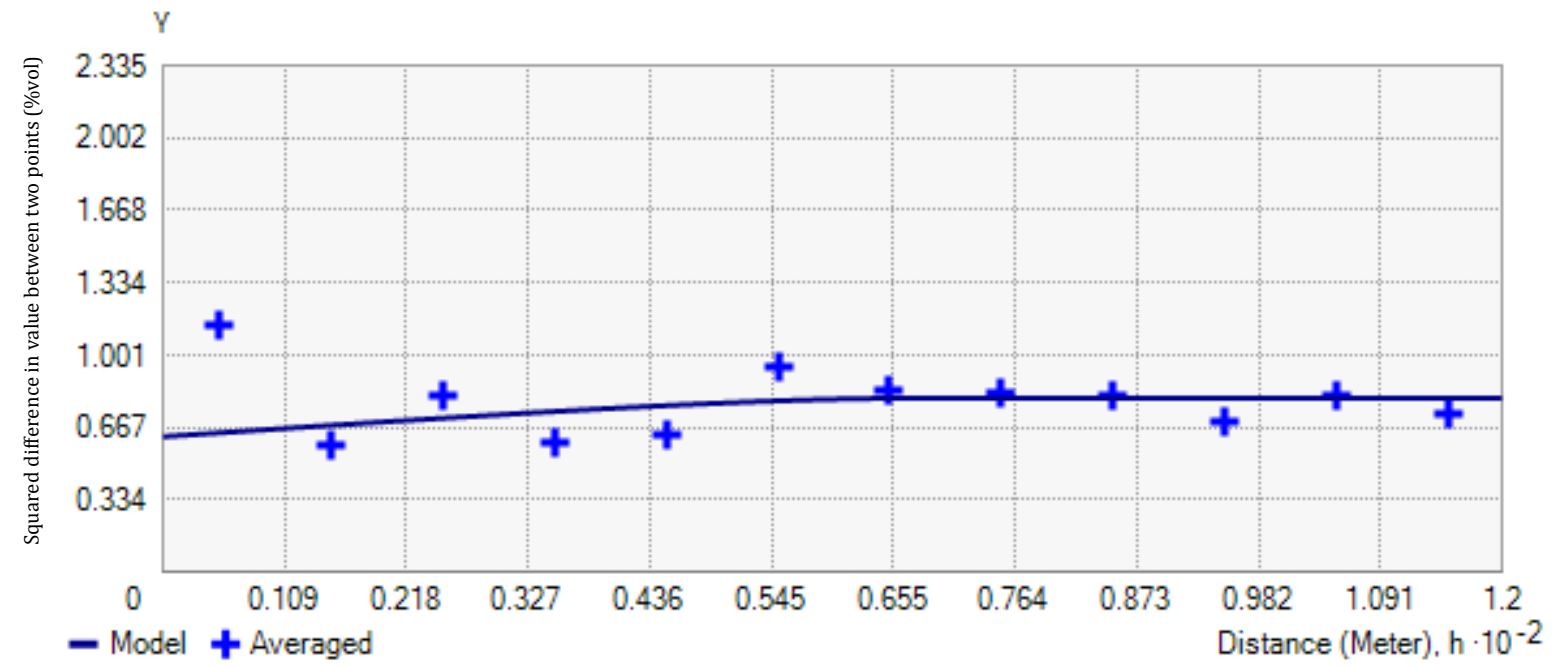

Set 15: Circular 


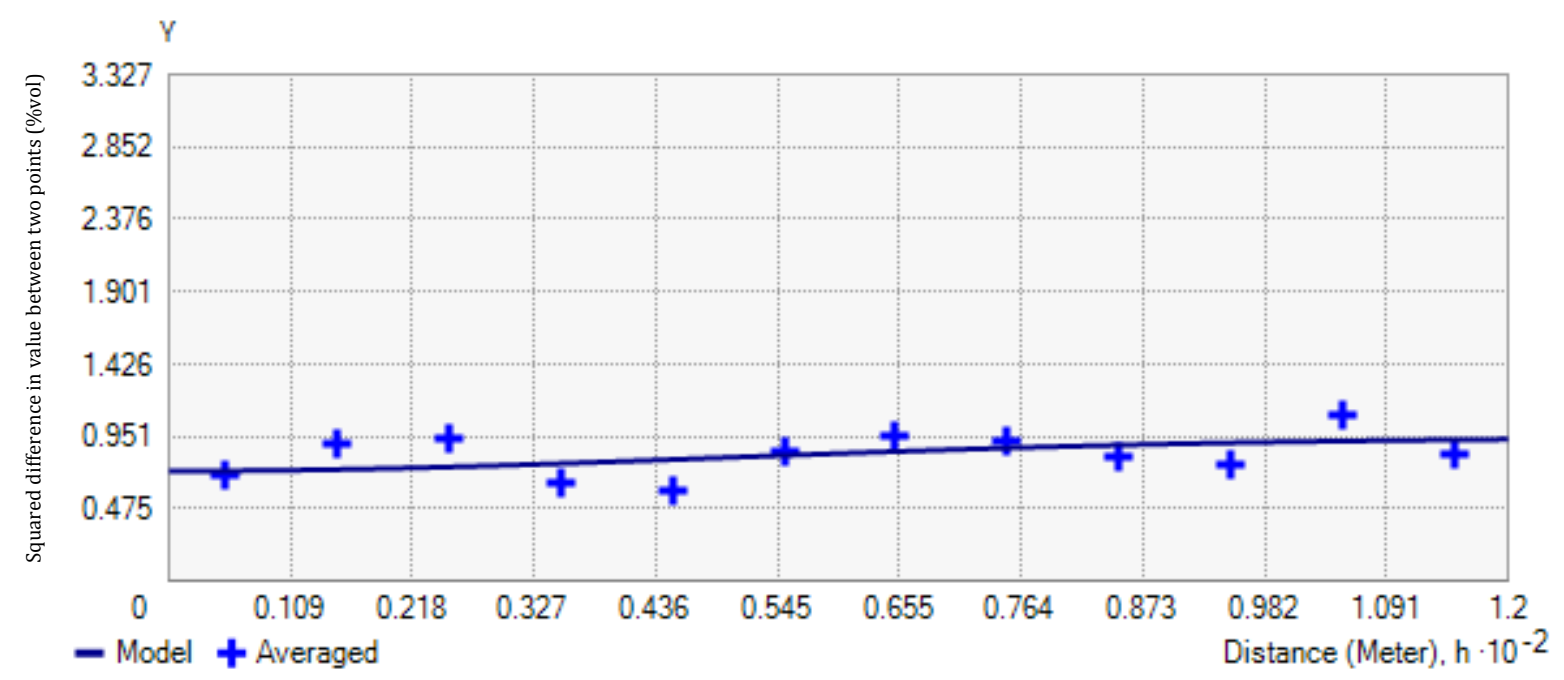

Set 16: Gaussian

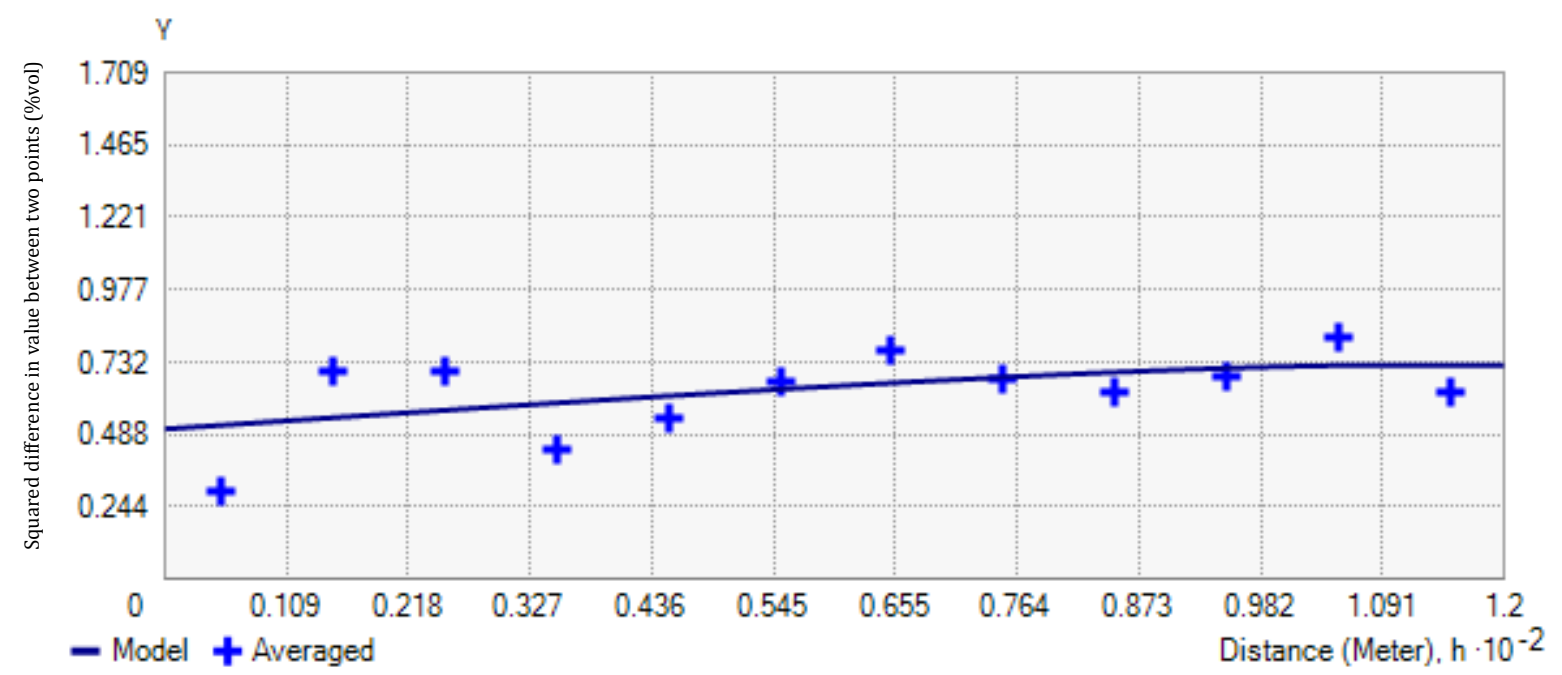

Set 17: Circular 


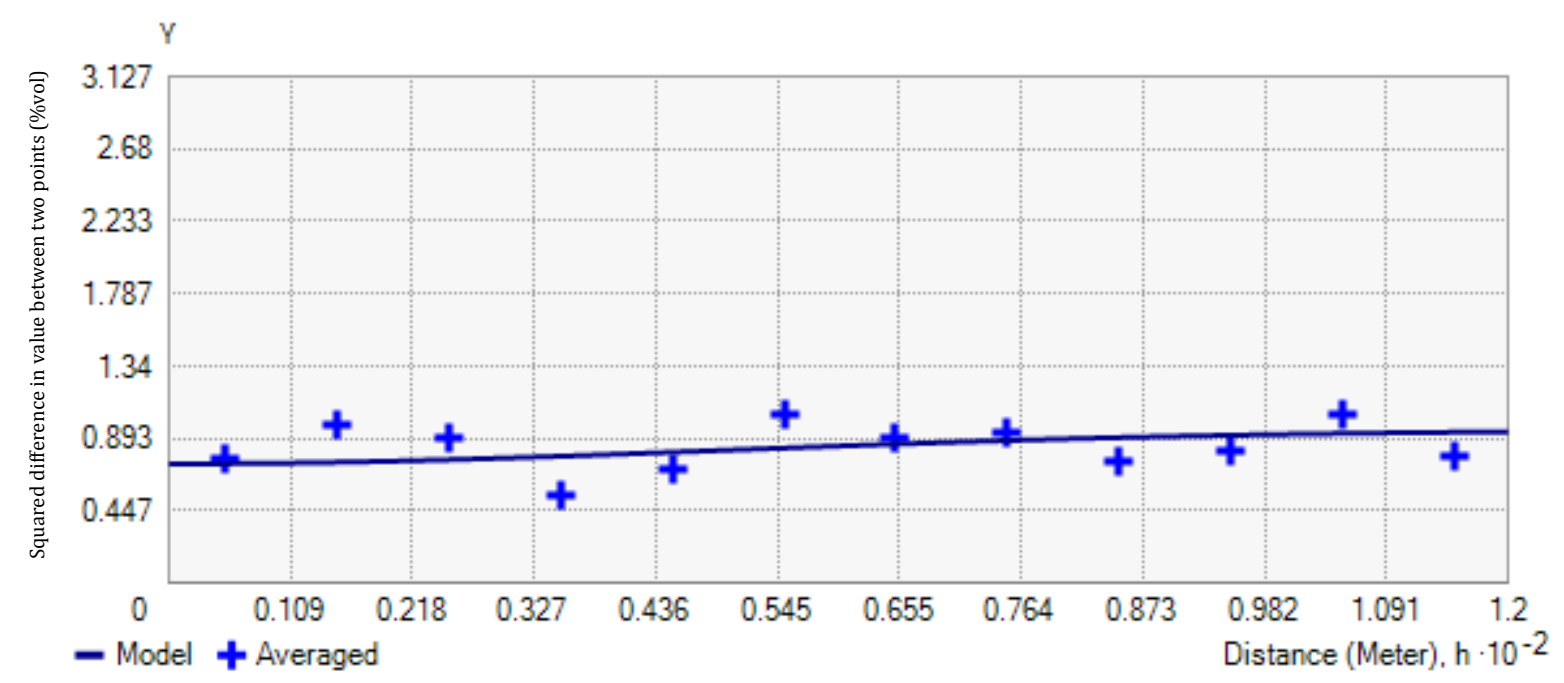

Set 18: Gaussian

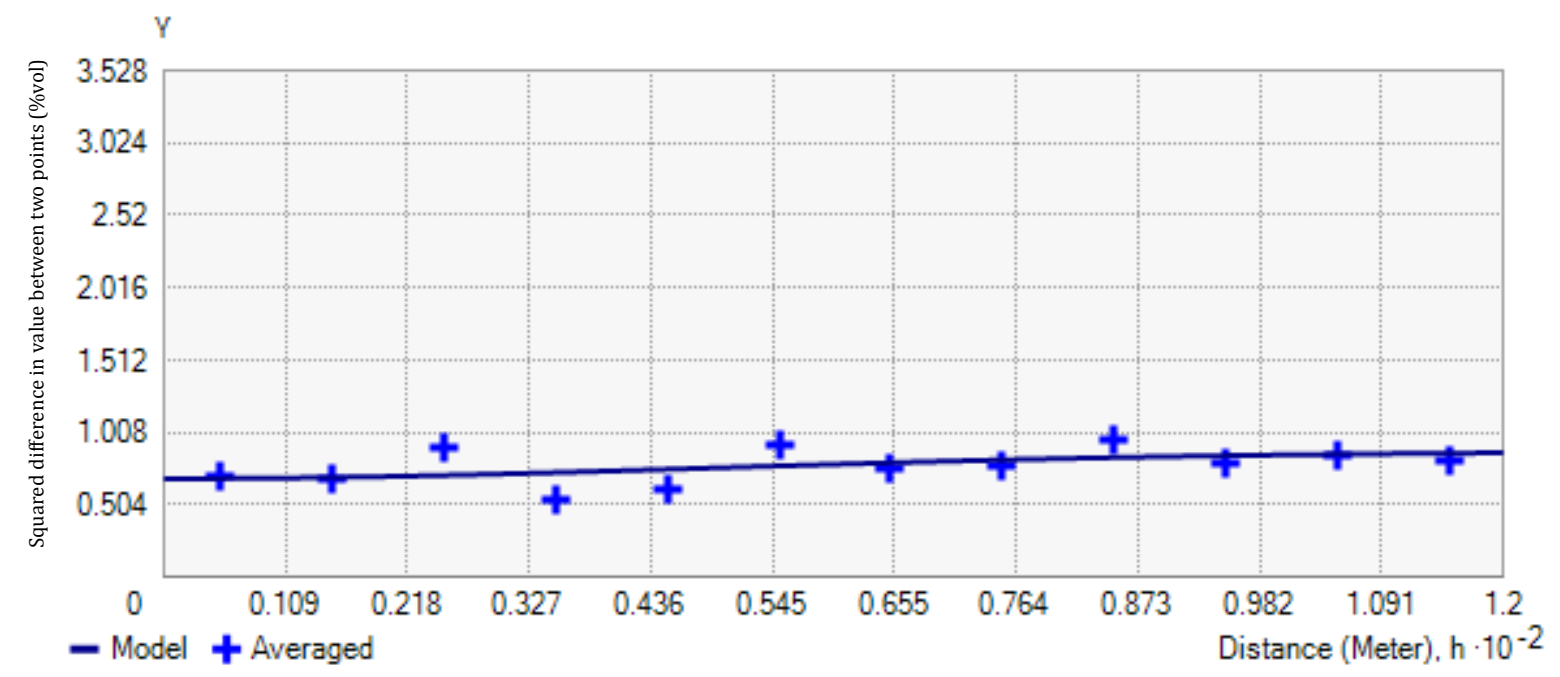

Set 20: Gaussian 


\section{References}

Abnizova, A., \& Young, K. L., (2010). Sustainability of High Arctic ponds in a polar desert environment. Arctic, 63(1), pp.67-84.

Anisimov, O. A., (2007). Potential feedback of thawing permafrost to the global climate system through methane emission. Environmental Research Letters, 2(4). 045016.

Atkinson, D. M., \& Treitz, P., (2012). Arctic ecological classifications derived from vegetation community and satellite spectral data. Remote Sensing, 4, pp.3948-3971.

Atkinson, D. M., \& Treitz, P., (2013). Modeling biophysical variables across an arctic latitudinal gradient using high spatial resolution remote sensing data. Arctic, Antarctic, and Alpine Research, 45(2). Pp.161-178.

Buttle, J. M., \& Fraser, K. E., (1992). Hydrochemical fluxes in a High Arctic wetland basin during spring snowmelt. Arctic and Alpine Research, 24(2), pp.153-164.

Chen, I. C., Hill, J. K., Ohlemüller, R., Roy, D. B., \& Thomas, C. D., (2011). Rapid range shifts of species associated with high levels of climate warming. Science, 333(6045), pp.1024-1026.

Collingwood, A., (2014). Modelling biophysical variables in the Canadian high arctic using synthetic aperture radar data. PhD Thesis. Queen's University. 
Dagg, J., \& Lafleur, P., (2011). Vegetation community, foliar nitrogen, and temperature effects on tundra $\mathrm{CO} 2$ exchange across a soil moisture gradient. Arctic, Antarctic, and Alpine Research, 43(2), pp.189-197.

Ellis, C. J., \& Rochefort, L., (2006). Long-term sensitivity of a High Arctic wetland to Holocene climate change. Journal of ecology, 94(2), pp.441-454.

Elmendorf, S. C., Henry, G. H. R., Hollister, R. D., Björk, R. G., Bjorkman, A. D., Callaghan, T. V., Collier, L. S., Cooper, E. J., Cornelissen, J. H. C., Day, T. A., Fosaa, A. M., Gould, W. A., Grétarsdóttir, J., Harte, J., Hermanutz, L., Hik, D. S., Hofgaard, A., Jarrad, F., Jónsdóttir, I. S., Keuper, F., Klanderud, K., Klein, J. A., Koh, S., Kudo, G., Lang, S. I., Loewen, V., May, J. L., Mercado, J., Michelsen, A., Molau, U., Myers-Smith, I. H., Oberbauer, S. F., Pieper, S., Post, E., Rixen, C., Robinson, C. H., Schmidt, N. M., Shaver, G. R., Stenström, A., Tolvanen, A., Totland, O., Troxler, T., Wahren, C. H., Webber, P. J., Welker, J. M., \& Wookey, P. A., (2012). Global assessment of experimental climate warming on tundra vegetation: heterogeneity over space and time. Ecology Letters, 15(2), pp.164-175.

Ford, J. D., \& Beaumier, M., (2011). Feeding the family during times of stress: experience and determinants of food insecurity in an Inuit community. The Geographical Journal, 177(1), pp.44-61. 
Ford, J. D., \& Pearce, T., (2012). Climate change vulnerability and adaptation research focusing on the Inuit subsistence sector in Canada: Directions for future research. The Canadian Geographer/Le Géographe canadien, 56(2), pp.275-287.

Ford, J. D., Bolton, K. C., Shirley, J., Pearce, T., Tremblay, M., \& Westlake, M., (2012). Research on the human dimensions of climate change in Nunavut, Nunavik, and Nunatsiavut: a literature review and gap analysis. Arctic, 65(3), pp.289-304.

Glenn, M. S., \& Woo, M. K., (1997). Spring and summer hydrology of a valley-bottom wetland, Ellesmere Island, Northwest Territories, Canada. Wetlands, 17(2), pp.321-329.

Hodgson, D. A., Vincent, J. S., \& Fyles, J. G., (1984). Quaternary geology of central Melville Island, Northwest Territories. Ottawa: Geological survey of Canada. Paper 83-16.

Hyndman, D. W., (2014). Impacts of Projected Changes in Climate on Hydrology. Global Environmental Change, 1, pp.211-220.

IPCC, (2014). Climate Change 2014: Synthesis Report. Contribution of Working Groups I, II and III to the Fifth Assessment Report of the Intergovernmental Panel on Climate Change [Core Writing Team, R.K. Pachauri and L.A. Meyer (eds.)]. IPCC, Geneva, Switzerland, 151 pp. 
Johnston, K., Ver Hoef, J. M., Krivoruchko, K., \& Lucas, N., (2001). Using ArcGIS geostatistical analyst (Vol. 300). Redlands: Esri.

Lennihan, R., Chapin, D. M., \& Dickson, L. G., (1994). Nitrogen fixation and photosynthesis in high arctic forms of nostoc commune. Canadian Journal of Botany. 72, pp.940-945

Levermann, A., Bamber, J. L., Drijfhout, S., Ganopolski, A., Haeberli, W., Harris, N. R., Huss, M., Krüger, K., Lenton, T. M., Lindsay, R. W., Notz, D., Wadhams, P., \& Weber, S., (2012). Potential climatic transitions with profound impact on Europe. Climatic Change, 110(3-4), pp.845-878.

Lin, H. S., Kogelmann, W., Walker, C., \& Bruns, M. A., (2006). Soil moisture patterns in a forested catchment: A hydropedological perspective. Geoderma, 131(3), pp.345-368.

Liu, J., Curry, J. A., Wang, H., Song, M., \& Horton, R. M., (2012). Impact of declining Arctic sea ice on winter snowfall. Proceedings of the National Academy of Sciences, 109(11), pp.40744079.

Liu, J., Song, M., Horton, R. M., \& Hu, Y., (2013). Reducing spread in climate model projections of a September ice-free Arctic. Proceedings of the National Academy of Sciences, 110(31), pp.12571-12576. 
Lobell, D. B., Schlenker, W., \& Costa-Roberts, J., (2011). Climate trends and global crop production since 1980. Science, 333(6042), pp.616-620.

Loya, W.M. \& Grogan, P., (2004). Carbon conundrum on the tundra. News and Views. Nature, 431, pp.406-408

MacDonald, J. P., Harper, S. L., Willox, A. C., Edge, V. L., \& Government, R. I. C., (2013). A necessary voice: Climate change and lived experiences of youth in Rigolet, Nunatsiavut, Canada. Global Environmental Change, 23(1), pp.360-371.

Martin, T. E., \& Maron, J. L., (2012). Climate impacts on bird and plant communities from altered animal-plant interactions. Nature Climate Change, 2(3), pp.195-200.

Nobrega, S., \& Grogan, P., (2008). Landscape and ecosystem-level controls on net carbon dioxide exchange along a natural moisture gradient in Canadian low arctic tundra. Ecosystems, 11(3), pp.377-396.

Nyberg, L., (1996). Spatial variability of soil water content in the covered catchment at Gårdsjön, Sweden. Hydrological Processes, 10(1), pp.89-103.

Pan, Y. X., Wang, X. P., Jia, R. L., Chen, Y. W., \& He, M. Z., (2008). Spatial variability of surface soil moisture content in a re-vegetated desert area in Shapotou, Northern China. Journal of arid environments, 72(9), pp.1675-1683. 
Petrone, R. M., Price, J. S., Carey, S. K., \& Waddington, J. M., (2004). Statistical characterization of the spatial variability of soil moisture in a cutover peatland. Hydrological Processes, 18(1), pp.41-52.

Roulet, N. T., \& Woo, M. K., (1986a). Hydrology of a wetland in the continuous permafrost region. Journal of Hydrology, 89(1), pp.73-91.

Roulet, N. T., \& Woo, M. K., (1986b). Low Arctic wetland hydrology. Canadian Water Resources Journal, 11(1), pp.69-75.

Rouse, W. R., (2000). The energy and water balance of high-latitude wetlands: controls and extrapolation. Global Change Biology, 6(S1), pp.59-68.

Schellnhuber, H. J., \& Cramer, W. P., (Eds.). (2006). Avoiding dangerous climate change. Cambridge University Press.

Schlesinger, M. E., Yin, J., Yohe, G., Andronova, N. G., Malyshev, S., \& Li, B., (2006). Assessing the risk of a collapse of the Atlantic thermohaline circulation. Avoiding Dangerous Climate Change. Cambridge University Press, Cambridge, pp.37-47. 
Schneider, K., Huisman, J. A., Breuer, L., \& Frede, H. G., (2008). Ambiguous effects of grazing intensity on surface soil moisture: A geostatistical case study from a steppe environment in Inner Mongolia, PR China. Journal of arid environments, 72(7), pp.1305-1319.

Schuur, E. A., Vogel, J. G., Crummer, K. G., Lee, H., Sickman, J. O., \& Osterkamp, T. E., (2009). The effect of permafrost thaw on old carbon release and net carbon exchange from tundra. Nature, 459(7246), pp.556-559.

Screen, J. A., \& Simmonds, I., (2012). Declining summer snowfall in the Arctic: Causes, impacts and feedbacks. Climate dynamics, 38(11-12), pp.2243-2256.

Siska, P. P., \& Hung, I. K., (2001, July). Assessment of kriging accuracy in the GIS environment. In 21st Annual ESRI International Conference, San Diego, CA.

Sharma, S., Couturier, S., \& Cote, S. D., (2009). Impacts of climate change on the seasonal distribution of migratory caribou. Global Change Biology, 15(10), pp.2549-2562.

Stieglitz, M., Giblin, A., Hobbie, J., Williams, M., \& Kling, G., (2000). Simulating the effects of climate change and climate variability on carbon dynamics in Arctic tundra. Global Biogeochemical Cycles, 14(4), pp.1123-1136.

Stow, D. A., Hope, A., McGuire, D., Verbyla, D., Gamon, J., Huemmrich, F., Houston, S., Racine, C., Sturm, M., Tape, K., Hinzman, L., Yoshikawa, K., Tweedie, C., Noyle, B., Silapaswan, C., 
Douglas, D., Griffith, B., Jia, G., Epstein, H., Walker, D., Daeschner, S., Petersen, A., Zhou, L., \& Myneni, R., (2004). Remote sensing of vegetation and land-cover change in Arctic Tundra Ecosystems. Remote Sensing of Environment, 89(3), pp.281-308.

Tarnocai, C., Canadell, J. G., Schuur, E. A. G., Kuhry, P., Mazhitova, G., \& Zimov, S., (2009). Soil organic carbon pools in the northern circumpolar permafrost region. Global biogeochemical cycles, 23(2), GB2023.

Thompson, D. K., \& Woo, M. K., (2009). Seasonal hydrochemistry of a high Arctic wetland complex. Hydrological processes, 23(10), pp.1397-1407.

Vaughan, D.G., Comiso, J. C., Allison, I., Carrasco, J., Kaser, G., Kwok, R., Mote, P., Murray, T., Paul, F., Ren, J., Rignot, E., Solomina, O., Steffen, K., \& Zhang, T., (2013) Observations: Cryosphere. In: Climate Change 2013: The Physical Science Basis. Contribution of Working Group I to the Fifth Assessment Report of the Intergovernmental Panel on Climate Change [Stocker, T.F., Qin, D., Plattner, G.-K., Tignor, M., Allen, S. K., Boschung, J., Nauels, A., Xia, Y., Bex, V., \& Midgley, P. M. (eds.)]. Cambridge University Press, Cambridge, United Kingdom and New York, NY, USA.

Vincent, W. F., Callaghan, T. V., Dahl-Jensen, D., Johansson, M., Kovacs, K. M., Michel, C., Prowse, T., Reist, J. D., \& Sharp, M., (2011). Ecological implications of changes in the Arctic cryosphere. Ambio, 40(1), pp.87-99. 
Walker, D. A., (2000). Hierarchical subdivision of Arctic tundra based on vegetation response to climate, parent material and topography. Global change biology, 6(S1), pp.1934.

Walker, D. A., Raynolds, M. K., Daniëls, F. J., Einarsson, E., Elvebakk, A., Gould, W. A., Katenin, A. E., Kholod, S. S., Markon, C. J., Melnikov, E. S., Moskalenko, N. G., Natalia, G., Talbot, S. S., \& Yurtsev, B. A., (2005). The circumpolar Arctic vegetation map. Journal of Vegetation Science, 16(3), pp.267-282.

Wang, G., Li, Y., Wu, Q., \& Wang, Y., (2006). Impacts of permafrost changes on alpine ecosystem in Qinghai-Tibet Plateau. Science in China Series D: Earth Sciences, 49(11), pp.1156-1169.

White, D. M., Gerlach, S. C., Loring, P., Tidwell, A. C., \& Chambers, M. C., (2007). Food and water security in a changing arctic climate. Environmental Research Letters, 2(4), 045018.

Williams, M., Rastetter, E. B., Shaver, G. R., Hobbie, J. E., Carpino, E., \& Kwiatkowski, B. L., (2001). Primary production of an arctic watershed: an uncertainty analysis. Ecological applications, 11(6), pp.1800-1816.

Woo, M. K., \& Young, K. L., (1998). Characteristics of patchy wetlands in a polar desert environment, Arctic Canada. In Proceedings of the Seventh International Conference on Permafrost, Yellowknife, NWT, 23-27 June 1998, 57, pp.1141-1146. 
Woo, M. K., \& Young, K. L., (2003). Hydrogeomorphology of patchy wetlands in the high arctic, polar desert environment. Wetlands, 23(2), pp.291-309.

Woo, M. K., \& Young, K. L., (2006). High Arctic wetlands: their occurrence, hydrological characteristics and sustainability. Journal of Hydrology, 320(3), pp.432-450.

Woo, M. K., Young, K. L., \& Brown, L., (2006). High Arctic patchy wetlands: hydrologic variability and their sustainability. Physical Geography, 27(4), pp.297-307.

Yang, Z., Ouyang, H., Zhang, X., Xu. X., Zhou, C. \& Yang, W., (2011). Spatial variability of soil moisture at typical alpine meadow and steppe sites in Quinhai-Tibetan Plateau permafrost region. Environmental Earth Science, 63, pp.477-488. 